Portland State University

PDXScholar

\title{
A Structural Model and Test of the Antecedents and Outcomes of Organizational and Professional Commitment
}

Mary Ann Evans

Portland State University

Follow this and additional works at: https://pdxscholar.library.pdx.edu/open_access_etds

Part of the Business Administration, Management, and Operations Commons Let us know how access to this document benefits you.

Recommended Citation

Evans, Mary Ann, "A Structural Model and Test of the Antecedents and Outcomes of Organizational and Professional Commitment" (1991). Dissertations and Theses. Paper 1378.

https://doi.org/10.15760/etd.1377

This Dissertation is brought to you for free and open access. It has been accepted for inclusion in Dissertations and Theses by an authorized administrator of PDXScholar. Please contact us if we can make this document more accessible: pdxscholar@pdx.edu. 
A STRUCTURAL MODEL AND TEST OF THE ANTECEDENTS AND OUTCOMES OF

ORGANIZATIONAL AND PROFESSIONAL COMMITMENT

by

MARY ANN EVANS

A dissertation in partial fulfillment of the requirements for the degree of

\author{
DOCTOR OF PHILOSOPHY \\ in \\ SYSTEMS SCIENCE: BUSINESS ADMINISTRATION
}

Portland state University

-1991 
TO THE OFFICE OF GRADUATE STUDIES:

The members of the Committee approve the dissertation of Mary Ann Evans presented October 30, 1991.

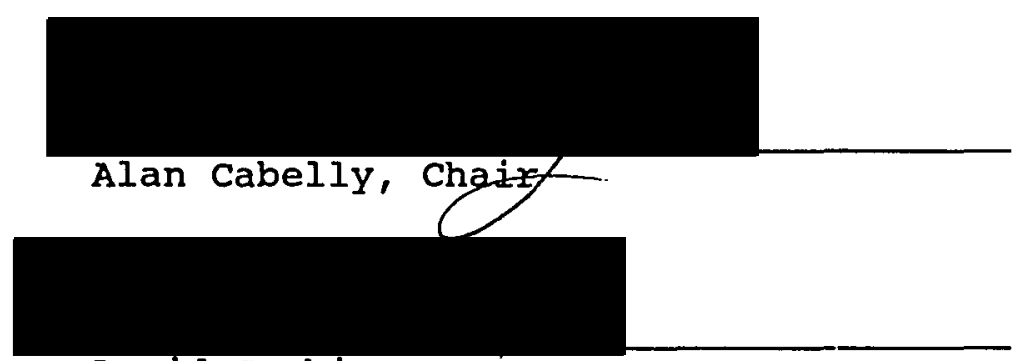

David Gerbing

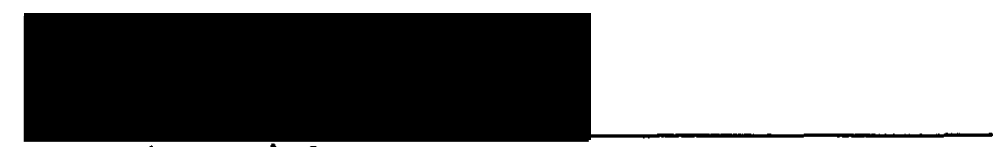

Marty Zwick

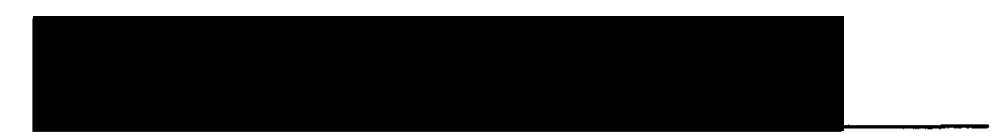

Donald K. Freeborn

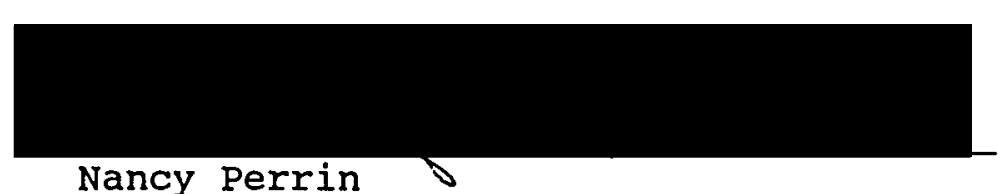

APPROVED:

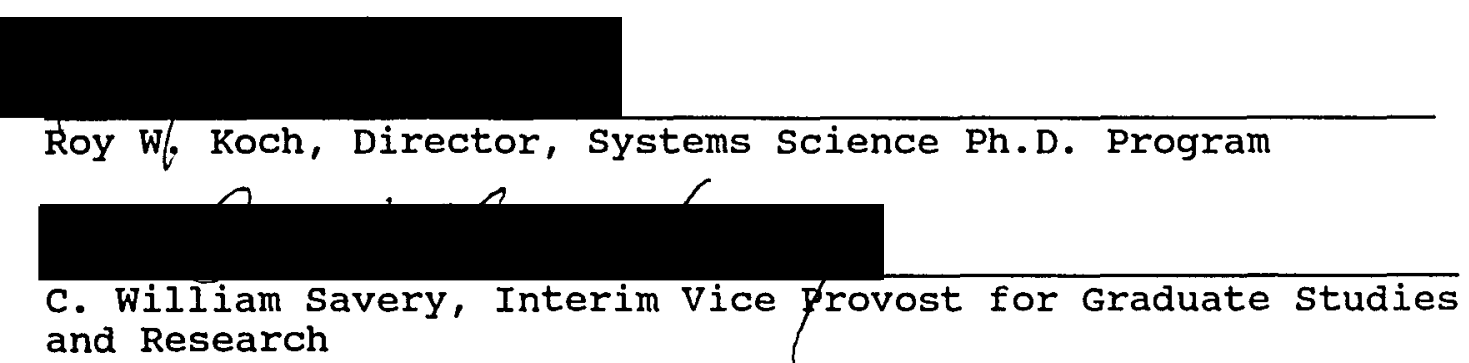




\section{AN ABSTRACT OF THE DISSERTATION OF Mary Ann Evans for the Doctor of Philosophy in Systems Science: Business Administration presented October 30, 1991.}

Title: A Structural Model and Test of the Antecedents and Outcomes of Organizational and Professional commitment.

\section{APPROVED BY THE MEMBERS OF THE DISSERTATION COMMITTEE:}

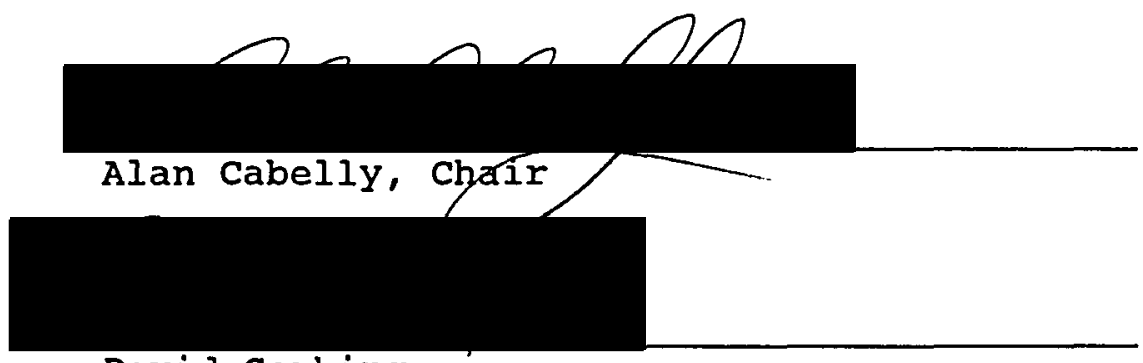

David Gerbing

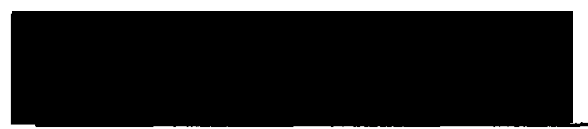

Marty Zwick

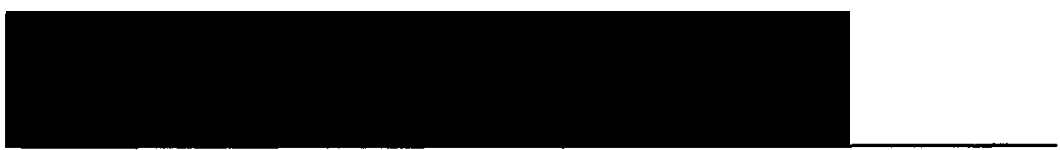

Donald K. Freeborn

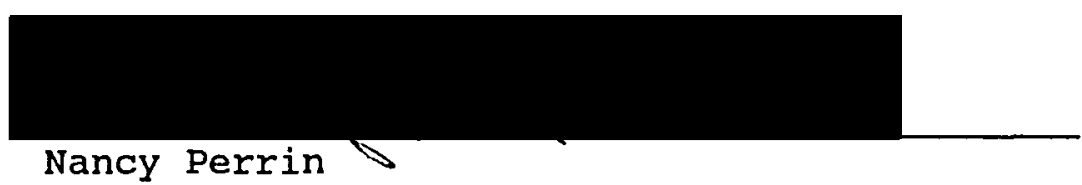

The major purpose of this study was to investigate the relationship between commitment to one's profession and 
commitment to one's employer and the role this relationship plays in predicting satisfaction, performance and turnover. In order to accomplish this purpose the antecedents and outcomes of the commitments were modeled and tested using covariance structural modeling techniques.

The data source was the 1990 Kaiser Permanente, Northwest Region Employee Survey. The study included a wide range of occupations.

The literature is ambiguous about the definition and measuremenc of professional and organizational commitment. Professional commitment is characterized either as a unidimensional or multidimensional construct where only members of the traditional professions are included.

organizational commitment is defined either as investments in the organization or as alignment of attitudes and goals. Organizational and professional commitment are rarely studied in unison and have never been modeled in unison as independent variables in a system of antecedents and outcomes.

A first and second-order confirmatory factor analysis demonstrated that measures of education, job demands, age tenure, organizational characteristics, rewards, professional commitment, organizational commitment, satisfaction, performance and turnover measures were reliable, valid and not redundant.

A model of the relationships among the variables was 
tested using general maximum likelihood procedures in SAS. Organizational characteristics was the single best predictor of both commitments. When the commitments were modeled and tested in unison, the results indicate that organizational commitment plays a minor role in predicting outcomes. Professional commitment was the best predictor of satisfaction and performance.

The structural model was unable to account for turnover. A regression analysis showed that organizational commitment was the most important variable for predicting turnover.

The Analysis of Variance results supported differences across occupations for the professional commitment measure. Managers and professionals had the highest level of professional commitment. 


\section{P.CKNOWLEDGEMENTS}

I would like to express my appreciation and gratitude to the members of my dissertation committee for serving so willingly and ably. It was a privilege to have had such a supportive and skilled committee. I am especially grateful to Dr. Alan Cabelly for chairing my committee and for motivating me to persist. I appreciate his many significant contributions to my professional development. I thank Dr. Nancy Perrin for her prompt feedback, careful editing, and sound suggestions. I benefitted greatly from her participation. I thank Dr. David Gerbing for his valuable methodological contributions. Without his tutelage, I would not have survived the initial data analyses. I thank Dr. Donald Freeborn for his encouragement and support. Dr. Freeborn was instrumental in helping me to transform my ideas about commitment into a dissertation. He also helped make it possible for me to include my questionnaire items in the Employee Survey. I thank Dr. Marty Zwick for his support and insightful comments. He helped me to think beyond the bounds of my dissertation.

Special thanks must go to the center for Health Research and Kaiser Permanente for allowing me to use data 
from the Employee Survey and for all of their support. I especially want to acknowledge Laura Schrager for guiding me through the Employee Survey Data set and providing information about the survey and the respondents. I thank Sara Lamb, Employee Survey Project Director, for providing historical information about the survey and supporting my efforts.

Special thanks must go to my wonderful husband, Gary, who has patiently supported me in every way, and to my parents, relatives, and friends who managed to be enthusiastic about a seemingly endless endeavor. Without their love and support I would never have been able to complete this dissertation. Finally, I thank God for making it all possible. 
TABLE OF CONTENTS

PAGE

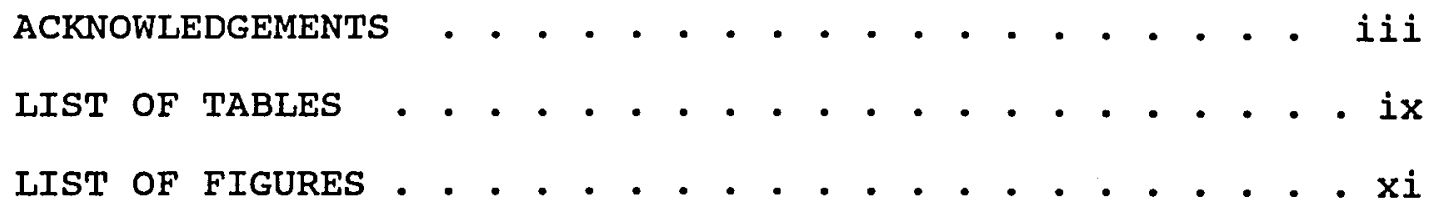

CHAPTER

I INTRODUCTION . . . . . . . . . . . . . . . 1

Research Issues . . . . . . . . 3

II LITERATURE REVIEW . . . . . . . . . . . 10

Commitment: The Construct in General . . 12

Definition

Previous Studies

Organizational Commitment . . . . . 20

Conceptual Definition

Operational Definition

Previous Studies

Professional Commitment . . . . . . 72

Conceptual Definition

operational Definition

Historical Background and Significance

Organizational and Professional commitment 94

Research Problems

Previous studies

Outcome Variables . . . . . . . . 103

Performance-Satisfaction

Withdrawal 
Reliability

Structural Model . . . . . . . . 177

Initial Findings

Structural Model Modifications

Simultaneous Measurement and structural Model

Cross Validation . . . . . . . . 192

Measurement Model

Structural Model

Multiple Regression . . . . . . 196

Analysis of Variance . . . . . . . 201

V DISCUSSION . . . . . . . . . . . . . . 204

Definition and Measurement of

Commitments . . . . . . . . . . 205

Measurement Model . . . . . . . 206

Structural Model . . . . . . . . 209

Antecedents of Professional Commitment

Antecedents of organizational Commitment Relationship Between the Commitments

outcomes of organizational commitment

outcomes of professional commitment

Performance and Satisfaction

overall Model

Conclusion

Cross Validation . . . . . . . . 220

Multiple Regression . . . . . . . . 221

Analysis of Variance . . . . . . . . 222

Additional Applications and

Recommendations . . . . . . . . . 223

Recommendations for Researchers

Recommendations for Management

Conclusion 
viii

REFERENCES . . . . . . . . . . . . . . . . 230 APPENDICES

A QUESTIONNAIRE ITEMS . . . . . . . . . . . . 248

B $65 \times 65$ INTERITEM CORRELATION MATRIX . . . . 258

C $64 \times 19$ ITEM-FACTOR CORRELATION MATRIX • . . 277

D $12 \times 4$ FACTOR-FACTOR CORRELATION MATRIX . . 280 


\section{LIST OF TABLES}

TABLE

PAGE

I

II

III

IV

V

VI

VII

VIII

IX

$\mathrm{x}$

XI

XII

XIII

XIV

XVI

XVI

XVII

XVIII

XIX
Definitions of Commitment . . . . . . . . . 14

OCQ Reliability . . . . . . . . . . . . 31

oce Validity-Dimensionality . . . . . . . 34

OCQ Validity-Discriminant . . . . . . . . . 42

OCQ Validity-Convergent . . . . . . . . . 45

OCQ Validity-Predictive . . . . . . . . . 47

Hrebiniak \& Alutto Psychometric Properties . . 52

Commitment as an Independent Variable . . . 64

Commitment as a Dependent Variable . . . . 65

Commitment Studies with Both Antecedent and

Outcome Measures . . . . . . . . . . 70

Studies Investigating Both Organizational and Professional Commitments . . . . . . . . 98

Sources of Unreliability in Withdrawal Data . 116

Type of Sample Size Effects . . . . . . . 129

Analytic Techniques of Past Research . . . 134

Sample Size. . . . . . . . . . . . 140

Employee Survey Respondents Job Category

Distributions . . . . . . . . . . . . 145

Initial Measurement Model Items and Factors - 156

Hypothesized Causal Relationships Among Study

Variables . . . . . . . . . . . . . . 159

Hypothesis of Structural Relationships . . . 162 
Proposed Measurement Model Items and Factors 165

XXI ITAN Measurement Model Items and Factors . 169

XXII LISREL Measurement Model Items and Factors • 171

XXIII First-order Factor Analysis Results . . . . . 173

XXIV Second-order Factor Analysis Results • • • • 176

$\mathrm{XXV}$ Reliability coefficients . . . . . . . . 178

XXVI Initial structural Model Results . . . . . . 181

XXVII Structural Model Modifications . • . . . • 183

XXVIII Summary of Structural Equations . . . . . . 190

XXIX Variance Accounted for in Endogenous

Variables . . . . . . . . . . . . . . 191

XXX Summary of Cross Validated structural

Equations . . . . . . . . . . . . . 194

XXXI Cross Validated Variance Accounted For • • 195

XXXII Scale Score Summary Information . . . • • • 198

XXXIII Regression Results . . . . . . . . . . . . 200

XXXIV Occupational Group Mean Differences . • • • 202 


\section{LIST OF FIGURES}

FIGURE

PAGE

1. A General Model of Work Behavior . . . . . 153

2. First-order Factor Analysis Structure . . 157

3. Second-order Factor Analysis Structure . . 158

4. Initial Structural Model . . . . . . . 160

5. Proposed First-order Factor Analysis Structure . . . . . . . . . . . . . 166

6. Proposed Second-order Factor Analysis structure . . . . . . . . . . . . . . 174

7. Proposed Structural Model . . . . . . . 179

8. Structural Model Modification 1. . . . . 184

9. Structural Model Modification 2. . . . . 186

10. Structural Model Modification 3. . . . . 187

11. Final Structural Model . . . . . . . . 189 
CHAPTER I

\section{INTRODUCTION}

My interest in professional and organizational commitment originated in a human resource management seminar. Many of the readings and discussions focused on professionals in organizations. One of the themes was that professionals were different from nonprofessionals. For this reason it was suggested that managing professionals called for different management skills and behaviors. This seemed reasonable if there were true differences. What caught my attention was how "professional" was defined. Doctors, lawyers, certified public accountants, and scientists were defined as "professionals". Secretaries, clerks, nurses and teachers were not.

The definition of professional was based solely on membership in a particular occupation and not on any selfperception or behaviors. This is a limited view of "professional" behavior in organizations.

In my work experience and in discussions with others, I discovered that managers and others were able to identify "professionally" behaving individuals in the work place and it had relatively little to do with their occupational status. The behavior of these "professional" individuals 
differed markedly from others in that they were committed to their work. Through their commitment their motivation and performance were perceived to be superior to noncommitted individuals.

The behavior of professionals within organizations has been extensively studied, while the study of professional behavior or commitment within organizations has not. There is a difference between these two approaches. The first approach focuses on a particular occupation. The second approach is concerned with how an individual's commitment to his or her profession or occupation affects his or her behavior in the work place. One of the purposes of this study was to explore the second approach.

How individuals behave "professionally" in the work place may be more important than their occupational status in understanding "professionals" in organizations. Professional commitment crosses the boundaries of occupational groups. It assumes that members within and across all occupations possess varying levels of commitment to their occupation/profession. It is the level of commitment to the profession that may distinguish differences in behavior within organizations and not necessarily membership in a particular occupation.

In order to investigate the impact of professional commitment in the work place, it was necessary to frame it in the context of other organizationally relevant behaviors. 
Organizational commitment was selected because of its recognized importance in the work place and because of the idea that individuals experience multiple commitments. In order to better understand how commitment affects behavior, it is necessary to examine variables that are antecedent to commitment and variables that may be affected by commitment. Antecedent and outcome variables provide an integrated examination of how commitments may operate in the work place. Job characteristics, individual characteristics, satisfaction, performance and turnover are other organizationally relevant variables that were selected for study.

This study had four main purposes:

* To investigate the relationship between commitment to one's profession and commitment to one's organization.

* To examine the role the commitments play in predicting satisfaction, performance, and withdrawal from an organization while controlling for other antecedent variables.

* To use covariance structural modeling (CSM) techniques to model and test the measurement and structural properties of the relationships between the variables.

* To investigate how individuals across different occupations vary in their professional commitment.

RESEARCH ISSUES

Despite the large number of research studies that have focused either on organizational commitment or professionalism, a number of research issues remain: 
* There has been a lack of examination of the relationship between professional and organizational commitment.

* There is continued ambiguity in the conceptualization and measurement of organizational and professional commitment.

* Researchers have failed to provide a framework for understanding the system of relationships between the commitments and their antecedents and outcomes.

* Methodological issues threaten the usefulness of past research.

* Investigators have limited their research primarily to the study of either the antecedents or outcomes of commitment and have tended to focus on only one category of antecedent or outcome variables.

* Researchers have used only nembers of the traditional professions as subjects to test and validate measures of professionalism.

These shortcomings in the literature have important theoretical and applied significance. The shortcomings formed the basis of this investigation.

The first research problem, the lack of examination of the relationship between professional and organizational commitment is due in part to a concentration in the past on what was thought of as an inherent conflict between professionals and the organization. The stidy of a possible dual nature of multiple commitments went largely ignored.

Few researchers attempted to study both organizational and professional commitment within the framework of a single study. The primary interest of the studies that have incorporated both organizational and professional 
commitments was to establish the temporal sequence of the two commitments and then correlate the commitments with satisfaction or turnover. No study has examined professional and organizational commitments both as independent variables in a system of antecedent and outcome variables.

The second research problem is that there is ambiguity in the conceptualization and measurement of organizational and professional commitment. Organizational commitment has been conceptualized either as attitudinal alignment with the organization or as investments in the organization.

Attitudinal alignment conceptualizations state that individuals perceive an agreement between their personal values, attitudes, and goals and those of the organization. Because of this agreement, individuals become bound to the organization and are willing to exert effort on the organization's behalf.

The investment model characterizes commitment in terms of investments in the organization that the individual accumulates over time. Investments include such items as pension plan, seniority, promotion opportunities, and profit sharing.

The trend has been for researchers to use attitudinal alignment rather than investment model scales for measuring organizational commitment. However, empirical research has 
not established which measure is superior or what the differences may be.

Professional commitment has been conceptualized either as a unidimensional or multidimensional construct. Unidimensional studies argue that individuals are either committed to their profession or to the organization. Multidimensional studies suggest that professional commitment is conceptually distinct from organizational commitment and is composed of separate factors.

The measurement of professional commitment has not been established as well as has organizational commitment. There are no agreed upon, validated measures for the construct.

The mix of attitudinal and investment models of organizational commitment combined with either a unidimensional or multidimensional model of professional commitment makes it difficult to compare results across studies. There exists a real need for researchers to further examine the measurement and conceptualization issues surrounding both organizational and professional commitment.

The third research shortcoming is that a framework for understanding the system of variables is lacking. The system of variables of interest includes antecedents to the commitments, the commitments themselves, and the outcomes of the commitments. The antecedent variables in this study were personal characteristics, job characteristics, and organizational factors. Organizational and professional 
commitment were the primary commitments of interest. The outcome variables included satisfaction, performance, and withdrawal from the organization.

To facilitate a better understanding of how these variables are interrelated, a framework for understanding was needed. This study used a general model of work behavior to frame the variables of interest.

Fourth, methodological issues threaten the usefulness of past research. There were six primary methodological issues.

1. The majority of studies on commitment have relied upon various regression techniques to analyze the proposed relationships. Regression techniques do not allow the researcher to model multiple dependent variable or networks of interlinking relationships. Furthermore, regression does not account for error in measurement.

2. Confirmatory factor analysis has not been fully used to assess the dimensionality and validity of the variables.

3. No second-order confirmatory factor analyses have been conducted on the commitments, performance, rewards and organizational characteristics constructs.

4. Past researchers have not linked the results of their confirmatory factor analyses of commitment with the evaluation of covariance structural models.

5. The use of small sample sizes in past research may have resulted in poor representativeness and generalizability.

6. The final method problem was the absence of the confirmation of results on hold-out sample data. 
The fifth research problem is the concentration of past studies on either the antecedents or outcomes of professional or organizational commitment. The concentration on only the antecedents or outcomes of commitment provides an incomplete picture of behavior. This practice was useful to reduce complexity in the early phases of research on commitment. The time has come now to integrate the pieces and look at the entire system of relevant variables.

This observation is also applicable to the past research that examined only one category of antecedents or outcomes. Individual, job and organizational characteristics are categories of antecedent variables. Satisfaction, performance, turnover, and absenteeism are categories of outcome variables. In order to determine the importance of these variables, multiple categories need to be examined in the same study. Covariance structural modeling techniques are best suited for this task.

The final research problem is the absence of examination of the construct of professionalism across a variety of occupations. Only members of the traditional professions are typically studied by researchers investigating professionalism. This is a shortcoming. The basis for using only members of the traditional professions such as doctors and lawyers, is the notion that professionals are different from the rest of the 
occupations. If there are true differences between the professions and other occupations, then the responses of these two groups on the professionalism scale should vary significantly. The measurement of professionalism has not been tested in this way.

The structural model did not take into account or model occupational differences. While mean differences on the professional commitment scale may exist across occupations, the causal structure between the variables was not hypothesized to vary.

This study attempted a resolution of these shortcomings via the use of second-order confirmatory factor analysis accompanied with covariance structural modeling of the antecedents and outcomes of organizational and professional commitment. This study also included a wide variety of occupations in the sample and confirmation of results on a hold-out sample of data. 
CHAPTER II

\section{LITERATURE REVIEW}

The accompanying literature review covered several distinct bodies of literature. The review was separated into different sections in order to provide clarity for the reader.

The first body of literature reviewed was the commitment construct in general. Commitment is widely addressed by different disciplines for different purposes. One of the important elements of commitment is the object of the commitment. The review of the literature on the construct in general focused on the process and definition of commitment and not on any particular object of commitment. An understanding of commitment in general provided the basis for understanding and evaluating organizational and professional commitment.

The second body of literature reviewed was organizational commitment. Building on the foundation presented in the construct of commitment in general, in organizational commitment the object of the individual's commitment is the organization. Theoretically, this commitment should be distinct from the general construct. The distinction is based on the object of the commitment. 
The review addressed the following issues: conceptual definition, different approaches to measurement, psychometric properties of the measurements, and significance of the construct.

The third body of literature reviewed was professional commitment. The individual's profession/occupation is the object of commitment in this review. Theoretically, this commitment should be distinct from commitment in general and organizational commitment. This review followed the format laid out in the organizational commitment review section. The fourth body of literature reviewed was organizational and professional commitment. This review was not simply a combination of the two previous reviews. The examination of multiple commitments is a recent phenomena. This may be one reason why this body of literature is comparatively smaller. In combining the two commitments, researchers examined how individual behavior is affected by multiple objects of commitment i.e., the organization and the profession. This review followed the format outlined previously.

The fifth literature review section was on outcome measures. Because the outcome measures were not the primary variables of interest in this study, their review was not as extensive as the reviews for the commitments. Major aspects of satisfaction, performance, and withdrawal from the organization were outlined as they pertained to commitment. 
COMMITMENT: THE CONSTRUCT IN GENERAL

\section{Definition}

Commitment is a central psychological process. Unlike love, freedom, or happiness, commitment is not a universal value. Following is a sampling of previous definitions of commitment from both psychology and sociology.

Abramson, Cutter, Kautz and Mendelson (1958) defined commitments as sequences of action with penalties and costs associated in such a way as to guarantee their selection. Becker (1960) describes commitment as a process by which an individual becomes bound to his actions through his investments that were not originally related to the action. Gerard (1965) referred to commitment as constraints that operate against changing behavior. Kiesler (1971) defined commitment as the binding of the individual to behavioral acts. Commitment is whatever it is that makes a person engage in or continue to engage in a course of action when difficulties or positive alternatives influence the person to abandon the action (Brickman, 1987).

Kanter (1972) offered the clearest definition of commitment. "In sociological terms, commitment means the attachment of the self to the requirements of social relations that are seen as self-expressive. Commitment links self-interest to social requirements. A person is committed to a relationship or to a group to the extent that he sees 
it as expressing or fulfilling some fundamental part of himself; he is committed to the degree that he perceives no conflict between its requirements and his own needs; he is committed to the degree that he can no longer has to have his needs met elsewhere. When a person is committed, what he wants to do is the same as what he has to do, and thus he gives to the group what it needs to maintain itself at the same time that he gets what he needs to nourish his own sense of self" (Kanter, 1972, pp.66-67). Kanter's definition of commitment includes factors that are important in commitment to organization and profession.

The common theme in all of these definitions is that commitment is a force that stabilizes individual behavior under circumstances where the individual might otherwise be tempted to change his behavior. The following is a review of previous studies on commitment.

\section{Previous studies}

Researchers have developed different ideas of how commitment develops and operates. Table I summarizes different authors definitions of commitment. Commitment can take many forms. Each of the developments offers some insight into the nature of commitment. Together they form a continuum of commitment with flow at one extreme and alienated commitment at the other.

Becker (1960) developed the notion of commitments as 
TABLE I

DEFINITIONS OF COMMITMENT

1. Side bets

- Commitment is a function of the rewards and costs associated with membership;

2. Attributions

-Commitment is a binding of the individual to behavioral acts that results when individuals attribute an attitude of commitment to themselves after engaging in behaviors that are explicit and irrevocable.

3. Individual/organizational

Goal congruence

-Commitment occurs when individuals identify with and extend effort toward common goals and values.

4. Flow

-Commitment occurs when individuals experience and act with total

involvement. 
side bets. An example will serve to explain this. A man has been working for a company for many years. During this time both he and the company have made regular contributions to a pension plan for his retirement. He then receives an offer of a more attractive job at a higher salary from another company. If he moves, he loses all of the money the company has invested in his pension plan. The pension plan is in a sense a bet the person has made that he will stay with his present job. A bet he stands to lose if he changes jobs.

Becker called this a side bet because it was not the main reason the person accepted the job. In this case the side bet or the commitment is something the person accumulated gradually over the years.

A side bet can have symbolic value rather than material value. For example, a person may turn down an attractive offer simply because he has given his word that he will stay with his present job. In this example the person loses not a pension, but a reputation for honesty or trustworthiness if he changes jobs.

The are several requirements for something to be a side bet. First, that the person has linked the item to a course of action that was initially unrelated to it. Second, that he stands to lose the item if that course of action is not followed. Third, that the person has chosen by prior actions to make this linkage. Finally, that the person is 
aware of having made the linkage. In a sense the person is committed not to the job at all but only to the pension fund. If he could keep the pension, he would most likely leave the job. In fact, following a line of reasoning familiar in social psychology, one way the person knows how valuable the pension is to him is by observing how reluctant he is to give it up.

Csikszentmihalyi in his book Beyond Boredom and Anxiety (1975) described the activities of chess players, mountain climbers, dancers, composers, and surgeons. The author identified the sensation people experience when they act with total involvement and called it "flow". According to his description, flow has several characteristics. First, the activity has the person's undivided attention. Second, all potentially intruding stimuli are kept out of attention. Third, the person feels in control. Fourth, the experience itself contains coherent, noncontradictory demands for action. Fourth clear, unambiguous feedback is provided. Finally, the activity is self-motivating and appears to need no goals or rewards external to itself.

The elements of "flow" clearly satisfy the essential fragment of meaning called commitment. Giving something one's undivided attention and pursuing the activity for years, often without appreciable reward, specifies an important kind of commitment. 
Commitment associated with the experience of flow in one's work is the opposite extreme of the alienated commitment in Becker's example of the man committed to his job solely because of the pension. People committed in the "Becker" sense do not feel free at all. Commitment as flow or as alienated commitment are both extreme. Neither is typical of the psychological state of most commitments. The extremes are needed to recognize the common elements of commitment.

One of the important elements of commitment is the object of the commitment. For example, in the alienated commitment example the object of commitment was the investment in the pension plan and not the job. The object of the commitment is important because it describes what the individual is committed to.

Commitment can mean very different things. One response to this was Johnson's (1973) differentiation between personal commitment and behavioral commitment. Personal commitment was defined as a strong personal dedication to a decision or to carrying out a line of action. Behavioral commitment refers to prior actions by the individual that force him or her to continue a line of action. This occurs whether he or she feels personally committed to it or not.

Related to the separation of commitments was Masters and Johnson's (1974) distinction between commitments of 
obligation and commitments of responsiveness. An example of a commitment of obligation is the situation in which marital partners stay together despite the fact that they are no longer giving each other pleasure. An example of a commitment of responsiveness is the situation in which marital partners stay together to affirm and extend the pleasure they experience with each other. These two examples capture the distinction between alienated commitment and commitment as flow.

Generally speaking, commitment is about the relationship between "want to" and "have to." Commitment involves three elements: A positive element, a negative element, and a bond between the two. The psychological manifestation of commitment where the negative element is salient is persistence. The psychological manifestation of commitment where the positive element is salient is enthusiasm. These are not mutually exclusive elements. They are logically independent. One can persist in a line of behavior without being enthusiastic, and one can be enthusiastic in an activity without persisting (Brickman, 1987) .

The three elements, positive, negative and the bond between the two, coincide with the conditions that have been found necessary for the occurrence of cognitive dissonance. The theory of cognitive dissonance has been a dominant 
influence in the shaping of modern experimental social psychology.

Dissonance theory has one central postulate as suggested by Festinger (1957). The occurrence of two thoughts that were dissonant or inconsistent with one another would be a source of psychological tension, which the person would be motivated to remove or reduce. A person's attitude is inconsistent with his behavior if he believes one thing while behaving in a way that is inconsistent with this belief. Dissonance can be reduced by changing one's behavior or adding new beliefs that support the behavior. Hundreds of experiments studying what people do in these situations have been reviewed by wicklund and Brehm (1976).

Dissonance theorists have been interested in commitment as an independent variable. Studies of marriage or work careers have been interested in commitment as a dependent variable. This study is interested in commitment as something that grows and changes over time and the process by which people attach positive and negative value to events in their lives. Professional and organizational commitments were examined in a system of antecedent and outcome variables in this study.

Becker, Csikszentmihalyi, Brickman, Johnson, and Masters and Johnson, suggested different ideas of how commitment develops and operates. Commitments can take many 
forms. Each of the developments offers some insight into the nature of commitment. Together they form a continuum of commitment with flow on one end and alienated commitment on the other. Professional commitment and organizational commitment are two forms of commitment that are important because they shape behaviors and attitudes in the work place.

One of the important elements of commitment is the object of the commitment. The object of the commitment is important because it describes what the individual is committed to.

ORGANIZATIONAL COMMITMENT

There are two ways of defining a concept: theoretically and operationally (Blalock, 1968). Validation is what ties these two definitions together. Validation can be partitioned into different strategies: face or content, discriminant, convergent, construct, and predictive. The merit of a construct can be judged on its evidence of validity. Another criterion for determining the worth of a construct is its consistency or reliability.

Validity is a unitary concept. There are not different kinds of validity, only different strategies for analyzing validity. Validity always refers to the degree to which the evidence supports inferences that are made from the measure. 
It is these inferences that are validated and not the measure itself (APA standards, 1985).

In accordance with the validation process outlined, the items necessary to examine in establishing the validity of the organizational commitment construct are: 1) the conceptual definition of organizational commitment; 2) the psychometric properties of its operationalization; and 3 ) the relationship between the conceptual and operational definitions (Nunnally, 1978).

\section{Conceptual Definition}

Considerable conceptual overlap exists between organizational commitment and a number of other work related attitudes i.e., loyalty, organizational attraction, identification, and involvement. Morrow (1983) documented how the growth in the volume of literature on work related attitudes such as commitment was not accompanied by careful examination and segmentation of the theoretical domain of each concept or the relationship between concepts. Commonly confounded constructs in commitment research include workrelated attitudes such as identification and involvement, proposed antecedents and consequences of commitment such as satisfaction and tenure and variables associated with the development of commitment such as behavior attribution (Morrow, 1983; O'Reilly \& Chatman, 1986). In presenting the various conceptual definitions of 
organizational commitment it is sometimes difficult to maintain clear distinctions. This is due to different authors defining their concepts poorly or ambiguously and because the same terms are used by different authors to denote theoretically different constructs. Attitudinal, behavioral and normative commitment are the most frequently used definitions of organizational commitment. Some researchers use one definition exclusively, while others combine or use multiple definitions of organizational commitment. Each of the primary definitions were reviewed. Porter, Steers, Mowday \& Boulian Attitudinal Approach. The Porter et al. definition states that commitment to an organization reflects the relative strength of an individual's identification with and involvement with that organization (Steers, 1977). Organizational commitment can be portrayed as having three major components: a) a person's strong belief in and an acceptance of the organization's goals; b) a person's willingness to exert considerable effort on behalf of the organization; and c) a person's desire to maintain membership (Porter, Steers, Mowday, and Boulian, 1974).

The three components of organizational commitment are operationalized in the organizational commitment Questionnaire (Porter et al., 1974). This definition and measurement are the most widely used. 
Mowday, Porter and steers (1982) made a distinction between attitudinal (normative) and behavioral (instrumental or calculative) commitment. Attitudinal commitment represents "a state in which an individual identifies with a particular organization and its goals and wishes to maintain membership in order to facilitate these goals" (Mowday et al., 1982).

Behavioral commitment involves the attachment of the individual to one or more behaviors. These behaviors cause the individual to become locked into an organization (Mowday et al., 1982).

The Porter et al. approach focuses on attitudinal commitment. They posit a cyclical relationship between attitudinal and behavioral commitment, but their model of organizational commitment is primarily concerned with attitudinal commitment. The reason for this focus is grounded in the object of commitment. Attitudinal commitment involves attachment to the organization, while behavioral commitment involves attachment to one or more behaviors. As outlined in the literature review on the commitment construct in general, what distinguishes commitment is the object of the commitment. clearly the focus of organizational commitment is the organization. This is not to say that behavioral commitment is unimportant or unrelated. In fact, Mowday et al. (1982) make specific reference to the idea that understanding the commitment 
process is facilitated by viewing these approaches as inherently interrelated.

Calculative Approach. The second most common definition of organizational commitment studied is calculative or behavioral commitment. Calculative commitment is built upon the work of Becker (1960). Hrebiniak and Alutto (1972) defined calculative commitment as a structural phenomenon which occurs as a result of individual-organizational transactions and alterations in side-bets or investments over time. Individuals become bound to the organization because they have investments in the organization.

The object of commitment in this approach is not the organization, but rather investments in the organization. For this reason, the calculative approach was rejected as defining organizational commitment.

Normative Approach. A departure from the Porter et al. (1974) model is the strictly normative approach. Buchanan (1974), Wiener (1982), and Scholl (1981) view organizational commitment as the affective attachment of the individual to the goals and values of the organization. The committed individual does not attach to the organization in return for rewards. The implication is that commitment is unaffected by organizational rewards, hence the link between committed individuals and the organization are more enduring. 
While theoretically possible, this approach is unrealistic. Individuals are offered rewards in organizations. These rewards are going to have an effect on behavior. The examination of only affective commitment does not exclude or seek to control the effects of rewards on commitment behavior; it simply doesn't investigate their effects.

Multidimensional Approach. A final approach to conceptualizing organizational commitment is the development of commitment through a variety of mechanisms and not simply through either attitudinal or behavioral attachments. O'Reilly and Chatman (1986), Meyer and Allen (1984), Penley and Gould (1988) refer to more than one dimension in their conceptualizations of organizational commitment.

o'Reilly and Chatman defined commitment in terms of internalization of organizational perspectives, compliance to gain rewards, and identification. Meyer and Allen referred to two independent types of commitment: affective and normative. Penley and Gould proposed three independent commitments: alienative, moral and calculative.

The main idea of multidimensional approaches is that the elements of organizational commitment are independent. This is contrary to Mowday, steers and Porter's (1979) unidimensional conceptualization of organizational commitment as measured by the OCQ. 
Conclusion. The review of the different approaches to defining organizational commitment formed the foundation for this study. Some of the discrepancies in the research on organizational commitment can be traced to the conceptual definition selected or failure to explicitly define concepts. The Porter et al. definition of organizational commitment was adopted for this study because it clearly defined the object and process of commitment and because the definition was congruent with the purposes of this study.

\section{operational Definition}

The two most popular approaches to measuring organizational commitment are the organizational commitment Questionnaire (OCQ) (Porter et al., 1974) and the Hrebiniak and Alutto (1972) Model. This review focused on these two approaches. As an example of the proliferation of new instruments, the Meyer and Allen (1984) approach received a limited review.

The OCQ measures moral commitment and identification with the organization. The Hrebiniak and Alutto Model is a measure of rewards and costs or side bets associated with organizational membership. Although the Hrebiniak and Alutto approach was rejected as defining organizational commitment its psychometric properties were reviewed. It is the second most widely used measure of organizational commitment and for this reason its psychometric properties 
merited review.

organizational commitment Questionnaire. The psychometric properties of the organizational commitment Questionnaire (OCQ) were analyzed in the following section. other operationalizations of organizational commitment were contrasted with the $O C Q$.

Content Validity. The OCQ, developed by Porter et al. (1974), is a 15 item questionnaire with six reverse scored items or a modified nine item version without reverse scored items (See Appendix A). The response format is a 7point Likert scale with the following anchors: strongly agree, moderately agree, slightly agree, neither agree nor disagree, slightly disagree, moderately disagree, strongly disagree. The mean score on the questionnaire represents a summary indicator of employee commitment to the organization.

The development approach used by Mowday et al. (1979) was to identify items that appeared to tap the three aspects of commitment (goal congruence, membership and effort on behalf of the organization). The items were submitted to a rigorous validation strategy which confirmed the usefulness of these items in measuring organizational commitment (Mowday et al., 1979). The validation strategy included measures of convergent, divergent and predictive validity of the nine and 15 item $O C Q$. 
Cooke (1989) argued in her dissertation that the content validity of the oce was in doubt. This criticism was based on her judgement that researchers were unable to place the 15 items in the Mowday et al. (1979) three aspects of commitment: belief and acceptance of organizational goals, willingness to exert effort on the organization's behalf, and a strong desire to remain with the organization. To demonstrate this, Cooke had 40 MBA students place each of the 15 items into one of the three categories. Based on the results of the student classifications, cooke rejected the content validity of the 15 item OCQ. Consequently, she reduced the OCQ to nine items. The nine items did not correspond with Porter et al.'s nine item scale. The remainder of her validation process was based on the nine items selected by the MBA students.

Cooke (1989) made an erroneous assumption about the 15 item OCQ. She assumed that the three components should not only be distinct, but also uncorrelated. According to Cooke, judges should be able to place the items of the OCQ into one of the three categories exclusively. Their failure to do so supports the notion that the OCQ has no content validity.

The problem with this logic and process is that the items are correlated to varying degrees. Overlap that exists between the items may cause the judges some difficulty in placing an item into a single category. 
Furthermore, if cooke's (1989) content analysis results are examined closely, it is apparent that the 15 items were judged essentially to belong to one of the categories. True correlation between items may account for the inability of the judges to place the 15 items into three exclusive categories.

Cooke (1989) went on to state that because the content validity of the $O C Q$ was in doubt, the general validity of the OCQ was questionable. The problem with this observation is that content validity is not considered validity at all (APA standards, 1985). Content validity is a subjective measure with no empirical component. Judgments about the content of measures are likely to differ from one individual to another. These judgments alone are not reason enough to reject a measure.

The content of the $O C Q$ has also been criticized on other grounds. Reichers (1985) and Scholl (1981) pointed out that the wording of some oce items that appear to assess the desire to maintain membership in the organization, may actually assess intention to quit or remain, rather than organizational commitment. This may account for the consistent relationship found between organizational commitment and turnover. The items Reichers and Scholl refer to are the reverse scored items. This criticism is not applicable to the nine item version proposed by Porter et al. (1979) because these items are left out. The 
criticism does, however, apply to Cooke's (1989) nine item version.

The psychometric properties of the OCQ were examined through a validation strategy that included multiple and diverse samples, cross-validation, and the use of a variety of other measure to assess the reliability, predictive, convergent and discriminant validity of the OCQ (Mowday et al., 1979). Reasonably strong evidence has been presented for each of these measures.

Reliability. Reliability estimates from various studies are listed in Table II. When multiple samples were used in a single study, the reliability estimates were averaged. Reported coefficient alphas were consistently high ranging from .76 to .93 with a median of .89 . The results of Mathieu and Zajac's (1990) meta-analysis showed the average reliability to be .88 across 90 samples. Test-retest reliability coefficients ranged from .65 to .90 with a median of .77 . The OCQ's test-retest reliability compared favorably with other attitudinal measures. These studies demonstrate strong support for the reliability of the organizational Commitment Questionnaire (Mowday et al., 1979)

It is worth noting that the negatively phrased items that were excluded in the nine item version of the ocd have lower average item-total correlations than did the positively worded items. This is a common occurrence, 
TABLE II

OCQ RELIABILITY

\begin{tabular}{|c|c|c|c|}
\hline$\overline{\text { NAME }}$ & DATE & $\begin{array}{c}\text { AVERAGE } \\
\text { RELIABILITY }\end{array}$ & $\begin{array}{c}\text { AVERAGE } \\
\text { TEST/RETEST }\end{array}$ \\
\hline Angle \& Perry & $1981 / 1983$ & .90 & \\
\hline Arnold \& Feldman & 1982 & .91 & \\
\hline Barling \& Wade & 1990 & .92 & \\
\hline Bateman \& strasser & 1984 & .90 & .65 \\
\hline Beauvais et al. & 1991 & .90 & \\
\hline Blau & 1986 & .86 & \\
\hline Blau \& Boal & 1989 & .84 & \\
\hline Bluedorn & 1982 & .90 & \\
\hline Colarelli \& Bishop & 1990 & .87 & \\
\hline Dornstein \& Matalon & 1989 & .83 & \\
\hline Dougherty et al. & 1985 & .90 & \\
\hline Ferris \& Aranya & 1983 & .90 & \\
\hline Glisson \& Durick & 1988 & .91 & \\
\hline Gray & 1989 & .88 & \\
\hline Hom et al. & 1979 & .89 & \\
\hline Jamal & 1990 & .86 & \\
\hline Jermier \& Berkes & 1979 & .91 & \\
\hline Lachman \& Aranya & 1986 & .91 & \\
\hline Luthans et al. & 1987 & .90 & \\
\hline Luthans et al. & 1985 & .91 & \\
\hline Martin \& $0^{\prime}$ Laughlin & 1984 & .84 & \\
\hline Mathieu & 1988 & .89 & \\
\hline Mathieu \& Hamel & 1989 & .90 & \\
\hline Mathieu \& Kohler & 1990 & .86 & \\
\hline Mathieu \& Zajac & 1990 & .88 (across & 90 samples) \\
\hline Meyer \& Allen & 1987 & .90 & \\
\hline Michaels \& Spector & 1982 & .90 & \\
\hline Morris \& Sherman & 1981 & .91 & \\
\hline Morris \& steers & 1980 & .88 & \\
\hline Morrow \& McElroy & 1986 & .90 & \\
\hline Mottaz & 1986 & .86 & \\
\hline Mottaz & 1988 & .85 & \\
\hline Mowday et al. & 1979 & .90 & .65 \\
\hline O'Reilly \& Caldwell & 1980 & & .88 \\
\hline Ormsby \& Watts & 1989 & & .90 \\
\hline Podsakoff et al. & 1986 & .87 & \\
\hline Porter et al. & 1974 & & .88 \\
\hline Putti et al. & 1989 & .76 & \\
\hline Randall et al. & 1990 & .82 & \\
\hline Randall & 1988 & .90 & \\
\hline Reichers & 1985 & .88 & \\
\hline
\end{tabular}


TABLE II

OCQ RELIABILITY

(continued)

\begin{tabular}{lccc}
\hline NAMI & DATE & $\begin{array}{c}\text { AVERAGE } \\
\text { RELIABILITY }\end{array}$ & $\begin{array}{c}\text { AVERAGE } \\
\text { TEST/RETEST }\end{array}$ \\
\hline Shore \& Martin & 1989 & .90 & \\
Steers & 1977 & .88 & \\
Stumpf \& Hartman & 1984 & .93 & \\
Van Maanen & 1975 & .73 & \\
Zaccaro \& Dobbins & 1989 & .93 & \\
Zahra & 1984 & .86 & \\
\end{tabular}


according to schmitt and stults (1985). They investigated this tendency and found that if ten percent of a sample carelessly responds to items, then the negative items would define a separate factor. This is important when trying to interpret negative factors. There is no way of knowing whether the results constitute a true factor or response error. This was another reason for excluding the negatively scored items in the OCQ.

Factor Analysis. Separate studies have assessed the dimensionality of the OCQ using factor analytic techniques. Exploratory, principal components, and confirmatory factor analysis are three methods of factor analysis which produce different results. For this reason each method was reviewed separately. Table III lists the number of factors that were found in each factor analytic study of the $O C Q$. The results are divided into each of the factor analytic methods.

\section{A. Exploratory Factor Analysis. Exploratory} factor analysis is a blind procedure whereby a computational algorithm is used to uncover a structure purely on the basis of the correlational structure of the items (Hunter \& Gerbing, 1982). There are several problems with this analytic technique. First, this method tends to lump all highly correlated variables into the sam factor. This makes it necessary to subcluster the results. Second, there is no "garbage can" for bad items. Every item has its highest 
TABLE III

OCQ VALIDITY-DIMENSIONALITY

\begin{tabular}{|c|c|c|c|c|}
\hline \multirow[t]{2}{*}{ NAME } & \multirow[t]{2}{*}{ DATE } & \multicolumn{3}{|c|}{ FACTOR ANALYSIS METHOD } \\
\hline & & EXPLORATORY & $\begin{array}{l}\text { PRINCIPAL } \\
\text { COMPONENT }\end{array}$ & CONFIRMATORY \\
\hline $\begin{array}{l}\text { Angle \& Perry } \\
\text { Blau } \\
\text { Brooke et al. } \\
\text { Cooke } \\
\text { Ferris \& Aranya } \\
\text { Geyer \& Pond } \\
\text { Luthans et al. } \\
\text { Mathieu \& Farr } \\
\text { Morrow \& McElroy } \\
\text { Mowday et al. } \\
\text { Putti }\end{array}$ & $\begin{array}{l}1981 \\
1986 \\
1988 \\
1989 \\
1983 \\
1988 \\
1985 \\
1991 \\
1986 \\
1979 \\
1989\end{array}$ & $\begin{array}{l}2 \\
1\end{array}$ & $\begin{array}{l}3 \\
1 \\
1\end{array}$ & $\begin{array}{l}1 \\
2\end{array}$ \\
\hline
\end{tabular}


loading on some factor and may be retained in the analysis in error. A final problem is the failure on the part of researcher to evaluate the scales for unidimensionality. For these reasons, the results of exploratory factor analysis studies are not weighted as heavily as methods that do not have these problems.

Mowday et al. (1979) factor analyzed the 15 item OCQ and found that all three samples had two factor solutions after varimax rotation. The first factor accounted for 83 to 93 percent of the variance. The second factor accounted for between 2 and 11 percent of the common factor variance. The eigenvalue for the second factor never exceeded 1.0 . For these reasons, the OCQ was interpreted as a unidimensional measure of organization commitment.

Three additional samples were factor analyzed using the nine item OCQ (Mowday et al., 1979). Two of those samples had one factor solutions and one had a two factor solution. The second factor accounted for 15.5 percent of the common factor variance.

Angle and Perry (1981) found three factors that had eigenvalues greater than 1.0. Only one item loaded on the third factor. Because the single item factor was considered unstable, the third factor was discarded. The first factor was named "value commitment" and included items $1,2,4,5$, $6,8,10,13 \& 14$ from the OCQ. The second factor was named "commitment to stay" and included items $3,7,9,11, \& 15$. 
All of the items in the second factor were reverse scored. Correlations between indicators of organizational effectiveness and the second and third factors were not found to be statistically significant.

Ferris and Aranya (1983) conducted a factor analysis of the $O C Q$ and the Hrebiniak and Alutto Scale. Their results indicated single factor solutions for each of the scales.

Blau (1986) factor analyzed the OCQ and job involvement items using first a principal components factor analysis to determine the number of factors and then a factor analysis with varimax rotation. Blau (1986) found that job involvement and the OCQ were independent. However, he failed to report the item correlation matrix or starting communality estimates, factor loadings, number of factors, or eigenvalues. These shortcomings make it difficult to evaluate his results.

Putti, Aryee and Liang (1989) factor analyzed the oce using varimax rotation with Kaiser normalization and found a two factor solution accounting for $46.3 \%$ and $9.3 \%$ of the variance, respectively. There was no clear pattern to the items loading on the second factor. For this reason and the small amount of variance accounted for, Putti et al. (1989) dropped the second factor and interpreted the OCQ as having one underlying construct.

Angle and Perry (1981), Ferris and Aranya (1983) and Putti et al. (1989) failed to report which factor analytic 
method was used in their studies. This shortcoming makes it difficult to evaluate the usefulness of their results. These studies were included in the exploratory factor analysis section, although it was unclear what factor analytic technique was used.

\section{B. Principal Components Factor Analysis. Geyer} and Pond (1988) conducted a principal components analysis on the $O C Q$ and two other measures. Their results indicated a three factor solution for the OCQ with one factor composed primarily of reverse scored items.

Morrow and McElroy (1986) compared five different work commitment measures using principal components factor analysis with varimax rotation. They found that the oce was independent from protestant work ethic, career salience, central life interest, and job involvement measures.

Luthans, McCaul and Dodd (1985) used principal factor analysis with varimax rotation to assess the internal consistency of the OCQ. The results indicated that for the U.S. and Japan samples, the $O C Q$ measured a single underlying construct. In the Korean sample two factors emerged. The second factor was composed entirely of the reverse scored items. There may have been some language translation problem, response bias or both operating in the Korean study. Caution should be used when interpreting this study. The usefulness of principal component factor analysis for assessing the validity of any scale is questionable. 
Principle component analysis does not account for common and unique variance related to each variable. It only calculates shared variance (Pedhazur, 1982).

c. Confirmatory Factor Analysis. Cooke (1989) used confirmatory factor analysis to assess the dimensionality and discriminant validity of the ocQ.

A confirmatory factor analysis of competing single factor and two factor models was performed to test the factor structure of the nine items of the OCQ selected by Cooke. The Goodness of Fit Index for two samples for the single factor model were .91 and .87 , respectively. The Goodness of Fit Index for the two factor model for both samples were .93 and .94. The Chi-square to degrees of freedom ratios for both models exceeded the 2.0 benchmark. Cooke selected the 2 factor model because of its modest improvement in fit. Reasons of parsimony contradict this decision.

Note, the nine items selected by cooke differed from any scale other researchers have used. Because she selected a unique subset of items, her analytic work can't be generalized to other studies using traditional modifications of the OCQ.

To assess the discriminant validity of the OCQ, cooke used separate discriminant validity analyses of the oce with the Minnesota Satisfaction Questionnaire (Weiss, Dawis, England \& Lofquist, 1967) and the Withdrawal Cognitions 
Scale (Blau \& Boal, 1987). While the separate analyses provide information about the OCQ and each of the scales, information about the relationship between all three scales was lost. Possible redundancies between the three measures were not tested. One of the strengths of a confirmatory factor analysis design is its capability of testing multiple scales simultaneously.

Finally, cooke tested various antecedent and outcome variables with the full 15 item OCQ and her nine item two dimensional OCQ. The antecedents were two justice variables and four leader characteristics. The outcomes variables were decision, role behaviors and withdrawal behaviors. Cooke selected a bivariate correlation method to assess the relationships. The specified one-dimensional model was found to have a superior fit.

Having used CFA to assess the measurement properties of the OCQ, it is unclear why cooke decided not to use CFA to assess the measurement properties of the other measures. This is a shortcoming. An assessment of the measurement properties of the various antecedents and outcomes could have been accomplished within the framework of the confirmatory factor analysis.

Brooke, Russell and Price (1988) and Mathieu and Farr (1991) also conducted confirmatory factor analyses of the OCQ. Their confirmatory factor analyses tested whether measures of organizational commitment, job involvement, and 
job satisfaction were assessing distinct attitudinal

dimensions. For this reason these studies were reviewed in the discriminant validity section.

The results of the exploratory factor analyses, principal components analyses and confirmatory factor analyses listed in Table III jointly support a unidimensional interpretation of the ocQ. organizational commitment was modeled as a unidimensional construct based on these findings.

\section{Discriminant Validity. Discriminant and} convergent validity are assessed by comparing the measurement scale of interest to other established measures. Convergent validity is established when the scale of interest is shown to be sufficiently related to similar measures. Divergent validity is established when the scale of interest is shown to be sufficiently unrelated to dissimilar measures. The methods for establishing discriminant and convergent validity are identical. The principal statistical techniques for assessing convergent and divergent validity are correlational analysis, exploratory factor analysis and confirmatory factor analysis.

Correlational analyses correlate the summary scores of different measures. A subjective judgement is made as to whether the coefficient is high enough to support convergent validity or conversely, low enough to demonstrate divergent 
validity. The problem with this method is that judgments differ on what level of coefficient indicates convergent or divergent validity.

Exploratory factor analysis indicates how items from each scale load on different factors. Divergent validity is demonstrated when items from each scale load on separate factors and those factors are sufficiently uncorrelated. Convergent validity is indicated when factors from similar scales are correlated at some acceptable level. This method has the same shortcoming as the correlational method. Additionally, there is no "garbage" category for bad items or factors. All items load highly on some factor. For this reason there is error that may cause artificial inflation or deflation of the coefficient.

Confirmatory factor analysis has advantages over both correlational analysis and exploratory factor analysis. Item-factor loadings are defined prior to the analysis. "Bad" items can be identified and eliminated based on this technique. Additionally, goodness of fit indices and significance tests indicate whether factors are sufficienily distinct and significant. For these reasons, studies using this methodology were weighed more heavily.

Studies assessing the discriminant validity of the ocQ are listed in Table IV. Brooke et al. (1988) examined the discriminant validity of the nine item OCQ, Kanungo's (1982) 
TABLE IV

OCQ VALIDITY-DISCRIMINANT

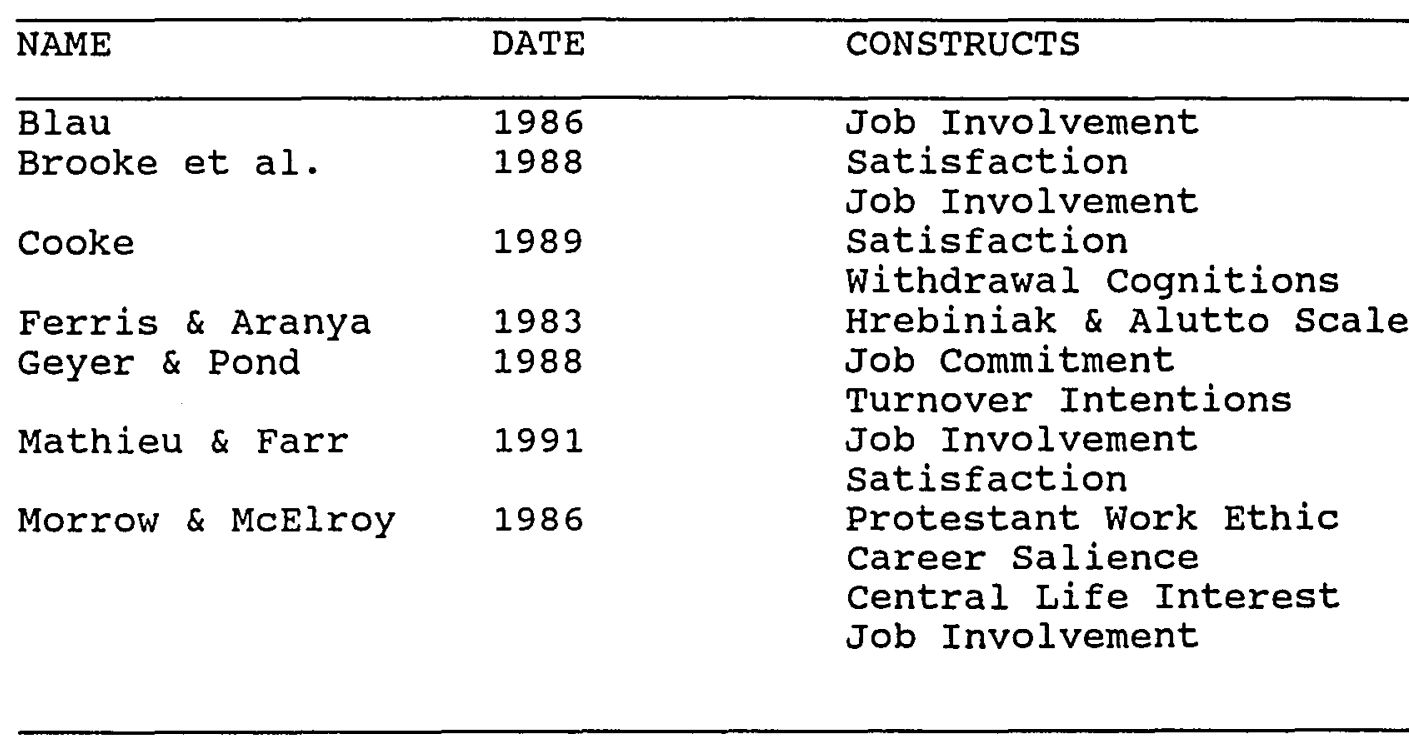


Job Involvement Scale, and Price and Mueller's (1981) six item Job Satisfaction Index. Using confirmatory factor analysis, they found these measures to be empirically distinct. A single factor model and a three factor model were tested. The three factor model provided a significantly better fit to the data. This conclusion was supported by the chi-square statistic, the normed fit index, and the ratio of chi-square to degrees of freedom index.

Mathieu and Farr (1991) replicated Brooke et al.'s findings in their study of the discriminant validity of organizational commitment, job involvement, and job satisfaction. They tested a three factor and several two and one factor models using confirmatory factor analysis. They found support for a three factor solution consistent with Brooke et al.'s (1988) findings.

As discussed previously, cooke (1989) used confirmatory factor analysis to assess the discriminant validity of the OCQ with the Minnesota Satisfaction Questionnaire (Weiss et al., 1967) and the Withdrawal Cognitions Scale (Blau \& Boal, 1987). The shortcoming of her work was the use of separate discriminant analyses.

Blau (1986) used principal components analysis and exploratory factor analysis to demonstrate the discriminant validity of the OCQ with Job Involvement. This approach differs from the confirmatory factor analysis approach to assessing discriminant validity. CFA examines the item 
correlations, while this approach examines summary score correlations. Both approaches provide acceptable, but different evidence of discriminant validity. Ferris and Aranya (1983), Geyer and Pond (1988), and Morrow and McElroy (1986) used approaches similar to Blau's in assessing the discriminant validity of the OCQ.

These studies provide support for the discriminant validity of the $O C Q$. No studies have assessed the discriminant validity of job characteristics, organizational characteristics, and performance with organizational commitment. The measurement properties of these variables were assessed in this study to determine whether concept redundancies may exist.

Convergent Validity. Studies assessing the convergent validity of the OCQ are summarized in Table $V$. Mowday et al. (1979) provided favorable evidence for the convergent validity of the OCQ. They investigated the relationship of different constructs which measure similar affective responses. The OCQ was found to be correlated with the Sources of Organizational Attachment Questionnaire, intention to leave, intended length of service, intrinsic motivation, motivational force to perform, Central Life Interest and Behavioral Ratings. Their findings when taken together support the convergent validity of the OCQ. Penley and Gould (1988) correlated the OCQ with measures of alienative, calculative and moral commitments, 
TABLE V

OCQ VALIDITY-CONVERGENT

\begin{tabular}{|c|c|c|}
\hline$\overline{\text { NAME }}$ & DATE & CONSTRUCTS \\
\hline Allen \& Meyer & 1990 & $\begin{array}{l}\text { Affective Commitment } \\
\text { Normative Commitment } \\
\text { Continuance Commitment }\end{array}$ \\
\hline Mowday et al. & 1979 & $\begin{array}{l}\text { Organizational Attachment } \\
\text { Intent to Leave } \\
\text { Length of Service } \\
\text { Intrinsic Motivation } \\
\text { Motivational Force } \\
\text { Central Life Interest } \\
\text { Behavioral Ratings }\end{array}$ \\
\hline Penley \& Gould & 1988 & $\begin{array}{l}\text { Moral Commitment } \\
\text { Alienative Commitment } \\
\text { Calculative Commitment } \\
\text { Hrebiniak \& Alutto Scale } \\
\text { Hall et al. Scale (1968) }\end{array}$ \\
\hline
\end{tabular}


the Hrebiniak and Alutto Scale and the Hall scale.

Significant correlations were found between the $O C Q$ and each of the other measures.

Allen and Meyer (1990) developed their own measures of organizational commitment and correlated these with the OCQ. Their Affective Commitment Scale was correlated .83 with the OCQ and their Normative Commitment scale was correlated .51 with the OCQ. Their continuance commitment scale was correlated -.02 with the $0 \mathrm{CQ}$. This study provided evidence of convergent validity between the Affective and Normative Commitment scales with the OCQ.

The evidence from Mowday et al., Penley and Gould, and Allen and Meyer provide support for the convergent validity of the OCQ. As noted by Mowday et al. (1979), one of the difficulties in assessing the convergent validity of the OCQ is the absence of acceptable standards for comparison.

Predictive Validity. Listed in Table VI is a summary of studies examining the predictive validity of the OCQ. The Table is divided into different sections for studies of the relationship between the $O C Q$ and turnover, absenteeism, satisfaction, and performance.

organizational commitment has frequently been studied as a predictor of turnover in organizations. Generally, the OCQ is correlated with measures of behavioral intentions of turnover and less frequently with actual turnover data. The 
TABLE VI

OCQ VALIDITY-PREDICTIVE

\begin{tabular}{|c|c|}
\hline NAME & $\overline{D A T E}$ \\
\hline $\begin{array}{l}\text { TURNOVER } \\
\text { Angle \& Perry } \\
\text { Arnold \& Feldman } \\
\text { Blau \& Boal } \\
\text { Blau \& } \\
\text { Bluedorn } \\
\text { Cotton \& Tuttle } \\
\text { Dougherty et al. } \\
\text { Ferris \& Aranya } \\
\text { Hom et al. } \\
\text { Mathieu \& Zajac } \\
\text { Meyer \& Allen } \\
\text { Michaels \& Spector } \\
\text { Mowday et al. } \\
\text { Porter et al. } \\
\text { Porter et al. } \\
\text { Shore \& Martin } \\
\text { Steers \& Hartman } \\
\text { stumpf \& Ha Hazer } \\
\text { Williams \& Hala } \\
\text { Zahra }\end{array}$ & $\begin{array}{l}1981 \\
1982 \\
1986 \\
1989 \\
1982 \\
1986 \\
1985 \\
1983 \\
1979 \\
1990 \\
1987 \\
1982 \\
1979 \\
1974 \\
1976 \\
1989 \\
1977 \\
1984 \\
1986 \\
1984\end{array}$ \\
\hline $\begin{array}{l}\text { ABSENTEEISM/TARDINESS } \\
\text { Blau } \\
\text { Mathieu \& Zajac } \\
\text { Mathieu \& Kohler } \\
\text { Mowday et al. } \\
\text { Steers } \\
\text { Zahra }\end{array}$ & $\begin{array}{l}1986 \\
1990 \\
1990 \\
1979 \\
1977 \\
1984\end{array}$ \\
\hline $\begin{array}{l}\text { PERFORMANCE } \\
\text { Darden et al. } \\
\text { Mowday et al. } \\
\text { Shore \& Martin } \\
\text { Steers } \\
\text { Stumpf \& Hartman } \\
\text { Van Maanen } \\
\text { Zahra }\end{array}$ & $\begin{array}{l}1989 \\
1979 \\
1989 \\
1977 \\
1984 \\
1975 \\
1984\end{array}$ \\
\hline $\begin{array}{l}\text { SATISFACTION } \\
\text { Bateman \& strasser } \\
\text { Darden et al. } \\
\text { Dougherty et al. } \\
\text { Curry et al. } \\
\text { Meyer \& Allen }\end{array}$ & $\begin{array}{l}1984 \\
1989 \\
1989 \\
1986 \\
1987\end{array}$ \\
\hline
\end{tabular}


evidence supports an inverse relationship between organizational commitment and turnover.

In the six studies where measures of absenteeism were available, the inverse relationship between organizational commitment and absenteeism was supported. The magnitude of the relationship was generally low. This was, however, to be expected since a number of factors in addition to organizational commitment are likely to affect absenteeism.

Few studies have investigated the relationship between performance, satisfaction and organizational commitment. The results of the studies listed in Table VI show modest support for positive relationships between performance, satisfaction and organizational commitment.

The results across these studies indicate strong support for the predictive validity of the OCQ. Additional research is needed to better examine the relationship between commitment, performance and satisfaction. Conclusion. The organizational commitment Questionnaire has acceptable psychometric properties. Separate studies support the reliability and validity of the instrument for measuring organizational commitment and predicting behaviors of interest to organizations.

Hrebiniak and Alutto Model. The properties of the Hrebiniak and Alutto Model were addressed in the same order as the Porter et al. approach. Content validity, 
reliability, dimensionality, discriminant, convergent and predictive validity were analyzed.

content validity. This approach defined organizational commitment in terms of exchange or rewardcost notions (Hrebiniak \& Alutto, 1972). The index for organizational commitment is a 12 item scale. Participants are asked to respond to questions concerning the conditions under which they would leave their present organization to join a different organization i.e., no increase in pay, a large increase in pay, more freedom or status, and friendlier coworkers.

The responses of no, uncertain, and yes are coded 3, 2, and 1, respectively. Summation of individual responses across the 12 items constitutes the summary score. The higher the score, the greater the individual's organizational commitment.

This scale measures the conditions under which individuals are likely to leave their present organization. It is unclear how this operationalizes the organizational commitment construct. It is also unclear how a committed individual differs from an uncommitted individual. Based on the summary score information, highly committed individuals are people who would not leave the organization under any circumstances. On the other hand, low or noncommitted individuals would leave the organization for very small improvements. 
To state that one is committed to an organization, is not to say that the individual will never leave that organization under any condition. organizational commitment is not absolute.

The object of commitment in this approach is not the organization, but rather is the commitment to investments or side-bets. For this reason the Hrebiniak and Alutto (H-A) approach does not fit the definition of organizational commitment. Because of the widespread use of this instrument for assessing organizational commitment, its psychometric properties were reviewed.

The interest in organizational commitment stemmed from the idea that committed employees would differ from uncommitted employees in systematic ways in terms of attitudes, performance, satisfaction and withdrawal behaviors. Through the measurement of commitment, researchers hoped to determine its processes, antecedents and consequences in order to improve organizationally relevant behaviors. Commitment in this sense has a broader meaning then leaving or staying in the organization. This scale does not measure attitudinal or behavioral commitment, but rather under what conditions individuals are likely to leave the organization. Leaving the organization may be a function of organizational commitment or other variables, but is not a measure of the commitment construct. 
The content of this approach can also be criticized on other grounds. Reichers (1985) criticism of the OCQ is applicable to this model. The $\mathrm{H}-\mathrm{A}$ Scale is composed entirely of responses to the question: "Would you leave your present organization under any of the following conditions?" Conceptual overlap may exist between this scale and measures of turnover. This may account for the consistent relationship found between turnover and this measure of organizational commitment.

Reliability. Internal reliability estimates for the $\mathrm{H}-\mathrm{A}$ Scale are listed in Table VII. Mathieu and Zajac (1990) provide a more comprehensive summary of reported reliability estimates in their meta-analysis. They reported an average reliability of .88 across 23 studies. There are no reported data on the test-retest reliability of the Scale. These studies provide support for the reliability of the $\mathrm{H}-\mathrm{A}$ Scale.

$$
\text { Dimensionality. Evidence of the H-A Scale's }
$$
dimensionality, convergent and divergent validity was limited. Ferris and Aranya (1983) conducted a factor analysis of the H-A Scale and found a single factor solution. This suggests that the scale measures a single underlying construct.

Penley and Gould combined items from alienative, moral and calculative commitment scales and conducted a principal components factor analysis. The analysis supported three 
TABLE VII

HREBINIAK \& ALUTTO PSYCHOMETRIC PROPERTIES

\begin{tabular}{|c|c|c|c|c|c|c|}
\hline NAME & DATE & REL & DIM & DISC & CONV & PRED \\
\hline $\begin{array}{l}\text { Alutto et al. } \\
\text { Aranya \& Ferris } \\
\text { Ferris \& Aranya } \\
\text { Hrebiniak \& Alutto } \\
\text { Kidron } \\
\text { Mathieu \& Zajac } \\
\text { Meyer \& Allen } \\
\text { Penley \& Gould }\end{array}$ & $\begin{array}{l}1973 \\
1983 \\
1983 \\
1972 \\
1978 \\
1990 \\
1984 \\
1988\end{array}$ & $\begin{array}{l}.69 \\
.95 \\
.93 \\
.79 \\
.84 \\
.88 \\
.87 \\
.72\end{array}$ & 1 & $\mathrm{x}$ & $\begin{array}{l}x \\
x\end{array}$ & $\begin{array}{l}X \\
X\end{array}$ \\
\hline
\end{tabular}


factors representing moral, calculative and alienative commitment. New scales were created/that corresponded with the different commitments. Because the calculative commitment scale was not directly comparable to the Hrebiniak and Alutto Scale, the factor analysis was not considered a test of the dimensionality of the Hrebiniak and Alutto scale.

\section{Discriminant Validity. The Ferris and Aranya} (1983) factor analysis of the OCQ and H-A Scale supported a single factor solution for each of the scales. Meyer and Allen (1984) reported that the $\mathrm{H}-\mathrm{A}$ scale correlated significantly with their Affective commitment scale and Kidron (1978) found the H-A scale to be significantly correlated with Hall's (1968) Moral Commitment Measure. The findings of the last two studies were contrary to expectations and raise concern about the discriminant validity of the scale.

Convergent Validity. Meyer and Allen (1984) and Ferris and Aranya (1983) found significant correlations between the Hrebiniak and Alutto Scale and the $O C Q$. Additionally, Meyer and Allen found significant correlations between the H-A Scale and the Ritzer and Trice Scale (1969), and their continuance commitment measure. These studies support the convergent validity of the $H-A$ scale. Kidron (1978) reported no significant relationship between the Hrebiniak and Alutto Scale and Protestant Work Ethic. This 
finding differed from the relationship found with other organizational commitment measures.

Predictive Validity. Cohen and Lowenberg (1990)

reviewed over 250 studies of which 50 included correlational data dealing with side-bet variables and organizational commitment. The results of their meta analysis of the sidebet variables indicated that there was very little empirical support for the side-bet theory. The side bet variables had no meaningful or generalizable relationship with organizational commitment. Side-bet variable included: age, tenure, education, gender, marital status, children, level in the organization, number of jobs in the organization, skill level, job alternatives and pay.

Ferris and Aranya (1983), Aranya and Ferris (1983) and Mathieu and Zajac (1990) have studied the relationship between the $\mathrm{H}-\mathrm{A}$ scale and turnover. These studies reported limited support for the predictive validity of the $\mathrm{H}-\mathrm{A}$ scale and are listed in Table VII.

Conclusion. This scale was rejected as the measure of organizational commitment for several reasons. The primary reason was because the object of commitment was investments and not the organization. Furthermore, the psychometric properties of this scale were not strongly supported. A summary of the studies investigating the psychometric properties of the $\mathrm{H}-\mathrm{A}$ Scale are listed in Table VII. 
Meyer and Allen Approach. Meyer and Allen (1984) were motivated to develop their scales because of the confusion surrounding the conceptual and measurement properties of organizational commitment. Their approach was to make a distinction between different conceptualizations of organizational commitment, develop measures of each, and demonstrate how these measures were different and linked to organizational commitment.

Content Validity. Meyer and Allen (1984) and Allen and Meyer (1990) developed new scales to measure what they termed continuance, normative and affective commitment. Each scale contained eight items.

Continuance commitment (CCS) was purported to measure the extent to which employees feel committed to their organization due to the costs associated with leaving. This is similar to the Ritzer and Trice (1969) and Hrebiniak and Alutto (1972) scales. The content of this scale differs from the two previous measures in that it does not specify costs associated with leaving the organization. The nature of the costs is left up to the respondents.

Affective commitment (ACS) is purported to measure emotional attachment to the organization. The items do not differ significantly from the OCQ.

Normative commitment (NCS) measures organizational commitment in terms of individual beliefs about one's responsibility to the organization. Wiener, Vardi and 
Muczyk (1980) developed a similar scale whose psychometric properties have gone untested.

Meyer and Allen's rationale for designing a new measure for organizational commitment was weak. Allen and Meyer (1990) stated that the OCQ and Cook and Wall (1980) measurements had acceptable psychometric properties. Their reasoning for developing a new measure was because of the confusion surrounding the existing measures. Their new measures do not solve this problem. They add to the conceptual and measurement difficulties.

Reliability. Meyer and Allen (1984) and Allen and Meyer (1990) reported an average alpha coefficient of .72 for the continuance commitment Scale (CCS). McGee and Ford (1987) found an alpha coefficient of .70 for the cCs.

Meyer and Allen (1984) and Allen and Meyer (1990) found the average alpha coefficient of .71 for the Affective Commitment Scale (ACS). McGee and Ford (1987) reported an alpha coefficient of .88 for the ACS.

Allen and Meyer (1990) reported an alpha coefficient for the Normative Commitment Scale (NCS) to be .79. No other researchers have reported using the NCS.

Data on the test-retest reliability of these scales was not available.

Validity. Allen and Meyer (1990) conducted a factor analysis of the Affective, Continuance and Normative Commitment scales. They reported a three factor solution, 
accounting for $58.8,25.8$, and 15.4 percent of the total variance, respectively.

No adjustments were made to their scales even though information from their factor analysis warranted it. Two items in the ACS loaded highly on factors 1 and 2 . One item in the ccs loaded highly on factor 1 and 3 .

Allen and Meyer (1990) correlated the ACS, CCS, and NCS with the $O C Q$ and found the OCQ to be significantly correlated with the ACS and NCS. The authors also found the NCS and ACS to be significantly correlated. The only scale found to be tapping into a different construct was the ccs. They went on to claim that the results of the correlations between the ACS, NCS, CCS, and OCQ provided evidence of the convergent and discriminant validity of the ACS, CCS, and NCS scales. This conclusion is unclear. Their findings indicate convergent validity of the ACs and NCS with the OCQ. Evidence of discriminant validity is provided between the CCS and OCQ. But, evidence of discriminant validity for the ACS and NCS was not collected. Evidence of the convergent validity of the ccs was also not collected.

McGee and Ford (1987) factor analyzed the Affective and Continuance Commitment scales and found support for a one factor solution of the ACS. For the CCS, they found a two factor solution, one associated with alternatives and the other with personal sacrifice. 
With respect to predictive validity, the relationship between the ACS and CCS and performance was investigated by Meyer, Paunonen, Gellaty, Goffin and Jackson (1989). Affective commitment correlated positively with performance measures and continuance commitment correlated negatively with performance measures. The findings were in the predicted direction. However, it is important to note that those who returned the questionnaire received significantly higher performance ratings than those who did not. This is a problem in terms of range restriction and generalizability of the findings.

Conclusion. There is no evidence to suggest that the Meyer and Allen measures are superior. The convergent, discriminant, and predictive validity of the Meyer and Allen scales were not strongly tested or supported.

The benefits of the Meyer and Allen approach are questionable. Several researchers have elected to create new scales to measure organizational commitment. The reasons for creating new scales are varied. Cook and Wall (1980) created a new scale because they believed the phrasing of items in existing scales were not suited for their population. Other researchers created new scales because of problems with either the psychometric properties of existing scales (Penley \& Gould, 1988) or different definitions of commitment (Decotiis \& Summers, 1987). 
The creation of scales causes new problems and does not necessarily solve old ones. The psychometric properties of new scales need to be evaluated across many studies and populations. This practice is costly in terms of resources and time.

Testing and retaining elements of existing measures and theory is beneficial. If elements from existing measures are found to be empirically unsound, then the possibility exists that data already collected could be reanalyzed. In addition, researchers would not have to start over and repeat research unnecessarily on a seemingly new approach.

Selection of the OCQ. The OCQ was selected as the measure of organizational commitment in this study for several reasons. First, the definition underlying the OCQ was congruent with the purposes of this study. Second, the OCQ has been widely tested and accepted. Finally, the OCQ was selected because of its superior psychometric properties.

Conceptual difficulties related to the measure of commitment and turnover are avoided in this study. Because of Reichers (1985) criticism, items in the OCQ related to turnover were not used in the measurement of organizational commitment. The scale tests reliable and valid without these items (Mowday et al., 1979). 
Reichers (1985) suggested that the emphasis on organizational commitment as an intra-personal process should be shifted to increased attention to the nature of the organization. Examinations of the organization itself have been lacking.

For many employees the organization is an abstraction. What is real for them are co-workers, superiors, subordinates, and customers who collectively comprise the organization. The concept of organizational commitment may be better understood through an examination of the multiple components of commitment as well as characteristics specific to the organization.

This study addresses this issue by including organizational characteristics and rewards as antecedents to organizational commitment. Organizational characteristics are the environment in which employees establish or fail to establish organizational commitment. Supervision, clear work objectives, performance review processes, advancement opportunities, educational opportunities, and openness to new ideas are characteristics of the organization which may cause varying levels of commitment. Wages and benefits that are offered by the organization in exchange for employee performance and membership may also have a causal relationship with the development of organizational commitment. 
Wages and benefits in this study are modeled as a characteristic of the organization and not as individual investments or "side bets". This reflects more accurately organizational behavior. Wages and benefits are modeled as organizational characteristics because the organization has direct control over the nature and distribution of these variables. Individual perceptions, attitudes, and investments with respect to wages and benefits are dependent on organizational characteristics.

A second reason for modeling rewards as characteristics of the organization and not the individual, was that individual wages and benefits were not measured. In order to assess investments accurately, researchers need to measure each participant's wages and benefits accrued over time.

\section{Previous Studies}

In a recent book Mowday, Porter, and Steers (1982) provided an extensive review of the theoretical and empirical work completed on the concept of organizational commitment. organizational commitment has consistently been shown to be related to: a) employee behaviors such as job search activities, turnover, absenteeism and performance; b) attitudinal, affective, and cognitive constructs such as job satisfaction, job involvement, and job tension; c) characteristics of the employee's job such as autonomy, 
responsibility, role conflict, and ambiguity; d) personal characteristics such as age, sex, need for achievement, and job tenure. A host of other variables include unionization (Larson \& Fukami, 1984; Ormsby \& Watts, 1989; Barling \& Wade, 1990; Beauvais, Scholl \& Cooper, 1991), communication (Huff, Sproull \& Kieslex, 1989), gender issues (Gray, 1989), leader behavior (Luthans, Baack and Taylor, 1987), group commitment (Zaccaro \& Dobbins, 1989), career commitment (Darden, Hampton \& Howell, 1989; Colarelli \& Bishop, 1990), extra-organizational ties (Randall, 1988), and organization structure (Morris \& Steers, 1980; Podsakoff, Williams and Todor, 1986).

The diversity of the relationships coupled with the stability of the construct over time (Porter et. al., 1974), indicates the importance of this construct and provides a justification for pursuing a thorough understanding of organizational commitment.

Previous empirical research on organizational commitment is summarized in Tables VIII, IX and $\mathrm{X}$. Separate tables are provided for organizational commitment treated as an independent variable, dependent variable, and studies with both antecedents and outcomes of commitment. Only studies that used the organizational commitment Questionnaire (Mowday et al., 1979) are listed.

Independent variable. Studies of organizational commitment as an independent variable are listed in Table 
VIII. The primary outcome variables were performance, satisfaction, turnover and absenteeism. Organizational commitment was shown in these studied to be positively related to performance and satisfaction and negatively rejated to turnover and absenteeism.

Dependent Variable. The studies of organizational commitment as a dependent variable are listed in Table IX. The antecedents of organizational commitment are more varied and inconsistent (Reichers, 1985). The literature is characterized by a "laundry list" of significant antecedent variables. This inconsistency may be due to the manner in which organizational commitment was defined and operationalized.

The antecedent variables can be roughly grouped into three categories: individual characteristics, job characteristics, and organizational characteristics. Individual characteristics include: sex, age, race, marital status, tenure, self-image, education and personality characteristics. Job characteristics include: job demands, skill use, discretion, job challenge, job importance, and alternatives. Organizational characteristics include: rewards, job fit, opportunities, and supervision.

A meta-analysis of the correlates of organizational commitment was conducted by Mathieu and Zajac (1990). Their analysis was based on 124 published studies between 1974 and 1987. Organizational commitment measures were partitioned 
TABLE VIII

COMMITMENT AS AN INDEPENDENT VARIABLE

\begin{tabular}{|c|c|c|c|}
\hline RESEARCHERS & EAR & SAMPLE & OUTCOMES \\
\hline Aranya et al. & 1981 & Accountants & $\begin{array}{l}\text { Professional } \\
\text { commitment }\end{array}$ \\
\hline Arnold \& Feldman & 1982 & Accountants & $\begin{array}{l}\text { Search intent } \\
\text { Turnover }\end{array}$ \\
\hline $\begin{array}{l}\text { Bateman \& Strasser } \\
\text { Blau }\end{array}$ & $\begin{array}{l}1984 \\
1986\end{array}$ & $\begin{array}{l}\text { Nurses } \\
\text { Nurses }\end{array}$ & $\begin{array}{l}\text { Satisfaction } \\
\text { Turnover } \\
\text { Absenteeism }\end{array}$ \\
\hline $\begin{array}{l}\text { Blau \& Boal } \\
\text { Cotton \& Tuttle } \\
\text { Hom et al. } \\
\text { Mathieu \& Kohler } \\
\text { Mowday, Steers \& } \\
\text { Porter }\end{array}$ & $\begin{array}{l}1989 \\
1986 \\
1979 \\
1990 \\
1979\end{array}$ & $\begin{array}{l}\text { Insurance } \\
\text { Meta-Analysis } \\
\text { Military } \\
\text { Bus operators } \\
\text { Varied }\end{array}$ & $\begin{array}{l}\text { Turnover } \\
\text { Turnover } \\
\text { Turnover } \\
\text { Absenteeism } \\
\text { Absenteeism } \\
\text { Turnover } \\
\text { Tenure } \\
\text { Performance }\end{array}$ \\
\hline Porter et al. & 1976 & Management & Turnover \\
\hline Porter et al. & 1974 & Technicians & Turnover \\
\hline Randall et al. & 1990 & Manufacturing & $\begin{array}{l}\text { Behavioral } \\
\text { expressions }\end{array}$ \\
\hline Shore \& Martin & 1989 & $\begin{array}{l}\text { Bank tellers } \\
\text { Professionals }\end{array}$ & $\begin{array}{l}\text { Performance } \\
\text { Turnover }\end{array}$ \\
\hline Van Maanen & 1975 & Police recruits & Performance \\
\hline
\end{tabular}


TABLE IX

COMMITMENT AS A DEPENDENT VARIABLE

\begin{tabular}{|c|c|c|c|}
\hline$\overline{\text { RESEARCHERS }}$ & YEAR & SAMPLE & ANTECEDENTS \\
\hline Angle \& Perry & 1983 & Bus operators & $\begin{array}{l}\text { Individual } \\
\text { characteristics } \\
\text { Satisfaction }\end{array}$ \\
\hline Bartol & $1979 a$ & $\begin{array}{l}\text { Computer } \\
\text { scientists }\end{array}$ & $\begin{array}{l}\text { Professional } \\
\text { commitment }\end{array}$ \\
\hline Dornstein \& Matalon & 1989 & Israeli Army & $\begin{array}{l}\text { Individual } \\
\text { characteristics } \\
\text { Role } \\
\text { Structure } \\
\text { Work experience } \\
\text { Organizational } \\
\text { characteristics }\end{array}$ \\
\hline Glisson \& Durick & 1988 & $\begin{array}{l}\text { Human service } \\
\text { workers }\end{array}$ & $\begin{array}{l}\text { Job factors } \\
\text { Individual } \\
\text { characteristics } \\
\text { Organizational } \\
\text { characteristics }\end{array}$ \\
\hline Gray & 1989 & Nurses & $\begin{array}{l}\text { Individual } \\
\text { characteristics } \\
\text { Experience } \\
\text { Gender }\end{array}$ \\
\hline Jamal & 1990 & Nurses & $\begin{array}{l}\text { Stress } \\
\text { stressors } \\
\text { Type A }\end{array}$ \\
\hline Jermier \& Berkes & 1979 & Police & $\begin{array}{l}\text { Leader behavior } \\
\text { Task variety } \\
\text { Task dependence }\end{array}$ \\
\hline Luthans et al. & 1985 & $\begin{array}{l}\text { U.S.' Japan } \\
\text { Korea workers }\end{array}$ & $\begin{array}{l}\text { Age } \\
\text { Tenure }\end{array}$ \\
\hline Luthans et al. & 1987 & Variety & $\begin{array}{l}\text { Individual } \\
\text { characteristics } \\
\text { Locus control } \\
\text { Leader behavior }\end{array}$ \\
\hline Martin \& $O^{\prime}$ Laughlin & 1984 & Military & $\begin{array}{l}\text { Individual } \\
\text { characteristics } \\
\text { Job factors } \\
\text { Turnover }\end{array}$ \\
\hline Mathieu & 1988 & ROTC cadets & $\begin{array}{l}\text { Satisfaction } \\
\text { Training }\end{array}$ \\
\hline Mathieu \& Hamel & 1989 & $\begin{array}{l}\text { Government } \\
\text { employees } \\
\text { University } \\
\text { faculty }\end{array}$ & $\begin{array}{l}\text { Structure } \\
\text { Role } \\
\text { Motivation } \\
\text { Needs } \\
\text { Mental health } \\
\text { Satisfaction }\end{array}$ \\
\hline
\end{tabular}


TABLE IX COMMITMENT AS A DEPENDENT VARIABLE
(continued)

\begin{tabular}{|c|c|c|c|}
\hline RESEARCHERS & YEAR & SAMPLE & ANTECEDENTS \\
\hline Morris \& Sherman & 1981 & $\begin{array}{l}\text { Mental health } \\
\text { workers }\end{array}$ & $\begin{array}{l}\text { Individual } \\
\text { characteristics } \\
\text { Role } \\
\text { Work experience }\end{array}$ \\
\hline Morris \& steers & 1980 & $\begin{array}{l}\text { University } \\
\text { faculty }\end{array}$ & structure \\
\hline Mottaz & 1986 & $\begin{array}{l}\text { University staff } \\
\text { Elementary } \\
\text { Police }\end{array}$ & $\begin{array}{l}\text { Education } \\
\text { Rewards } \\
\text { Values } \\
\text { Individual } \\
\text { characteristics }\end{array}$ \\
\hline Mottaz & 1988 & Same as 1986 & $\begin{array}{l}\text { Individual } \\
\text { characteristics } \\
\text { Rewards } \\
\text { Values }\end{array}$ \\
\hline o'Reilly \& Caldwell & 1980 & MBAS & $\begin{array}{l}\text { Intrinsic } \\
\text { factors } \\
\text { Extrinsic } \\
\text { factors }\end{array}$ \\
\hline Putti et al. & 1989 & Electronics & $\begin{array}{l}\text { Individual } \\
\text { characteristics } \\
\text { Work values }\end{array}$ \\
\hline Reichers & 1986 & Mental health & $\begin{array}{l}\text { Conflict } \\
\text { Individual } \\
\text { characteristics } \\
\text { Satisfaction }\end{array}$ \\
\hline Welsh \& Lavan & 1981 & $\begin{array}{l}\text { Hospital } \\
\text { employees }\end{array}$ & $\begin{array}{l}\text { Individual } \\
\text { Characteristics } \\
\text { Satisfaction } \\
\text { Job factors } \\
\text { Climate } \\
\text { Professional } \\
\text { behavior }\end{array}$ \\
\hline Zaccaro \& Dobbins & 1989 & $\begin{array}{l}\text { R.O.T.C. } \\
\text { cadets }\end{array}$ & $\begin{array}{l}\text { Job factors } \\
\text { Organizational } \\
\text { characteristics } \\
\text { Satisfaction }\end{array}$ \\
\hline
\end{tabular}


into attitudinal, calculative and other categories. Correlations of $0-.20$ were considered small, between .21 and .40 were considered medium, and above .40 were considered large.

Mathieu and Zajac (1990) found no consistent relationship between the sex of the participants and organizational commitment. Marital status, tenure, autonomy, and performance exhibited small positive correlations with organizational commitment. Education and turnover exhibited small negative relationships with organizational commitment. Age and skill variety yielded a medium positive correlation with organizational commitment. Job involvement, occupational commitment, and satisfaction correlated highly with organizational commitment.

Mathieu and Zajac (1990) concluded that the relationship between personal characteristics and organizational commitment correlations was fairly small. The influence of organizational characteristics on organizational commitment was found to be weak. The relationship between commitment and its consequences, was suggested to be mediated or moderated by other factors.

Researchers have tended not to examine variables from each of the three categories in their studies of organizational commitment. The focus is usually on one category or another. Steers (1977) Glisson and Durick (1988) and Morris and Sherman (1981) are the exceptions. 
These researchers sampled variables from multiple categories in their studies.

Steers (1977) was the first researcher to propose the three categories of antecedents for organizational commitment. He found work experiences, personal characteristics and job characteristics to be significantly related to organizational commitment at the .001 level. Furthermore, he found organizational commitment to be significantly related to several outcome measures.

Glisson and Durrick's (1988) indicated that individual and organizational characteristics were both good predictors of organizational commitment. Job characteristics were found to be more important for satisfaction than commitment.

Using stepwise multiple regression analysis, Morris and Sherman (1981) found that a subset of variables from each of the categories (individual, job, and organizational characteristics) explained $47 \%$ of the variation in organizational commitment. Each of the variables made a unique and significant contribution to the variance explained in commitment. The findings in this study supported the three category model of antecedents of commitment proposed by steers (1977).

Studies with Both Antecedents and outcomes. Commitment studies with both antecedent and outcome measures are listed in Table $\mathrm{X}$. Asterisks denote outcome variables. There is diversity in the number and types of antecedent and outcome 
variables in these studies. Turnover, absenteeism and performance are the most frequently studied outcome variables. Various individual, job and organizational characteristics are the most frequently studied antecedents. There is no agreement on which variables are essential for understanding commitment.

What is lacking in these studies is a framework for understanding and evaluating the importance of each variable. Model building and evaluation are for the most part absent. The literature is rich with examples of variables that are related to commitment. This information was used to build the model tested in this study.

Significance. A great deal of research has been conducted in the area of organizational commitment and its relationship to employee satisfaction, turnover, and productivity. Organizational commitment has been repeatedly identified as an important variable in understanding the behavior of employees. In addition to individual commitment to the organization, individual's are committed to their profession or occupation.

Professional commitment may be an important variable in understanding the complexity of employee behavior. Understanding these two commitments and their relationship may lead to a greater understanding of the behavior of employees. 
TABLE $X$

COMMITMENT STUDIES WITH BOTH ANTECEDENT AND OUTCOME MEASURES

\begin{tabular}{|c|c|c|c|}
\hline RESEARCHERS & YEAR & SAMPLE & VARIABLES \\
\hline Angle \& Perry & 1981 & Bus operators & $\begin{array}{l}\text { Individual } \\
\text { characteristics } \\
\text { Effectiveness } \\
\text { *Turnover } \\
\text { *Absenteeism }\end{array}$ \\
\hline Aranya et al. & 1982 & Accountants & $\begin{array}{l}\text { Professional } \\
\text { commitment } \\
\text { Need } \\
\text { * Satisfaction } \\
\text { *Turnover }\end{array}$ \\
\hline Bluedorn & 1982 & Insurance & $\begin{array}{l}\text { Individual } \\
\text { characteristics } \\
\text { Satisfaction } \\
\text { *Turnover } \\
\text { *Intent }\end{array}$ \\
\hline Cooke & 1989 & Air traffic & $\begin{array}{l}\text { Leader behavior } \\
\text { Justice } \\
\text { Role behavior } \\
\text { *Withdrawal }\end{array}$ \\
\hline Curry & 1986 & Nurses & $\begin{array}{l}\text { Organizational } \\
\text { structure } \\
\text { Individual } \\
\text { characteristics } \\
\text { Environmental } \\
\text { characteristics } \\
\text { *Satisfaction }\end{array}$ \\
\hline Dougherty et al. & 1985 & varied & $\begin{array}{l}\text { Satisfaction } \\
\text { *Turnover }\end{array}$ \\
\hline Ferris \& Aranya & 1983 & Accountants & $\begin{array}{l}\text { Individual } \\
\text { characteristics } \\
\text { Alternatives } \\
\text { Conflict } \\
\text { Satisfaction } \\
\text { *Turnover }\end{array}$ \\
\hline Mathieu \& Zajac & 1990 & Varied & $\begin{array}{l}\text { Individual } \\
\text { characteristics } \\
\text { Job factors } \\
\text { Organizational } \\
\text { characteristics } \\
\text { * Satisfaction } \\
\text { *Performance }\end{array}$ \\
\hline Meyer \& Allen & 1987 & Students & $\begin{array}{l}\text { Work experience } \\
\text { Satisfaction } \\
\text { *Turnover }\end{array}$ \\
\hline
\end{tabular}


TABLE $X$

COMMITMENT STUDIES WITH BOTH ANTECEDENT AND OUTCOME MEASURES (continued)

\begin{tabular}{|c|c|c|c|}
\hline$\overline{\text { RESEARCHERS }}$ & YEAR & SAMPLE & VARIABLES \\
\hline Michaels \& Spector & 1982 & $\begin{array}{l}\text { Mental health } \\
\text { workers }\end{array}$ & $\begin{array}{l}\text { Age } \\
\text { Job factors } \\
\text { Leadership } \\
\text { Expectations } \\
\text { *Intent } \\
\text { *Turnover }\end{array}$ \\
\hline Podsakoff et al. & 1986 & $\begin{array}{l}\text { Pharmacy tech } \\
\text { Government } \\
\text { Mental health } \\
\text { workers }\end{array}$ & $\begin{array}{l}\text { Ambiguity } \\
\text { Formalization } \\
\text { Conflict } \\
\text { *Alienation }\end{array}$ \\
\hline steers & 1977 & $\begin{array}{l}\text { Scientists } \\
\text { Engineers }\end{array}$ & $\begin{array}{l}\text { Individual } \\
\text { characteristics } \\
\text { Job factors } \\
\text { Work experience } \\
\text { *Attendance } \\
\text { *Turnover } \\
\text { * Performance }\end{array}$ \\
\hline stumpf \& Hartman & 1984 & Students & $\begin{array}{l}\text { Job fit } \\
\text { Performance } \\
\text { *Turnover }\end{array}$ \\
\hline Zahra & 1984 & Engineers & $\begin{array}{l}\text { Individual } \\
\text { characteristics } \\
\text { Job factors } \\
\text { Leadership } \\
\text { Satisfaction } \\
\text { Involvement } \\
\text { *Performance } \\
\text { *Withdrawal }\end{array}$ \\
\hline
\end{tabular}


PROFESSIONAL COMMITMENT

\section{Conceptual Definition}

Professional commitment in this study is not occupation specific. It refers to employee identification and commitment to their profession/occupation.

It is important to distinguish between the definition of a professional and the definition of professional commitment. Definitions of a professional are concerned with characteristics that distinguish professionals from nonprofessionals. Professional definitions are constrained to identifying specific occupations that qualify as a profession from occupations that do not.

Professional commitment is not by definition concerned with differences between occupations. The focus of professional commitment is on individual identification and alignment of goals with a profession/occupation and how this commitment affects organizationally relevant behaviors. The definitions of professionals and professional commitment have been blurred in past research efforts.

The focus of this study is on how individuals across occupations behave "professionally". This is distinguished from being a "professional". People are able to identify individuals within organizations that behave professionally from those that do not. Their judgments are not necessarily based on the education, training or professional status of 
the individuals under observation, but focus rather on behavior. The variables of interest in this study, therefore, are those characteristics that distinguish employees that are committed their profession/occupation from those that are not committed.

While defining which occupations qualify as professions is not a purpose of this study, research on the definition of professionals contains information that is relevant. For this reason various definitions of professional were reviewed. The definitions of professionals were then contrasted with conceptualizations of professional commitment.

Definitions of a Professional. Several different approaches to the definition of professional are evident in the literature. A summary of the various approaches was outlined in a recent review article by Lichtenstein (1984). He made the point that while the approaches differ in orientation, they were complementary, rather than conflicting. The focus of the review was on defining the nature and work of a profession and on differentiating this from nonprofessionals. Although this differs from the purpose of this study, the review was valuable because it traced the different definitions and lines of research on professionals in organizations.

The three definitions outlined were structural, process and power (Lichtenstein, 1984). Structural approaches to 
defining profession are based on the delineation of a series of static characteristics possessed by a professional and absent in a nonprofessional. Examples included prolonged training and education, service orientation, a basis of systematic theory, and a code of ethics.

The process approaches focus on key attitudes held by professionals. The most distinguishing feature is autonomy. Autonomy holds a central role in their work. Power approaches define professionals in terms of their level of autonomy, status, and responsibility. Professionals occupy the highest level (Lichtenstein, 1984).

Freidson (1970a; 1970b) provided a much broader review and definition of professional. Freidson's definitions and research on professionals are frequently cited. Hence, a brief review of his work may foster continuity between past and present research efforts.

According to Freidson $(1970 \mathrm{a} ; 1970 \mathrm{~b})$, a profession is a group of people who perform a set of activities which provide them with the major source of their subsistenceactivities which are called "work" rather than "leisure" and "vocation" rather than "avocation". The activities are performed for compensation and not for their own sake. When a number of people perform the same activity with common methods, pass on their methods to new recruits, and the methods become conventional, it is said that workers have 
been organized into an occupation. A profession is a special kind of occupation.

Freidson $(1970 a ; 1970 b)$ argued that a profession is distinct from other occupations because it has been given the right to control its own work. The autonomy granted to professions includes the exclusive right to determine who can legitimately do its work and how the work should be done. The source of professional status is by virtue of the protection and patronage of an elite segment of society which has been persuaded that there is special value in their work. The position is secured by the political and economic influence of the elite which sponsors the profession. Freidson (1970a) traced how the position of physicians was established as a profession from the rise of the university in this manner.

Freidson (1970a), however, denied the importance of training and licensing as criteria for defining a profession. His contention was that these practices grew out of the process of an occupation purposefully trying to become or be recognized as a profession and not because a unique and systematic body of theory and knowledge existed.

Freidson (1970a) argued that the only truly important and uniform criterion for distinguishing professions from other occupations is the fact of autonomy-a position of legitimate control over work. That autonomy is not 
absolute, but rather depends upon the toleration and even the protection by the state.

This orientation views a profession as a group of workers joined together on the most general level by virtue of sharing a particular position in society and by common participation in a given division of labor. The assumption here is that one defines a professional by her status, regardless of the norms to which she may subscribe and explains behavior with respect to the work structure in which she participates (Freidson, 1970a).

A second orientation views a profession as an aggregate of people finding identity in shared values and skills absorbed during a course of intensive training and socialization through which they all have passed. A professional is primarily a particular kind of person in this view. One determines whether an individual is or is not a professional by examining whether or not she has internalized certain professional values and conforms to the given set of norms (Freidson, 1970a).

Guidelines for defining a professional along the lines of the second orientation have been established. Kerr, Von Glinow, and Schriesheim (1977) in reviewing the literature found six characteristics that are acknowledged as representing professional status (Raelin, 1985; Miller, 1986): 
1. Expertise: engaging in prolonged specialized training in a body of abstract knowledge.

2. Autonomy: possessing the freedom to choose the examination of and means to solve problems.

3. Commitment: showing primary interest in pursuing the practice of one's chosen specialty.

4. Identification: identifying with the profession or with fellow professionals through formal association structures or through external referents.

5. Ethics: rendering service without concern for oneself or without becoming emotionally involved with the client. 6. Standards: committing oneself to help in policing the conduct of fellow professionals. (Von Glinow, 1988, pp. 12)

What is important in these observations about professionals is the focus on self perception. Many people perceive themselves as professionals who are outside the traditional professional job classes i.e., doctors, lawyers, ministers. What matters is how the individual perceives herself. If the individual perceives herself as a professional then the behaviors associated with professionals may logicaliy follow. The title of "professional" without the associated self-perception of professional does not necessarily lead to the behaviors associated with professionals. Hence, the distinction of whether a person is a "professional" or not may not be as important. What matters is how the individual perceives herself. 
Conceptual Definition of Professional Commitment.

Neither of Freidson's orientations for defining professional was adopted for this study. Freidson's orientations were included in order to contrast this study's conceptualization of "professional commitment" with traditional

conceptualizations of a professional.

The definition of professional commitment in this study was a modification of Freidson's second orientation which includes members of all occupations. Professional commitment is defined as an individual finding identity in the shared values and skills of his or her occupation. Professional commitment is characterized by a particular kind of person in this view. One determines whether an individual is or is not professionally committed by examining whether or not she has internalized certain values and conforms to a given set of norms.

This study sought to examine a different aspect of the construct "professional." Rather than focusing on the differences between professional and nonprofessionals, this study investigated how individuals across different occupations were "professionally" committed to their occupation.

"Professional" is this sense is not defined by membership in a particular occupation. What delineates an individual's professional behavior is the degree to which they meet the set of criteria the literature suggests 
defines professional behavior. Expertise, autonomy, identification, commitment, standards and ethics are the characteristics of a professional outlined by Kerr et al. (1977) .

The measure of professional commitment used in this study was an adaptation of these criteria. Ethics were excluded because there was no modification that applied across the variety of occupations sampled in this study. Knowledge about the training, education and socialization process that a professional has experienced does not provide all of the information management needs. Not all professionals are alike. Examining only the presence or absence of professional status does not provide differential information about individuals. Within any profession/occupation people are going to behave differently. Commitment experienced by any one individual may differ markedly from that experienced by another (Reichers, 1985). Professional status does not guarantee that the person will behave in a professional manner. This is why its important to examine levels of commitment across occupations.

Measuring the degree to which the individual is professionally committed to their occupation may be a better indicator of an individual's likelihood to perform the associated "professional" behaviors. These "professional" behaviors are what the organization and management are 
interested in. They want to be able to identify employees with these behaviors or potential for these behaviors within their repertoire.

In summary, professional commitment reflects the relative strength of an individual's identification with and involvement in their profession or occupation. The underlying dimensions of professional commitment are: expertise, autonomy, identification, commitment, standards and ethics.

\section{Operational Definition}

A review of the major empirical studies revealed that professionalism has been operationalized mainly as a global, unidimensional concept or as one end of a cosmopolitan-local dichotomy (Merton, 1957; Davis, 1961; Blau \& Scott, 1962; Gouldner, 1957; Miller \& Wagner, 1971; Sorenson \& Sorenson, 1974). A secondary operationalization of professionalism is as a multidimensional construct. This conceptualization received little attention historically (Hall, 1968; Goldberg, Baker, and Rubenstein, 1965).

Although neither of these definitions fits the purposes of this study, they were reviewed to facilitate continuity across the professionalism literature. The measure of professional commitment proposed and tested in this study was adapted from these two lines of research. 
Unidimensional studies. The psychometric properties of the unidimensional approach were examined and contrasted with the multidimensional approach.

Content Validity. Although preceded by the work of researchers such as Merton (1957), Bentz (1950) and Reissman (1949), Gouldner's classic studies triggered much of the subsequent work on the cosmopolitan-local construct. For this reason, the present review of the unidimensional conceptualizations of professional commitment was limited primarily to Gouldner's work.

Gouldner $(1957,1958)$ designed a conceptual tool that distinguished different types of social identities. The distinction from Merton's (1957) earlier work was the examination of roles within a formal organization.

Cosmopolitan was used to describe individuals low on loyalty to the employing organization, high on commitment to specialized role skills, and likely to use an outer reference group orientation. Conversely, local was used to describe those individuals high on loyalty to the employing organization, low on commitment to specialized role skills, and likely to use an inner reference group.

An inverse relationship between commitment to organization and profession was assumed. Based on this assumption, the cosmopolitan-local construct implied conflict within an organization that employed professionals. 
Cosmopolitans were suggested to have widespread problems integrating into both the formal and informal structure of their organizations. They were thought to have marginal loyalty to the organization, preferring to align themselves with their professional colleagues and associations for recognition and evaluation. Gouldner's $(1957,1958)$ scale was designed to tap into three variables: reference group orientation, loyalty to the organization and commitment to specialized role skills. The actual items were designed specifically for university faculty issues such as: teaching, research, classroom time, and student behavior.

Some researchers have attempted to translate Gouldner's scales for application with other populations with limited success (Goldberg et al, 1965; Grimes \& Berger, 1970). The scales were judged to be nontransferable to the health care population in this study. Many items were not relevant or applicable to the health care population. The necessary modifications would have changed the scale, such that comparison to the original scale would not have been possible.

Gouldner conceptualized individuals as being either "cosmopolitan" or "local". This is a very limited view of human behavior within an organization. An examination of the continuous nature or properties of organizational behavior may be better. 
Reliability. No reliability estimates were reported by Gouldner $(1957,1958)$. Berger and Grimes (1973) reported reliability estimates for each of their five scales, but because of the content difference these estimates were not comparable to Gouldner's (1957) scale. Dimensionality. There were five factor analytic studies on the dimensionality of the local-cosmopolitan construct. 1) Gouldner (1958); 2) Goldberg et al. (1965); 3) Friedlanoier (1971); 4) Berger and Grimes (1973) and Grimes and Berger (1970); and 5) Flango and Brumbaugh (1974) conducted separate studies on the dimensionality of the construct.

The Goldberg and Friedlander studies were not tests of local-cosmopolitan construct as designed by Gouldner. Goldberg et al. (1965) created a new scale to measure professionalism. Results supported a two dimensional description of professionalism. The two dimensions were professional self-gratification and organizational responsibility. Organizational responsibility was composed primarily of items relating to costs, growth, product line and other uses of company resources. Professional gratification items had to do with coworkers, reputation, interest, enjoyment, and opportunities.

A review of the individual items and analytic work indicated that the Goldberg et al. (1965) scale was not consistent with Gouldner's conceptualization of the local- 
cosmopolitan construct. For this reason the study was rejected as a test of the dimensionality of the localcosmopolitan construct.

Friedlander (1971) used overt measures of professional orientation rather than values and beliefs that were more commonly associated with Gouldner's conceptualization of professionalism. For this reason the study was rejected as a test of the dimensionality of the local-cosmopolitan construct.

Gouldner (1958) used a centroid extraction method with a Quartimax system of rotation in the factor analysis of his local-cosmopolitan scale. Six factors were found. Although the results of Gouldner's (1958) factor analysis supports a multidimensional approach to operationalizing professionalism, Gouldner concluded that four of the factors were types of locals and two of the factors were types of cosmopolitans. The focus was on how individuals were committed either to the organization or to their profession. This was a unidimensional interpretation of professionalism. Grimes and Berger (1970) reanalyzed Gouldner's results and found that the factor structure did not support Gouldner's local-cosmopolitan construct. Their findings indicated that the empirical evidence on the construct was weak and inconsistent.

Berger and Grimes (1973) continued their investigation of the local-cosmopolitan construct in a later study. Based 
on a principal-axis factor analysis with varimax rotation five factors were identified: scientific research ethics, institutional research ethics, loyalty to the organization, ethics risk and outer reference group orientation. The factors had reliability coefficients ranging from .65 to .80. These factors were compared to Gouldner's. The results supported the specialized role skill and the loyalty to the organization dimensions. The findings supported a multidimensional approach to defining professionalism.

Flango and Brumbaugh (1974) reanalyzed Gouldner's (1958) data and an independent sample collected from faculty members in the Pennsylvania college system. The data was factor analyzed using principal components analysis with varimax rotation. Five factors were derived.

The inter-item correlation matrix, communality estimates, and cross factor item loadings were not reported. These shortcomings make it difficult to evaluate the usefulness of the research.

The dimensionality of the local-cosmopolitan construct is not agreed upon. Based on the different factor analytic studies it is appropriate to conclude that the localcosmopolitan construct is multidimensional. It is unclear how many dimensions there are or what items load on which dimensions. This is due in part to the inadequate reporting of results and may also be due to the difference in items included in the different measurements. 
Convergent and Divergent Validity. No studies were found that assessed the convergent and divergent validity of measures of the local-cosmopolitan construct. Predictive Validity. Gouldner (1958) found conflicting results between "locals" and "cosmopolitans" in measures of degree of influence, degree of participation, and rule tropism. Locals were hypothesized to have more influence, participate at a higher rate, and use fewer rules. The results did not support these hypotheses. This may be due to the way he measured "local" and "cosmopolitan", the categorical split of the responses, or inaccurate conceptualization of the factors relevant to organizational behavior.

The primary method in these studies was to split professionalism scales arbitrarily into high and low categories for analysis purposes. This practice may account for the disparate research results involving professionals. Conclusion. Local-cosmopolitan measures were not used in this study for several reasons. First, the localcosmopolitan scales were not congruent with the conceptualization of professional commitment adopted in this study. Second, the psychometric properties of the various scales were not acceptable.

The review of the local-cosmopolitan research was important in terms of understanding and interpreting the 
research on professionalism and contrasting it with the concept of professional commitment.

Multidimensional Approach. Multidimensional approaches to measuring professionalism were inspired primarily by the work of Hall (1968). For this reason the present review was framed around his research.

\section{Hall Model. Hall (1968) operationalized}

professionalism as a substantive multidimensional construct. The theoretical dimensions were: using the professional organization as a major referent, belief in public service, belief in self-regulation, sense of calling, and autonomy. This approach was significantly different than the common use of a global professionalism construct.

Hall (1968) used a wide variety of occupations in his sample: nurses, physicians, accountants, teachers, lawyers, social workers, stock brokers, librarians, engineers, managers, and advertisers. In summary, Hall collected responses to the five theoretical dimensions suggested to measure professionalism, information about the level of bureaucratization, and demographic information from each participant. Responses were summed for each group and then rank ordered across the dimensions. Bureaucratic dimensions were then correlated with the professional dimensions. Generally, an inverse relationship was found between the level of bureaucratization and professionalization. 
over the years a number of investigators have modified and applied Hall's model of professionalism. Two significant and lasting modifications to Hall's scale were from Schack and Hepler (1979) and Snizek (1972). Bartol (1979b) and Kerr et al. (1977) based their scales on Hall's research, but did not adopt or modify his scale directly. Schack and Hepler's (1979) modifications included the use of self-referent items exclusively and the addition of an attribute called belief in continuing competence. The purpose of these modifications was to adapt the scale for use in a population of pharmacists.

Snizek (1972) modified Hall's scale by eliminating items that had no fit, corresponded to more than one dimension, or loaded on dimensions other than originally intended. The new scale had five factors with marked improvement in the unidimensionality of each factor.

The reliability and validity of the Model were investigated be several researchers. No reliability estimates were reported by Hall (1968). Snizek (1972) reported reliability coefficients of .67 to .77 for Hall's scales and ranging from .45 to .73 for his modified scales. The overall reliability for Hall's scale was .86 and Snizek's was .79. No estimates were reported in Bartol (1979b) or Kerr et al. (1977).

Snizek (1972) used factor analytic methods to show that Hall's data had serious scalability problems. Snizek found 
that half of Hall's items had less than acceptable factor loadings. He modified Hall's scale to include items that had acceptable factor loadings. The modified scale had marked improvement in unidimensionality.

Rupp and Segal (1989) used a confirmatory factor analysis to assess the dimensionality of Schack and Hepler's (1979) modification of Hall's (1968) Professionalism Scale. The results indicated that the model did not fit the observed data. The lack of fit was supported by three goodness-of-fit indicators: chi-square, Tucker-Lewis coefficient rho and root mean square residual.

Rupp and Segal (1989) dropped five items from the scale and still did not find support for the model. Further modification of the Hall (1968) model was suggested. No studies reported evidence of convergent or divergent validity.

Factor analytic studies demonstrated that Hall's original scale had serious dimensionality and validity problems. The modifications of Hall's scale by snizek improved the dimensionality of the scale, but Rupp and Segal demonstrated with their confirmatory factor analysis that the scale still had serious problems. These studies indicate that the psychometric properties of the Hall Model are not strong.

Kerr et al. Model. Kerr, Von Glinow, and Schriesheim (1977); Raelin (1985); and Miller (1986) argued 
that professionalism should be examined as a multidimensional construct. According to these researchers, six dimensions characterize professionalism: autonomy, expertise, commitment, identification, ethics, and belief in collegial maintenance of standards. This approach classifies individuals as more or less professional according to the extent that they exhibit behaviors and attitudes consistent with these characteristics.

Bartol (1979b) developed a scale of professionalism based on the work of Hall (1968), Snizek (1972) and Kerr et al. (1977). Her primary purpose was to investigate individual versus organizational predictors of satisfaction and turnover. The measure of professional attitudes consisted of 20 items, reflecting the following subscales: autonomy, collegial maintenance of standards, ethics, commitment, and professional identification.

Bartol (1979b) factor analyzed her data using varimax rotation and unity communalities. The results supported the existence of five factors that corresponded with the five subscales. Five items were dropped because they did not load highly on their proposed subscales.

Bartol (1979b) did not provide an inter-item correlation matrix or item loadings across factor. She also failed to indicate which factor extraction method was used. For these reasons the usefulness of Bartol's (1979b) factor analytic work is difficult to evaluate. 
Bartol (1979b) correlated her professional scale with turnover and satisfaction. Professional attitudes were not found to be predictive of turnover. Contrary to her hypothesis, professional attitudes were found to be significantly related to satisfaction.

Selection of Commitment Measure. No measure exists that discriminates between different levels of professional commitment within a single profession or between different professions or occupations. A standardized measure is needed in order to examine the role of commitment to profession, its relationship with organizational commitment and the role that relationship may play in an organization. The major purpose of this research was to investigate the relationship between professional commitment and organizational commitment. A second purpose was to investigate how individuals across different occupations vary in their professional commitment. This was a departure from past research that focused exclusively on professional occupations.

In order to accomplish these purposes the measure of professional commitment used in this study was adapted from the work of Kerr et al. (1977) and Bartol (1979b). Modifications were based on the notion that professional commitment is a multidimensional construct characterized by autonomy, expertise, commitment, knowledge/standards and identification. Items related to ethics were not included 
because they represent behaviors and attitudes that result from commitment and are not considered part of the construct.

\section{Historical Background and Significance}

We as a nation are moving towards a more professional workforce. Professional status is more the norm. It is no longer reserved just for an elite group. Anthropologically speaking, man's work behavior has evolved. In the beginning man worked as a hunter-gatherer. He then progressed to the Agricultural Era where he farmed the land and raised animals for food. The Industrial Era brought many changes for man. The most significant for work behavior being the birth of Scientific Management. Frederick Taylor's (1911) time and motion studies focused on breaking a job down into its most basic components and teaching those components to man. Man was considered merely an extension of the machine. According to Taylor, the worker's exacting performance of carefully planned tasks would lead to maximum production.

Technology is the root of our new Information Age. Professionals armed with knowledge are the fabric of our information society. Knowledge and information are the currency of trade and the power base in this new age (Von Glinow, 1988). With this new age we have witnessed the rise of the "professional" worker. 
The new age has focused attention on the professional worker. Organizations are more likely to employ professionals and have a larger number of professionals in their workforce then ever before. Research is needed to determine if workers across different occupations behave professionally and whether professional attitudes and behaviors make a difference in terms of increased performance and satisfaction and decreased turnover and absenteeism.

It has been suggested that managing professionals should be approached differently from traditional management practices (Von Glinow, 1988, Raelin 1985). This idea stems from the notion that professionals are somehow different from nonprofessionals. There are various theories about how and why professionals are different (Kerr et al., 1977; Kleingartner \& Anderson, 1987; Von Glinow, 1983). One line of thought is that the specialized training, education and socialization process that professionals experience makes them different. other theories focus on autonomy, identification with the profession, tension between professional goals and organizational goals, and tension between the pursuit of technical expertise and organizational needs. Empirical support for these theories is lacking.

As the number of professionals in the workforce increases, it has been suggested that the pressure on 
management to adapt will grow stronger (Schriesheim, Von Glinow, and Kerr, 1977). How we traditionally think of professionals is changing. The title is no longer limited to doctors, lawyers, professors, engineers and the like. Many employees are claiming the title of professional. Behavior does not occur in a vacuum. For this reason it is important to investigate how other variables in the environment may affect, and be affected by, professional commitment. This study examines an entire system of variables that occur within the organization. Antecedent variables include individual characteristics, job characteristics and organizational characteristics. The independent variables of primary interest are organizational commitment and professional commitment. The outcome variables are satisfaction, performance, and withdrawal from the organization.

\section{ORGANIZATIONAL AND PROFESSIONAL COMMITMENT}

Over the years the concept of commitment has undergone a natural development from a general to a more specific orientation (Reichers, 1985; Randall, 1987). Initially, organizational commitment was distinguished from commitment to specific values, policies and goals. Morrow (1983) compared major forms of work commitment and their interrelationships. Reichers (1985) reconceptualized organizational commitment as a collection of multiple 
commitments. Randall (1987) called for research examining the effects of a web of varying levels of commitment to different goals and groups.

Following the recommendation of these researchers, this study measured multiple commitments of employees within an organization and linked them to specific outcomes. Organizational and professional commitment were the primary variables of interest. Modeling the two commitments as independent variables in a structural model of antecedents and outcomes was derived from the notion that individuals manage multiple commitments of varying levels to different goals and groups. Commitment to the profession and organization was viewed as the most general model of commitment in the workplace.

\section{Research Problems}

Although a variety of studies have reported examining aspects of professional and organizational commitment, several problems remain. First, there is continued disagreement over the conceptualization and measurement of the commitments. Second, none of the existing studies have treated professional and organizational commitment both as independent variables. Third, few studies have taken a systematic or comprehensive approach to the topic. As a result, model building attempts are lacking.

The differences in how researchers have defined and measured organizational commitment and professional 
commitment have produced disparate research findings. There are three sources of difficulty. First, researchers have conceptualized professional commitment either as a unidimensional or multidimensional construct. Second, researchers have conceptualized organizational commitment as an attitude, a behavior or both. Third, when investigating organizational and professional commitment, the commitments are examined either as dependent or independent of each other.

The first two difficulties were discussed in the preceding sections on organizational and professional commitment. The third difficulty is examined in the following section.

Dependent Approach. Traditional analyses of organizational commitment and professional commitment explicitly assumed that the individual had to choose one over the other (Marcson, 1960; Merton, 1957; Gouldner, 1954, 1957; and Shepard, 1956; Etzioni, 1964; LaPorte, 1965). In this approach, employees are thought to be committed either to the organization or to their profession. Professional and organizational commitments formed a single dimension with professional commitment on one end and organizational commitment at the other. According to this view, organizational and professional commitment are not independent. 
Independent. More recent investigations indicate that organizational commitment and professional commitment may be essentially independent such that individuals may be high on organizational loyalty and professional commitment, low on both, or high on one or the other (Rotondi, 1980; Flango \& Brumbaugh, 1974; Friedlander, 1971; Thornton, 1970; Jauch Glueck and Osborn, 1978; Koslowsky, 1990; Morrow, 1983; Jackofsky \& Peters, 1983). Bartol (1979b), Parasuraman and Nachman (1987) and Koslowsky (1990) empirically demonstrated that professional commitment and organizational commitment have different antecedents and affect outcomes differentially. The results support the hypothesis that organizational and professional commitment are independent constructs.

\section{Previous studies}

Previous studies investigating both organizational and professional commitment are listed in Table XI. Studies that did not use the $O C Q$ were included in the review and are distinguished by an asterisk in the table. Different instruments were used to assess professional and organizational commitment.

Rotondi (1980) failed to indicate which scales were used for measuring organizational and professional commitment. The failure to define how the constructs were measured rendered his research uninterpretable. 
TABLE XI

STUDIES INVESTIGATING BOTH ORGANIZATIONAL AND PROFESSIONAL COMMITMENTS

\begin{tabular}{lll}
\hline NAME & DATE & SUBJECTS \\
\hline Aranya et al. & 1981 & Accountants \\
Aranya et al. & 1982 & Accountants \\
Bartol & $1979 a$ & Computer \\
*Jauch et al. & 1978 & Professors \\
Koslowsky & 1990 & Police officers \\
Lachman \& Aranya & 1986 & Accountants \\
*Parasuraman \& Nachman & 1987 & Musicians \\
Rotondi & 1980 & Scientists \\
& & Engineers \\
*Thornton & 1970 & Teachers \\
& & \\
\hline DID NOT USE ORGANIZATIONAL COMMITMENT QUESTIONNAIRE
\end{tabular}


organizational commitment was operationalized by various measures. Jauch et al. (1978) and Thornton (1970) used their own scales for measuring organizational commitment. Parasuraman and Nachman (1987) used a modified Hrebiniak and Alutto scale for assessing organizational commitment. The remaining authors in Table XI used the OCQ. Professional commitment was operationalized by different measures. Jauch et al. (1978) used a localcosmopolitan scale for assessing professional commitment. Parasuraman and Nachman (1987) and Lachman and Aranya used a modified Hrebiniak and Alutto scale for assessing professional commitment. Thornton (1970) and Bartol (1979) modified Hall's scale for assessing professional commitment. Aranya et al. (1981, 1982) and Koslowsky (1990) substituted "professional" or "job" for "organization" in the oce for assessing professional commitment. The substitution of "professional" for "organizational" in the oce for assessing professional commitment is criticized based on the lack of theoretical reasoning. It is unclear how substituting "job" for "organization" in the OCQ measures professional commitment. Items tapping into attitudes toward the organization may not be indicative of attitudes towards professional commitment. The findings in the studies using the substitute OCQ for assessing professional commitment are not clearly interpretable and were given no further consideration. 
Bartol (1979a) investigated professionalism as a predictor of organizational commitment, role stress, and turnover in a multidimensional approach. She found that the five professional dimensions accounted for 19.64 percent of the variance in organizational commitment and 8.8 percent of the variance in turnover. Professional commitment was significantly and negatively related to turnover.

Parasuraman and Nachman (1987) found preliminary evidence that professional commitment and organizational commitment were the product of different antecedent factors and have different implications for continued membership and participation. Age and leadership were the dominant factors leading to organizational commitment. Full-time status and job involvement were the main determinants of professional commitment.

Path Model. Of the research listed in Table XI only two studies utilized a path model to test hypothesized relationships. Aranya, Lachman and Amernic (1982) used a path analytic method to test their model: Professional commitment caused need deprivation which caused organizational commitment which in turn affected satisfaction and migration tendencies.

No direct effect was found between job satisfaction and intention to leave the organization. A direct effect was found between organizational and professional commitment. 
The authors concluded that the model should be revised for the different settings.

The major criticism of this work was the operationalization of professional commitment as discussed previously. A second criticism is related to an earlier publication (Aranya et al, 1981). It appears that the authors used the same subject sample in both of these articles. In the first article the authors found that commitment to organization was the most powerful predictor of professional commitment. The second article conflicts directly with the first article.

It is difficult to conclude what the relationship is between professional and organizational commitment from these two studies. The authors failed to statistically control for the use of the same sample in multiple statistical tests. There is also considerable confusion about the authors hypotheses and results.

An additional criticism is that only one item was used to measure satisfaction and conflict. This is a very weak conceptualization of these constructs. Past research indicates that there are multiple variables that constitute satisfaction and conflict (Mobley, 1982). The use of only one item casts doubt on the soundness of the research findings.

Lachman and Aranya (1986) used path analysis to test different models of the relationships between organizational 
and professional commitment, expectations, satisfaction, turnover and organizational setting. In the first model professional and organizational commitment were modeled to have affects on expectations of professionals which, in turn, had an affect on satisfaction which, in turn; had an affect on turnover. Professional commitment preceded organizational commitment and had an indirect effect on it through expectations in the second model.

The data did not fit the first model and was rejected. The second model was accepted with modifications. The modifications included the addition of a direct path from professional to organizational commitment.

The major criticism of this work was its departure from past research efforts in the area of organizational commitment regarding the importance of individual and job characteristics. No individual or job characteristics were examined. The inclusion of these variables may result in different findings.

It is important to note that a significant positive relationship between organizational and professional commitment was found. The causal nature of these two constructs was not fully tested in the Lachman and Aranya study. They proposed and tested that professional commitment preceded organizational commitment, but did not test the opposite relationship. 
Conclusion. No studies have treated organizational and professional commitment both as independent variables. Multiple commitments in the work place are possible and important. These observations formed the basis for modeling the commitments together as independent variables in a system of antecedents and outcomes. The conceptual and measurement difficulties related to the commitments are compounded when both constructs are examined in one study. It is important to clearly define concepts and select measures that have strong psychometric properties.

\section{OUTCOME VARIABLES}

The primary reason for studying organizational and professional commitment was to examine their effect on organizationally relevant behaviors. In the system of variables identified in this study satisfaction, performance, and withdrawal from the organization were the outcome variables. The outcome variables received a limited review as they related to each other and the commitment variables.

\section{Performance-Satisfaction}

Satisfaction is conceptualized as the discrepancy between what an individual values and what the situation provides (Locke, 1976). Common operationalizations of 
satisfaction include measures of overall job satisfaction, satisfaction with pay, promotion opportunities, job content, coworkers, supervision, and working conditions.

Performance is something that people do all of the time. Appraising performance in an organizational setting is done both formally and informally. Performance appraisal can be simple on the surface. One individual observes another engaging in a task and evaluates how well that individual does. Difficulties arise in performance appraisal when the evaluator does not observe each task or when the tasks performed can not be observed. Designing performance appraisal systems is an endeavor worthy of a lengthy review, but such a review is beyond the scope of this paper. For an extensive review and detailed references see Mohrman, Resnick-West and Lawler (1989).

The research on the relationship between performance and commitment has received limited attention. This may be due in part to the difficulty of identifying and measuring performance. Van Maanen (1975), Steers (1977), Mowday et al. (1979), Stumpf and Hartman (1984), Zahra (1984), Shore and Martin (1989), and Darden et al. (1989) investigated the relationship between commitment and performance. Zahra (1984) used both self-reported and supervisory ratings of performance and found that both were positively correlated with commitment. Darden et al. (1989) and stumpf and Hartman (1984) used self-reported performance measures. The 
remaining authors used supervisory ratings. Results across these studies indicate a modest positive relationship between performance and organizational commitment. Performance in this study was limited to self-reported responses related to effectiveness in acquiring and using resources, dealing with work related problems and change, coordination of work effort, and quality and quantity of production. The importance of these variables was identified by Mott (1972) and Freeborn et al. (1990a). Mott (1972) and Heneman (1974) found that while there was a clear distinction between actual performance and self-reported performance, there was a strong relationship between the two. Additionally, self-reported measures were not confounded with factors beyond the individual's control.

Landy (1989) described the research on the relationship between satisfaction and performance best, "from the earliest days of industrial psychology, the relationship between satisfaction and performance represented a kind of Holy Grail. The Hawthorne studies and the later humanrelations movement sanctified the search for the relationship."

The results are discouraging. Brayfield and crockett (1955), Vroom (1964), and Locke (1976), found that "no appreciable relationship" existed between satisfaction and performance. A recent meta-analysis conducted by Iaffoldino and Muchinsky (1985) of 74 studies and 213 correlations 
examining the relationship between satisfaction and performance came to the same conclusion. The average correlation was +.14 . Although this correlation is low, it was consistent across the studies.

Historically, researchers investigated how satisfaction caused productivity. The implication was that by increasing employee satisfaction, organizations could increase productivity. The recommendation was to put resources into making employees more satisfied.

Later, the opposite relationship was suggested: productivity causes satisfaction (Locke, 1970; Porter \& Lawler, 1968). The implication was that by increasing performance, organizations could increase employee satisfaction which would lead to increased performance. The recommendation was to put resources into increasing performance.

The results and recommendations are contradictory and confusing. The reason behind the different findings may be based on where the investigator decided to begin the research process. How and when the investigator chose to measure satisfaction and/or performance may cause different findings.

Both groups of investigators found a circular pattern of relationships between satisfaction and performance. Performance caused satisfaction which sets the stage or caused performance. Satisfaction caused performance which 
set the stage or caused satisfaction. In organizations performance and satisfaction occur in a cyclical pattern. It is difficult to separate out where the cycle starts. The aspect of the performance-satisfaction question that was overlooked is that both exist in the organization at the same time in different amounts in different people. For these reasons a new approach to looking at the performance-satisfaction relationship in organizations is called for. Covariance structural modeling techniques may aid in the development of a model that better describes the relationship between satisfaction and performance. Covariance structural modeling allows for the modeling and testing of mutual causation.

This study examined two additional variables in predicting performance and satisfaction: Organizational and professional commitment. These variables may be helpful in explaining the relationship between performance and satisfaction.

Satisfaction-organizational Commitment. Researchers have identified a number of variables that contribute to either job satisfaction or organizational commitment. The variables can be divided into three groups: 1) variables that describe individual characteristics; 2) variables that describe characteristics of the job; and 3) variables that describe characteristics of the organization (for specific references see Tables VIII, IX, and X). 
Glisson and Durick (1988) pointed out that research efforts, with a few exceptions (Herman and Hulin, 1972; Buchanan, 1974; Herman, Dunham, and Hulin, 1975; Steers, 1977 ; Rousseau, 1978; Stevens, Beyer, and Trice, 1978; Morris and Sherman, 1981; and Staw and Ross, 1985), have tended to examine variables from only one or occasionally two of the three predictors at a time. This makes simultaneous comparisons of the unique effects of variables from all categories impossible.

Individual studies have tended to investigate either the predictors of satisfaction or organizational commitment. The relative effects of the predictors of satisfaction and organizational commitment can not be assessed with this approach. Glisson and Durrick (1988) and Shore and Martin (1989) are the exception. They conducted studies with variables from each of the categories.

Glisson and Durrick (1988) examined the effects of all three categories of variables on satisfaction and commitment. They found that job characteristics were better predictors of satisfaction, and that organizational characteristics and education were better predictors of organizational commitment. Sex and age were not significantly related to either satisfaction or commitment.

Shore and Martin (1989) found that commitment was more strongly related to turnover than satisfaction for bank tellers, but not for professionals. Job satisfaction, 
measured by a single item, was related more strongly to ratings of performance.

Several studies have reported a relationship between satisfaction and commitment, but there continues to be disagreement regarding any causal ordering. Bateman and Strasser (1984) found commitment to be a precursor of satisfaction. Marsh and Mannari (1977) and Williams and Hazer (1986) found satisfaction to be a precursor of commitment. Porter et al. (1974) found the two to be correlated. Curry et al.(1986) found no evidence of a causal relationship in either direction.

The Curry et al. (1986) study provided the best test. They used covariance structural modeling to test the causal orderings in a cross lagged study of commitment and satisfaction. A shortcoming of their research was the decision not to use multiple indicators in specifying the measurement model.

A second criticism of Curry et al. (1986) was the selection of the measure for satisfaction. Curry et al. (1986) adapted a measure from Brayfield and Rothe (1951). This measure is not commonly used and varies significantly from more common measures such as the Job Descriptive Index (JDI) or the Minnesota Satisfaction Questionnaire (MSQ). This scale assesses satisfaction in terms of how the individual feels about their job: enjoyment, seldom bored, enthusiastic, fairly satisfied, and likes better than 
average worker. The use of a different measurement may account for the differences found in this study.

The evidence on the causal ordering of satisfaction and organizational commitment is contradictory. The discrepancies are due in part to measurement selection and part to research design and method of analysis.

Satisfaction-Professional Commitment. No studies have examined the relationship between satisfaction and professional commitment without organizational commitment. Furthermore, no studies have examined both professional and organizational commitments as independent variables. For this reason it was not possible to assess the relative effects of job, individual and organizational characteristics on each of the commitments and satisfaction. of the studies that have attempted to investigate both organizational and professional commitments, only a few have included satisfaction as a variable. Aranya et al. (1982) investigated satisfaction as a dependent variable. In their path analytic model professional commitment caused organizational commitment and organizational commitment caused satisfaction.

Aranya et al., (1981) investigated satisfaction as a independent variable. In this model organizational commitment, satisfaction, and conflict caused professional commitment. Neither of these studies examined individual, job, or organizational characteristics. 
Satisfaction and Human Service organizations. Human service organizations have been reported to have particularly low levels of job satisfaction relative to other types of organizations (Solomon, 1986). Because of this observed relationship, examining the roles of professional and organizational commitment in relationship with satisfaction within a human service organization is particularly important and valuable.

Conclusion. There has been little or no attempt to challenge that satisfaction, professional and organizational commitment covary or are separate and distinct variables. There is no consensus to date about the different predictors of each of these variables. This study modeled and tested the predictors of organizational commitment, professional commitment, and satisfaction.

The scale for assessing job satisfaction in the current study was adapted from Freeborn et al. (1990a). The scale incorporates multiple elements that comprise the construct satisfaction. Items related to overall job satisfaction, job content, promotion opportunities, and working conditions were included.

Covariance structural modeling (CSM) was used to examine the hypothesized relationships. CSM may provide answers to the questions does performance cause satisfaction; does satisfaction cause performance; do performance and satisfaction cause each other; and what is 
the relationship between organizational and professional commitment and satisfaction.

\section{Withdrawal}

Turnover and absenteeism are often considered part of the same withdrawal process. The research evidence on this relationship is inconclusive. Whether absenteeism is best thought of as a precursor to turnover, as an alternate form of withdrawal, or, as having no consistent relationship needs to be determined (Burke and Wilcox, 1972; Mobley, 1982). Based on these studies, absenteeism and turnover were hypothesized to be part of a general process called withdrawal from the organization in this study.

Absenteeism. Absenteeism usually has fewer negative consequences for the individual, is a more spontaneous decision, and may substitute for turnover when turnover is precluded (Mobley, 1982; Rhodes \& Steers, 1990). Rhodes and Steers (1990) investigated the major causes of absenteeism and found that past theory and findings could be categorized into three types of explanatory models: 1) pain avoidance models, where absenteeism is viewed as a flight from negative work experiences; 2) adjustment-to-work models, where absence behavior is viewed as resulting from employee responses to change in job conditions; and 3) decision models, in which absenteeism is seen as a rational decision to attain valued outcomes. 
The assessment of absenteeism within the framework hypothesized in this study may provide a mechanism for better understanding the relationship between commitment and withdrawal from the organization.

Few studies have investigated the relationship between organizational commitment and absenteeism. No studies have investigated the relationship between professional commitment and absenteeism (See Tables VIII, IX and X).

Turnover. Employee turnover is important to organizations, individuals and society (Mobley, 1982). The costs of turnover and absenteeism are well documented (Mirvis \& Lawler, 1977; Steers \& Rhodes, 1978; Wanous, 1980).

organizationally, turnover can represent a significant cost in terms of lost recruiting, training, socialization investments, disruption and replacement costs and a variety of indirect costs (Flamholtz, 1974). On the other hand, turnover can have positive organizational benefits such as displacement of poor performers (Mobley, 1982; Staw, 1980), creation of promotion opportunities, and infusion of new people with new ideas.

Individually, turnover can have potentially positive and negative consequences. On the positive side, the decision to quit a job can be associated with the pursuit of career objectives or movement away from a stressful situation. Negative implications for individuals include: 
loss of nonvested benefits, disruption of family support systems, and potential disillusionment in future experiences (Steers \& Mowday, 1981).

The societal perspective can also have negative and positive consequences. Turnover is associated with mobility and migration to new industries and organizations which is related to economic development. Excessive turnover can also serve to depress productivity growth and orderly development.

From these three perspectives turnover is a significant concept. It is important that managers be able to analyze, understand, and effectively manage employee turnover. The important factors in developing an understanding of turnover according to Mobley (1982) are: 1) the causes and correlates of turnover; 2) consequences of turnover; and 3) analysis and control over turnover.

A general definition of turnover is: the cessation of membership in an organization by an individual who received monetary compensation from the organization. The U.S. Bureau of Labor statistics (1980) classifies cessation in three ways: "quit," "layoff," and "other." This is an important distinction for measuring and classifying types of turnover and for facilitating understanding and effective management.

A manager must be able to diagnose determinants of turnover, assess costs and consequences, design and 
implement policies, practices, programs, and processes, evaluate effectiveness and anticipate turnover through forecasting and planning.

Measuring Withdrawal. There are several ways that turnover and absenteeism can be measured. They can be measured directly by analyzing organizational or managerial records or measured indirectly by self-report or proxy variables.

Turnover rates are generally expressed as a percentage for a specified period of time. These rates are a function of what goes into the numerator and denominator. See Table XII for a variety of sources of unreliability in withdrawal data.

This study utilized proxy measures of turnover. Because of the confidential nature of the survey, it was not possible to obtain actual turnover data about the respondents.

Turnover and Commitment, Satisfaction, and Performance

Satisfaction. The relationship between turnover and satisfaction is consistent. The literature clearly shows that the lower the job satisfaction, the greater the probability of turnover (Brayfield and crockett, 1955; Price, 1977; Vroom, 1964; Porter and Steers, 1973; Locke, 1975; and Mobley, Griffeth, Hand, \& Meglino, 1979). Dissatisfied employees are more likely to leave the organization than satisfied employees (Mobley, 1977; 1982). 
TABLE XII

SOURCES OF UNRELIABILITY IN WITHDRAWAL DATA

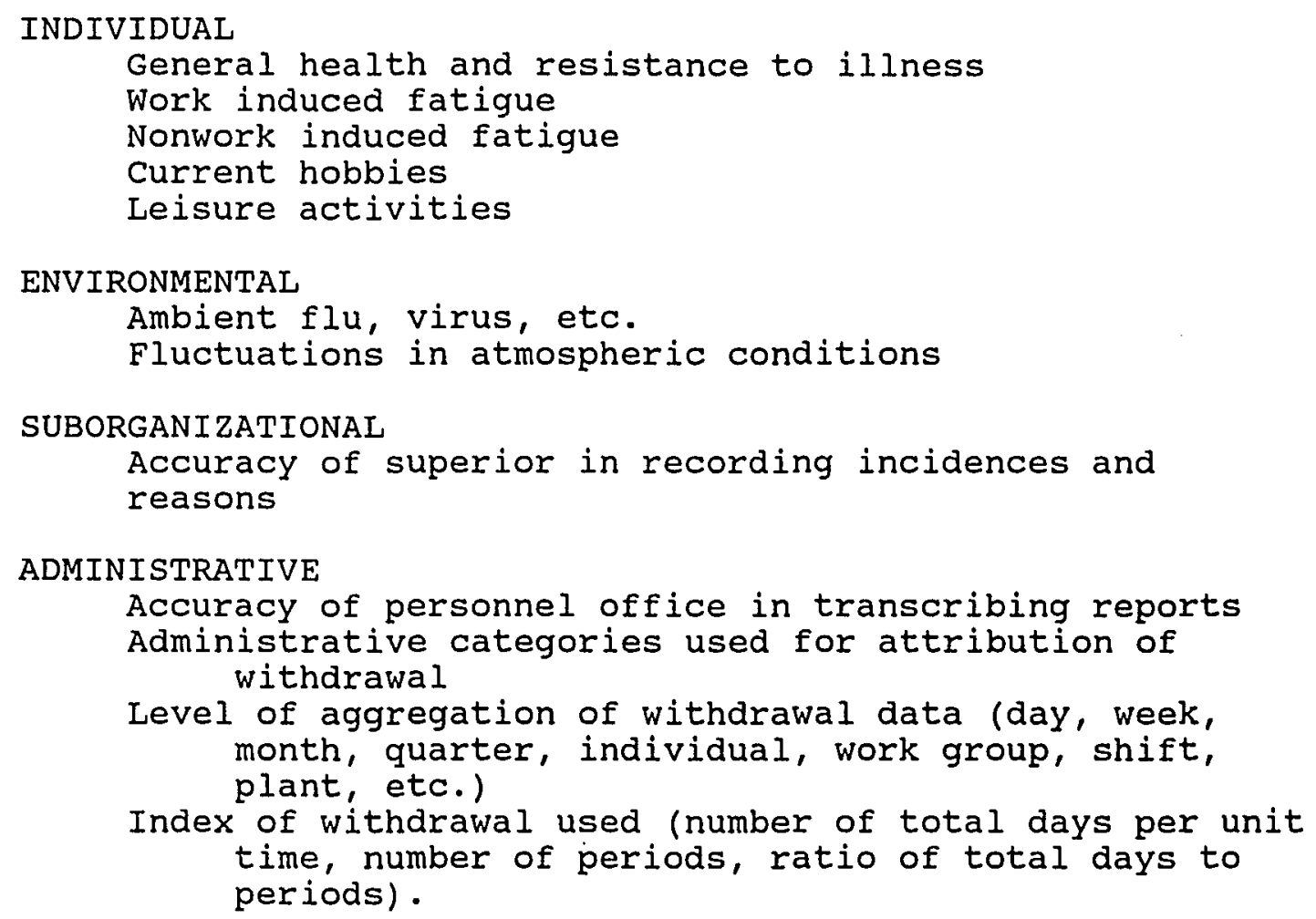

Source: From The Measurement of Work Performance (Table 2.2)

by J. Landy \& L. Farr. (1983). New York: Academic Press. 
The initial structural model in this study reflects this observed relationship.

Commitment. Commitment is associated with decreased propensity to leave the organization. Empirical research on organizational commitment has shown commitment to be a significant predictor of turnover. (Mowday et al., 1982; Steers, 1977, Mowday et al., 1979). There is also evidence that commitment is a better predictor of turnover than satisfaction (Porter et al., 1974; Mowday et al., 1979). The more committed employees are to the organization the less likely they are to leave the organization.

Commitment has accounted for as much as 34 percent of the variance (Hom et al., 1979) and as little as 3 percent (Michaels \& spector, 1982). The inconsistencies across studies may be due to any combination of three reasons: a) the way organizational commitment was conceptualized and operationalized; b) the way turnover was conceptualized and operationalized; and c) the result of statistical artifacts such as sampling and measurement errors.

Performance. Relatively few researchers have examined the relationship between turnover and performance at length (Porter and Steers, 1973; Price, 1977; and Martin, Price, and Mueller, 1981). The pattern of results was mixed. Higher performers were found to be more likely to leave in some studies and less likely to leave in others. The relationship is best characterized as inconclusive. In this 
study increased performance was hypothesized to cause a decrease in turnover.

The logic behind this hypothesis is that high performing employees are less likely to leave the organization than employees who are performing poorly. The inclusion of the commitments and other antecedent variables may produce more stable results for understanding the performance-withdrawal relationship.

Conclusion. Researchers have investigated the relationship between the independent variables, commitment and satisfaction and their ability to predict turnover. What has not been examined are the interrelationships between the independent variables, the commitments, satisfaction, performance and turnover. The model tested in this study may more accurately reflect organizational behavior. 
CHAPTER III

METHODS

METHODOLOGICAL ISSUES

\section{Confirmatory Factor Analysis}

There are two common approaches to factor analysis; exploratory and confirmatory. Exploratory factor analysis is used when the researcher has no hypothesis about the structure of the indicator-factor relationship. In confirmatory factor analysis (CFA) the structure of the indicator-factor relationships is specified prior to analysis. The specified structure can then be tested for significance as well as tested against other structures. The indicators in CFA can be questionnaire items or other measures of subject responses in either experimental or nonexperimental situations.

CFA assesses the degree to which the observed or manifest variables are explained by the latent or unobserved variables. Estimates of the pattern of relationships between the indicators and factors and between factors are produced. In CFA, tests of these estimates are generated. For relationships not specified by the researcher, CFA generates estimates of improvement in fit if that 
relationship was included in the model.

The evaluation of the model is based on overall

goodness of fit indices and detailed fit indicators. The overall fit indices are discussed in the structural model section.

Detailed fit is assessed by examining $t$-values, squared Multiple correlations (SMC), residuals, and modification indices. T-values test whether the indicators load on the specified factor and if any specified parameter is significantly different from zero. SMCs indicate the proportion of variance of the variables accounted for by the factors. Residuals are a product of the fit between the predicted and observed covariance matrices. Large residuals indicate a poorly specified model. Modification indices indicate items that load on factors other than those specified by giving the change in overall fit if the item was allowed to load on an additional factor. T-values allow the researcher to find indicators that were incorrectly specified and might allow the researcher to find items that load highly on other factors.

CFA has the ability to assess unidimensionality and redundancy. Unidimensionality is achieved when the items in a given scale measure only one factor. In CFA the indicator-factor matrix is specified to have indicators load on only factor to assess unidimensionality. Redundancy 
occurs when factors are highly related or overlap. The interfactor matrix provides information about redundancy.

Concept redundancy is a problem in commitment research as previously addressed by Morrow (1983). Redundancy has to do with overlap between factors. If factors overlap too much, they may not provide different information. It should be established that the various factors in a study are sufficiently distinct. This can be accomplished by examining the pattern of correlations among the factors and dropping factors that are not distinct. When factors are distinct there is evidence for the discriminant validity of the factors.

Unidimensionality is important for assigning meaning to the factor (Anderson \& Gerbing, 1982; 1988; Gerbing \& Anderson, 1988). Alternate indicators may have only one underlying factor in common in order to qualify as unidimensional measurement. Unidimensional measurement can be achieved in CFA by constraining items to load on only one factor and by dropping items for which the modification indices indicate high loadings on additional factors.

Unidimensional measurement is important for interpreting scale scores and investigating the relationships between factors. If a single item is allowed to load on more than one factor, the interpretation of the corresponding scale is difficult. Furthermore, how those 
factors relate to other factors cannot be interpreted in a straightforward manner.

CFA estimates error in the indicators. Rarely, if ever, in survey research are constructs measured without error. Analogous to the traditional exploratory factor analysis with communalities on the diagonal, CFA provides a means for estimating error in the measurement of the constructs that permits a better approximation of true scores.

Higher-order CFA. It is also possible to work with higher-order factors in CFA. In higher-order factor analysis, higher-order factors are comprised of multiple first-order factors. Higher-order factor analysis is based on the idea that the first-order factors are caused by some common underlying construct. The higher-order or secondorder confirmatory factor analysis is conducted in the same manner as the first-order CFA. In the second-order CFA the first-order factors are treated like indicators.

The data for higher-order factors can be derived from the correlations of the subject scale scores on the firstorder factors or from the correlations between the firstorder factors themselves. Both methods should produce similar results. For example, the factor job demands is measured by six items. The researcher may calculate a summary score for the factor for each respondent by adding their responses to each item. The summary scores can then 
be correlated with other summary scores and a factor analysis performed. Alternately, the researcher may use the estimates of the interfactor correlations from the firstorder factor analysis of the items.

\section{Covariance structural Modeling}

Covariance structural modeling (CSM) tests the CFA structure and the structural relationships among the factors simultaneously. It allows for errors in measurement as well as errors in prediction. The researcher specifies the relationships among the latent variables (factors) that can include both directional and nondirectional paths.

The structural model assesses simultaneously the relationships among the latent constructs. Like the measurement model, the researcher specifies the causal and correlational relationships between the constructs prior to analysis.

The structural model has exogenous and endogenous variables. Exogenous variable are outside the explanatory scope of the model. Exogenous variables have no paths leading to them and are not explained by the model. Because they are not accounted for, exogenous variables can be allowed to freely correlate. Endogenous variables are within the explanatory scope of the model and can have paths from exogenous or other endogenous variables. CSM can handle a wide range of submodels, such as 
common factor analysis, regression, and path analysis. In addition, CSM can handle several groups of data simultaneously along with equality of correlations, covariances or regression coefficients.

A CSM model is fully defined by the specification of the structure of eight matrices. Joreskog \& Sorbom (1978) described the matrices as follows:

1. Two matrices of coefficients or loadings relating indicators to the latent factors (Lambda $X$ and Lambda $\mathrm{Y}$ ).

2. Two matrices of regression coefficients of the effects of factors on factors (Beta and Gamma).

3. A variance-covariance matrix of latent exogenous variables (Phi).

4. A variance-covariance matrix of the residuals (Psi).

5. Two variance-covariance matrices of errors of measurement (Theta Delta and Theta Epsilon).

The elements of the matrices may be fixed, constrained, or free parameters. Fixed parameters are assigned a given value. When parameters are fixed at zero it means that relationship is not hypothesized in the model. Constrained parameters can be set to equal one or more other parameters. Free parameters are not constrained to be equal to any other parameter and are freely estimated. A model can be specified by the pattern of free and fixed elements in these matrices. Estimates of the elements in the matrices are 
generated by general maximum likelihood estimation. The estimation technique is discussed following the measurement and structural models.

CSM has two major parts; the measurement and structural models. An overview of the general properties of each of the models is provided in the following section. Specific aspects and advantages of the models were discussed as they applied to this study.

Measurement Model. The first model is the measurement model. This is the CFA part of CSM. Two equations describe the measurement model:

$$
\begin{aligned}
& y=\text { Lambda } y * \text { Eta + Epsilon } \\
& x=\text { Lambda } x * \text { Ksi + Delta }
\end{aligned}
$$

where Lambda $Y$ and Lambda $X$ are factor loading matrices, Eta is the unobserved endogenous variable matrix, Ksi is the unobserved exogenous variable matrix, and Epsilon and Delta are errors in variables matrices.

The measurement model specifies how latent variables or hypothetical constructs are measured in terms of the observed variables. The measurement model is used to establish the measurement properties of the observed variables. 
Structural Model. The second part of CSM is the structural model. The structural model is described fully by one equation:

$$
\mathrm{Eta}=\text { Beta *Eta + Gamma * Ksi + Zeta }
$$

where Beta and Gamma are matrices of regression coefficients and zeta is a vector of residuals or errors in equations.

The structural model assesses the relationships among the factors simultaneously. The causal and correlational paths are specified prior to data analysis by the researcher.

Maximum Likelihood Estimation. ML is sensitive to real world models and impurities in data, accordingly, it aims to optimize statistical inference. Computer programs that have CSM capabilities fit the specified model to the data by minimizing the maximum likelihood function with respect to the specified free parameters (Joreskog \& Wold, 1982). ML estimates are estimates of the parameters that are most likely to reproduce the generated data.

The idea behind ML is to compare the value of the variable observed with an expected population parameter and determine the likelihood of obtaining the observed value. With multiple values the joint likelihood of obtaining the observed values is estimated. ML provides estimates of the observed values with the greatest joint likelihood based on values of expected population parameters (Muliak, 1972). 
CSM Requirements. Multiple measures of each latent construct are required (Cole, 1987). This requirement can be violated when the latent construct is equivalent to a single measured variable. Age is an example of this. Age can be measured accurately be a single item.

Because CSM is based on large sample theory, a large sample is a requirement. There is no agreement upon what constitutes a large sample or the minimum number of subjects per variable. Cole (1987) suggested a sample size of at least 100. Anderson \& Gerbing (1988; 1984) suggested a minimum sample size of 150. Boomsma (1982) recommended a sample size of no less than 200 .

One of the reasons sample size is important is because studies with small sample sizes are prone to have convergence problems, improper solutions or stability problems (Anderson \& Gerbing, 1988). Another reason sample size is important is because of the role it plays in determining the fit of the model. As the size of the sample increases, the standard error estimates decrease. The result is increased stability and confidence in the estimates.

overall Fit indices. There are two kinds of overall fit indices. The first type of index assesses the degree to which the predicted correlation matrix reproduces the observed matrix. The Goodness of Fit Index (GFI) is an example of the first type of fit index. The second type of 
index assesses fit in terms of incremental fit. The fit of the hypothesized model is compared to either the null model where there is no structure or some other model. Examples of incremental fit indices are Delta2 and the Comparative Fit Index.

Some of the fit indices are normed to have a minimum of 0 and a maximum of 1 . The major advantage to having a normed index is ease of interpretation. The GFI and Comparative Fit Index are normed.

Sample size and fit indices are related. There are different sample size effects. Sample size can effect the calculation of the fit index or the mean of the sampling distribution. A summary of the type of sample size effects for overall fit measures is listed in Table XIII. The calculation of the Goodness of Fit Index (GFI), Adjusted Goodness of Fit (AGFI), Delta1, and RHO1 are unaffected by sample size, but are affected by the mean of the sampling distribution. The values of these indices tend to increase with large sample size. This makes comparison across samples risky. The calculation of Delta2, Rho2 are affected by sample size, but are unaffected by the mean of the sampling distribution. The values of these indices are stable across samples (Bollen, 1990). Fit indices that have their calculation affected by sample size are less favorable because they increase with sample size. 
TABLE XIII

TYPE OF SAMPLE SIZE EFFECTS

\begin{tabular}{|c|c|c|c|c|}
\hline \multirow[b]{2}{*}{$\begin{array}{l}\text { FIT } \\
\text { MEASURE }\end{array}$} & \multicolumn{2}{|c|}{ NORMED } & \multicolumn{2}{|c|}{ DOES N AFFECT } \\
\hline & MINIMUM & MAXIMUM & CALCULATION & $\begin{array}{l}\text { MEAN OF SAMPLING } \\
\text { DISTRIBUTION }\end{array}$ \\
\hline$\overline{\text { DELTA1 }}$ & 0 & 1 & NO & YES \\
\hline DELTA2 & No & NO & YES & NO \\
\hline RHO1 & NO & 1 & NO & YES \\
\hline RHO2 & No & NO & YES & NO \\
\hline GFI & NO & 1 & NO & YES \\
\hline AGFI & NO & 1 & NO & YES \\
\hline $\mathrm{CN}$ & NO & NO & NO & YES \\
\hline \multicolumn{5}{|c|}{$\begin{array}{l}\text { GFI = Goodness of Fit Index; AGFI = Adjusted Goodness of Fit } \\
\text { Index; } \mathrm{CN}=\text { Critical } \mathrm{N} \text {. }\end{array}$} \\
\hline
\end{tabular}


Fit indices are used to evaluate the fit of both the measurement and structural models and in making decisions about model modification. An acceptable level of fit is indicated by a result of between .80 and .90 (Anderson \& Gerbing, 1984; Bentler \& Bonnet, 1980). Anderson and Gerbing caution that as sample size increases relatively larger values of GFI and AGFI are needed to indicate acceptable fit. Bentler and Bonnet (1980) suggest that models with a fit of much less than .90 can be substantially improved.

Model Modifications. The overall fit indices and detailed fit indicators provide information about how to modify both the measurement and structural models. Small overall goodness of $\mathrm{fit}$ indices indicate that the overall fit of the model is poor and may be improved. Large residuals and the Root Mean Square Residual Index also indicate a poor fitting model.

Information about how to modify the model comes from the detailed fit indicators. T-values of less than two indicate that factor loadings and/or structural paths are not significant. Small SMCs indicate that the proportion of variance of the variables accounted for by the factor is small. Modification indices and residuals suggest which items want to load on other factors. Modification indices indicate which additional structural paths should be freed t-values indicate which paths should be dropped. Variance 
accounted for in endogenous variables is a detailed fit indicator specific to the structural model. It gives the amount of variance in the dependent latent variables accounted for by the other latent variables in the model. Negative variance accounted for indicates an overspecification problem.

The process of model modification begins with the examination of the overall fit of the model and then the detailed fit. An acceptable overall fit does not exclude examination of the detailed fit of the model. Model modifications are usually limited to one change per factor in any one modification. The changes are based on the detailed fit indicators. The revised model is then tested and evaluated for fit and further modification.

Power is an issue in model modification. Power is related to the ability to reject the null hypothesis and accept the alternate hypothesis. The null hypothesis in CSM is that the specified model holds in the population. The alternate hypothesis is that the specified model does not hold. Power is impaired with model modifications. Hayduk (1987) cautions that there is a fundamental difference between using the overall fit indices for testing a model and using the fit indices for improving the model. Once the data has been used to test the initial model, the data no longer provide a pure test of the modified model. 
One way to combat the problem of reduced power as a result of model modification is to cross validate results on hold-out sample data. Hold-out data provide a pure test of the modified model.

Cross validation. Cross validation allows the modified model to be tested on another sample. Cross validation on hold-out sample data controls for effects due to sampling errors or peculiarities that may have occurred during the modification process.

The overall fit of the cross validated measurement and structural models are expected to shrink, but not greatly. The cross validated structural path and factor estimates should be close to the original estimates. Stability in the overall indices and detailed fit indicators indicate support for the modified model.

\section{The selection of CSM in This study}

CSM was selected as the primary method of analysis in this study for several reasons. First, the research on organizational and professional commitment in the 1970's was predominantly correlational. Little theoretical rationale was evident in the selection of variables or how to relate them to commitment. Steers (1977) suggested three categories of antecedents for organizational commitment. Kerr et al. (1977) suggested five criteria for assessing professionalism. These two schemes guided much of the later 
research. The nature of the nomological network related to the commitments went largely ignored.

Second, no studies examined the commitments together in a system of antecedents and outcomes. This is important for determining whether the commitments have different predictors and affect outcomes differently.

Third, CSM permits the modeling and testing of mutually caused constructs. Satisfaction and performance have been suggested by past researchers to have causal effects on each other. Longitudinal analyses are typically used to assess this relationship.

The fourth reason for selecting CSM was to assess the unidimensionality of each construct. After establishing the unidimensionality of each construct, meaning could be assigned and the relationship between the constructs could be assessed.

Finally, concept redundancy is a problem in work related attitude research. The measurement model provided information used to evaluate whether the proposed constructs were sufficiently measured and distinct.

\section{REVIEW OF CSM IN COMMITMENT STUDIES}

A sampling of the analytic techniques used in past research on organizational and professional commitment are shown in Table XIV. The majority of studies used regression analysis. Few articles were found that used covariance 
TABLE XIV

ANALYTIC TECHNIQUES OF PAST RESEARCH

\begin{tabular}{|c|c|c|}
\hline RESEARCHERS & EAR & ANALYTIC TECHNIQUE \\
\hline Angle \& Perry & 1981 & $\begin{array}{l}\text { Correlational analysis } \\
\text { Factor analysis of OCQ }\end{array}$ \\
\hline Angle \& Perry & 1983 & Multiple regression \\
\hline Aranya et al. & 1981 & ANOVA \& regression \\
\hline Aranya et al. & 1982 & Path analysis \\
\hline Arnold \& Feldman & 1982 & Multiple regression \\
\hline Bateman \& strasser & 1984 & Multiple regression \\
\hline Blau & 1986 & $\begin{array}{l}\text { Hierarchical regression } \\
\text { Factor Analysis of } \mathrm{OCQ}\end{array}$ \\
\hline $\begin{array}{l}\text { Blau \& Boal } \\
\text { Bluedorn }\end{array}$ & $\begin{array}{l}1989 \\
1982\end{array}$ & $\begin{array}{l}\text { ANOVA \& ANCOVA } \\
\text { Path analysis } \\
\text { Cross validation }\end{array}$ \\
\hline Brooke et al. & 1988 & Covariance structural modeling \\
\hline Cooke & 1989 & Confirmatory factor analy \\
\hline Curry et al. & 1986 & Covariance structural modeling \\
\hline Darden et al. & 1989 & Covariance structural modeling \\
\hline Dornstein \& Matalon & 1989 & Stepwise multiple regression \\
\hline Dougherty et al. & 1985 & Path analysis \& ANOVA \\
\hline Ferris \& Aranya & 1983 & $\begin{array}{l}\text { Factor analysis } O C Q \& \mathrm{H}-\mathrm{A} \\
\text { Regression }\end{array}$ \\
\hline Glisson \& Durick & 1988 & Canonical correlation \\
\hline Gray & 1989 & Regression analysis \\
\hline Hom et al. & 1979 & Multiple correlation \\
\hline Jamal & 1990 & Moderated multiple regression \\
\hline Jermier \& Berkes & 1979 & Regression \\
\hline Luthans et al. & 1985 & $\begin{array}{l}\text { Principal factor analysis } \\
\text { Regression }\end{array}$ \\
\hline Luthans et al. & 1987 & Hierarchical regression \\
\hline Martin \& O'Laug & 1984 & Stepwise multiple regression \\
\hline Mathieu & 1988 & Path analysis \\
\hline Mathieu \& Farr & 1991 & Covariance structural modeling \\
\hline Mathieu \& Hamel & 1989 & Path analysis \\
\hline Mathieu \& Kohler & 1990 & Moderated regression analysis \\
\hline Meyer \& Allen & 1987 & Cross-lagged regression \\
\hline Michaels \& Spector & 1982 & Path analysis \\
\hline Morris \& Sherman & 1981 & Stepwise multiple regression \\
\hline Morris \& Steers & 1980 & Stepwise multiple regression \\
\hline Mottaz & 1986 & Multiple regression \\
\hline Mottaz & 1988 & Multiple regression \\
\hline Mowday et al. & 1979 & Factor analysis \& correlation \\
\hline O'Reilly \& Caldwell & 1980 & Canonical correlation \\
\hline Podsakoff et al. & 1986 & Covariance structural modeling \\
\hline Porter et al. & 1974 & Discriminant analysis \\
\hline putti et al. & 1989 & $\begin{array}{l}\text { Multiple regression } \\
\text { Factor analysis of } \mathrm{OCQ}\end{array}$ \\
\hline
\end{tabular}


TABLE XIV

ANALYTIC TECHNIQUE OF PAST RESEARCH (continued)

\begin{tabular}{lll}
\hline RESEARCHERS & YEAR & ANALYTIC TECHNIQUE \\
\hline Randall et al. & 1990 & $\begin{array}{l}\text { Multiple regression } \\
\text { Factor analysis }\end{array}$ \\
Reichers & 1986 & $\begin{array}{l}\text { Multiple regression } \\
\text { Rupp \& Segal }\end{array}$ \\
Shore \& Martin & 1989 & Confirmatory Factor Analysis \\
Steers \& Hartman & 1989 & Multiple regression \\
Stumpf \& Hartion \\
Van Maanen & 1984 & Multiple regression \\
Welsh \& Lavan & 1981 & Correlational analysis \\
Williams \& Hazer & 1986 & Correlational analysis \\
Zahra & 1984 & Correlational analysis
\end{tabular}


structural modeling (CSM). The contributions and weaknesses of each study were summarized and formed the basis for advancing the use of CSM in this study.

Jermier and Berkes (1979) studied the effects of leadership in a police department. They hypothesized that the use of human relations leadership style and high job complexity caused high satisfaction and commitment. They tested and confirmed these hypotheses using regression analysis. Hunter and Gerbing (1982) reanalyzed Jermier and Berkes (1979) data using covariance structural modeling techniques. They showed that the data fit several models which were quite different. One of the models tested confirmed the reverse relationship: high satisfaction caused people to perceive their leader's behavior to be participatory and perceived their jobs as complex.

In a second model, Hunter and Gerbing (1982) found that organizational commitment was causally prior to satisfaction, leadership and job complexity. The Jermier and Berkes (1979) model was rejected in favor of the Hunter and Gerbing models (1982) because the Hunter and Gerbing models were more parsimonious.

Williams and Hazer (1986) used a structural equation methodology to reanalyze data from Michaels and spector (1982) and Bluedorn (1982). They examined and identified the antecedents and consequences of satisfaction and commitment and their causal structure. Four causal models 
were tested. The results supported positive relationships between personal/organizational characteristics and satisfaction, satisfaction and commitment, and negative relationship between commitment and turnover intentions. Williams and Hazer (1986) did not conduct a confirmatory factor analysis to assess the measurement properties of the different scales. Although multiple indicators were available, the models tested used single indicators. The parameters were based on the reliabilities of the scales. This was a shortcoming. While this approach has some estimate of error, it does not take full advantage of the methodology.

Curry et al. (1986) used structural modeling techniques to test the causal ordering of job satisfaction and organizational commitment. Fifteen variables were included as exogenous determinants of both satisfaction and commitment. Nine measures of employee perceptions of organizational structure, four measures of employee characteristics, and two measures of environmental characteristics were included. The results provided no support for commitment having a causal effect on satisfaction or satisfaction having a causal effect on commitment.

Multiple indicators were not used to specify the measurement model. Factor based indexes were used in the place of the multiple indicators. Measurement error was 
accounted for by setting the indicators equal to the square root of the reliability coefficient.

While this approach is an improvement over the absence of a measurement model, it falls short of the capabilities of structural modeling. When multiple indicators are present, they should be used. Analysis based on multiple indicators provided information about individual item fit and error.

Darden et al. (1989) specified and tested both measurement and structural models of the antecedents and outcomes of organizational and career commitment. Separate models were proposed for each commitment. Antecedents variables were parent socioeconomic status, work values, role conflict and clarity, supervisory style, and perceived rewards. The consequences were job performance and satisfaction. The only difference in the models was the inclusion of either organizational or career commitment measures. Organizational and career commitment were not modeled together.

For the sample of retail salespeople, Darden et al. (1989) found that career and organizational commitment models were indistinguishable. This finding may reflect that salespeople do not distinguish between the career and the organization in which that career exists. Alternately, the findings may be due to the measure of organizational 
commitment that was selected. Darden et al. (1989) did not specify their measure of organization commitment.

Darden et al. (1989) estimated both the measurement and structural parameters simultaneously. Anderson and Gerbing (1988) made a recommendation against this practice because of interpretational confounding.

Podsakoff et al. (1986) used CSM to test how organizational formalization or structure, role ambiguity and conflict affected organizational commitment and how commitment led to alienation for professionals. This study shared the same problems as Darden et al. (1989). Single item indicators or summary scores were used in place of multiple indicators. In order to estimate error reliabilities were used as a starting point.

The results provided mixed support. Formalization decreased role ambiguity, but did not increase conflict. The path from commitment to alienation was not significant.

\section{Sample size}

A summary of CSM used in commitment studies is provided in Table XV. The studies of cooke (1989) and Williams and Hazer (1986) did not reach the 200 subject minimum sample size. Based on the 10 subjects per variable criteria cooke (1989), Brooke et al. (1988), and Podsakoff (1986) had acceptable sample sizes. The findings of these studies should be more stable. 
TABLE XV

SAMPLE SIZE

\begin{tabular}{lccll}
\hline RESEARCHERS & YEAR & $\begin{array}{l}\text { SAMPLE } \\
\text { SIZE }\end{array}$ & $\begin{array}{l}\text { RESPONSE } \\
\text { RATE }\end{array}$ & $\begin{array}{l}\text { NUMBER OF } \\
\text { ITEMS } \\
\text { (FACTORS) }\end{array}$ \\
\hline Brooke et al. & 1988 & 577 & $75 \%$ & $25(3)$ \\
Cooke & 1989 & 176 & $*$ NG & $9(1)$ \\
Curry et al. & 1986 & 508 & NG & $59(17)$ \\
Darden et al. & 1989 & 261 & $40 \%$ & $52(9)$ \\
Mathieu \& Farr & 1991 & $192 / 311$ & $96 \% / 65 \%$ & $35(3)$ \\
Podsakoff et al. & 1986 & 715 & NG & $45(6)$ \\
Williams \& Hazer & 1986 & $106 / 109$ & NG & $36(8)$ \\
\hline
\end{tabular}

* NG $=$ not given 
Conclusion. Covariance structural modeling techniques have not received wide attention in commitment research. The researchers that have attempted using CSM have used it in a limited way.

The commitment research has measurement and possible concept redundancy problems. Commitment has been correlated with many job relevant attitudes and behaviors. What has been lacking is an approach for identifying which subset of variables are important for predicting commitments and whichsubset of variables can the commitments predict. CSM is a robust methodology that models and tests both measurement and structural properties of multiple indicator and multiple latent construct models with estimation of errors in measurement and in paths.

THE RESEARCH SETTING

Kaiser Permanente is a federally qualified prepaid group practice Health Maintenance organization (HMO) and is the largest nongovernmental health care system in the world (Greenlick et al., 1988). It currently serves over five million enrollees in twelve different regions throughout the United states. More than six thousand physicians are affiliated with the Permanente medical group. Kaiser Foundation Hospitals and Kaiser Foundation Health Plan are not-for-profit, tax-exempt institutions. 
Northwest Region

Kaiser Permanente, Northwest Region is hospital-based. It organizes medical care services around the two plan-owned hospitals and twelve medical offices. The significance of a hospital-based approach is that it provides the opportunity for organizing and financing of medical care and for integrating inpatient and ambulatory services with the greatest degree of flexibility. Health services delivery is based on five basic principles that shape the organization of the system: voluntary enrollment, prepayment for comprehensive benefits on a service basis, preventive medical care, integrated, hospital-based health care facilities, and provision of physician services through group medical practice.

The Northwest Region has three components: Kaiser Foundation Health Plan, Kaiser Foundation Hospitals, and Northwest Permanente, Physicians and Surgeons Professional Corporation.

The Kaiser Foundation Health Plan contracts with Northwest Permanente, Physicians and Surgeons Professional Corporation, to provide medical care to enrolles, and with the Kaiser Foundation Hospitals to supply hospital care. The Region currently includes inpatient and outpatient facilities located in the Portland-Vancouver metropolitan area, Salem, oregon and Longview, Washington. 
The system provides services from a broad range of medical specialists and other health care professionals, and a range of educational, screening, diagnostic, treatment, and rehabilitation services. The benefit structure includes comprehensive coverage for a broad spectrum of services. The prepaid Health Plan benefits currently include complete coverage for physician, hospital, laboratory, and x-ray services. Chemical abuse/dependency treatment services are also covered, as are mental health services, drugs, and optical care, although some limitations apply to the latter three services.

\section{Membership Population}

Since Kaiser Permanente (KP) was established as a community-based program in Portland in 1943, it has grown to 370,000 members. The demographic and socioeconomic characteristics of KP members correspond very closely to those of the population of the area as a whole (Greenlick et al. 1988).

\section{Center for Health Research}

Recognizing the possibilities for research, Kaiser Permanente founded the Center for Health Research in 1959. It is professionally autonomous, but administratively affiliated with Kaiser Permanente. The Center for Health Research engages in research to help develop the knowledge upon which national health policy might be based. The 
Center conducts research in the public interest and makes its findings widely available.

The Northwest region had both the financial and administrative resources available to provide a dependable base of funding for research activity and leadership. There also existed a perceived obligation to contribute to a community services program. One way the center fulfills this role is by providing data to the health services field. The Center for Health Research receives funding primarily from Federal, state, and private research grant agencies. Approximately $20 \%$ of the funding comes from the parent company.

\section{STUDY GROUP}

Employees working for Kaiser Permanente in the Northwest Region in the fall of 1990 were the study group. The Northwest Permanente, Physicians and Surgeons Professional Corporation was not included. Physicians are not employees of Kaiser Permanente and are surveyed separately at different times.

The array of job classifications included in this study was thought to be sufficiently broad to tap a reasonably representative sample of health occupations. See Table XVI for job categories and numbers of each category within Kaiser Permanente, Northwest Region. 
TABLE XVI

EMPLOYEE SURVEY RESPONDENTS

JOB CATEGORY DISTRIBUTIONS

\begin{tabular}{llc}
\hline Job & $\begin{array}{l}\text { Number } \\
\text { in KPNW }\end{array}$ & $\begin{array}{l}\text { Percentage } \\
\text { of KPNW }\end{array}$ \\
\hline Management/Professionals & 857 & 14.5 \\
Supervisors & 337 & 5.7 \\
Medical Technicians & 531 & 9.0 \\
Non-Medical Technicians & 402 & 6.8 \\
Technical Aids & 348 & 5.9 \\
LPNs & 295 & 5.0 \\
Rns & 1222 & 20.7 \\
Clerks (no pnt contact) & 555 & 9.4 \\
Clerks (patient contact) & 956 & 16.2 \\
Service & 401 & 6.8 \\
& & 100.00 \\
\hline ToTALs & $* 5904$ & \\
\hline
\end{tabular}

Source: Freeborn, D., Schrager, L. \& Lamb, S. (1990b). Satisfaction by job category and by year. (unpublished) Center for Health Research, Kaiser Permanente, Northwest Region. 
The survey allowed for classification into 11 different job categories: managers, supervisors, professionals, medical technicians, non medical technicians, technical aides, licensed practical nurses and certified nursing assistants, registered nurses, clerks with no patient contact, clerks with patient contact, and service workers and housekeepers. In this study the 11 job categories were combined into six categories for analysis purposes. The sixcategories were: managers and supervisors, professionals, registered nurses (excluding supervisors and managers), skilled technicians, aids and licensed practical nurses, and clerks and service workers.

\section{DATA SOURCE}

The data source was the 1990 Kaiser Permanente Employee Survey. The survey was designed by staff from the center for Health Research and data are used for both research and program evaluation. Donald K. Freeborn, Ph.D. is the principal investigator and Sara Lamb is the Project Director. Data collection was supervised by staff from the Center for Health Research who are also responsible for data analysis.

A 70 item self-administered questionnaire was used to collect the data. The survey was voluntary and confidentiality was provided for all subject responses. No individual identifiers were used. A complete list of the 
items used in this study from the Employee Survey can be found in Appendix $A$.

The survey was first administered in 1975. Many additions and deletions have occurred through its 15 year history. The 1990 survey was an anniversary survey. One of its purposes was to compare responses from the 1980 and 1990 surveys.

The response rates for the survey have ranged from a high of $95 \%$ in 1975 to a low of $60 \%$ in 1980 . The response rate for the 1990 survey was $70 \%$. The number of respondents was 4331 .

The demographic characteristics of responders were similar to nonresponders. The age, length of service, and gender of responders compared favorably with responders.

\section{MEASURES}

\section{organizational commitment}

Organizational commitment was measured by Porter et al. (1974) Organizational Commitment Questionnaire (OCQ). This questionnaire is shown in Appendix A. The response format is a 7-point likert scale with the following anchors: strongly agree, moderately agree, slightly agree, neither agree nor disagree, slightly disagree, moderately disagree, strongly disagree.

Negatively phrased items in the original scale were not used in this study for two reasons. First, the negative 
items were the items criticized by Reichers (1985) for conceptual problems with turnover. Second, the Employee Survey was kept as short as possible. The instrument was tested valid and reliable without these items (Mowday et al., 1979).

The additional item about commitment to the organization was added as a part of this study. The reliability and validity has not been assessed.

\section{Professional commitment}

The items for the professional commitment scale were derived from the criteria defining professional as outlined by Kerr et al. (1977), Raelin (1985), and Miller (1986). Expertise, autonomy, identification, knowledge, and membership were the measured dimensions of professional commitment.

\section{Satisfaction}

The items for the satisfaction scale were derived from research conducted at the Institute for Social Research at the University of Michigan. A collection of surveys and their results conducted by the Institute can be found in the book Survey of organizations (1978).

The satisfaction scale was adapted, modified, and validated over the 15 year period of the Employee Survey (Freeborn et al., 1990a). The scale consisted of the first six items listed in Appendix A: control over pace/quality of 
work, variety in work, security, coworkers, physical surroundings, opportunities for advancement, continuing education and training, amount of responsibility, supervision, and job overall. The coefficient alpha for this scale was .78 (Freeborn et al, 1990a). The results of exploratory factor analysis on the items showed that there was one factor.

This scale is similar to the often used Job Descriptive Index (JDI). The JDI measures satisfaction in terms of five aspects of the subjects' job: supervision, co-workers, work, pay, and promotion. Validity and reliability data for the JDI are described in Smith, Kendall, and Hulin (1969).

\section{Performance}

The items for the performance scale were derived from Mott (1972). Freeborn et al. (1990a) constructed the remainder of the items.

Freeborn et al. (1990a). performed an exploratory factor analysis on the first six items listed in Appendix A under performance. They reported a single factor solution. The coefficient alpha was .86. The additional items related to quality of production, production quantity, and coordination of work activities were not included in the scale. These items were added because they fit conceptually with the construct. 
Withdrawal

The scale for withdrawal from the organization is composed of items related to turnover and absenteeism. Both of these are thought to be part of a general process of witharawal from the organization. The first two items in the scale tap into respondents intentions to leave or remain with the organization in the future. The last three items tap into the reasons why and how often respondents have been absent in the past year.

The items in the scale were constructed by Freeborn et al. (1990a).

Job Demands

The items for the job demand scale were adapted from the work of Karasek (1979) and Karasek and Theorell (1990). The coefficient alpha was .77 for the scale (Freeborn et al., 1990a). The results of an exploratory factor analysis showed that the items loaded on one factor.

\section{Rewards}

The items for the rewards scale were developed by Freeborn and Center for Health Research Staff. The reward scale has two factors: wages and benefits. The coefficient alpha for the wage factor is .73 . The coefficient alpha for the benefit factor was .81 (Freeborn et al., 1990a). 


\section{Organizational Characteristics}

organizational characteristics have three factors: quality of supervision, views about the organization, and performance appraisal process. The items for the quality of supervision scale were derived from the Quality of Employment Survey conducted by the Institute for social Research, University of Michigan referenced in Karasek and Theorell (1990). The items for the performance review and views about the organization scales were from Freeborn et al. (1990a).

The coefficient alpha for the supervision scale was .97 and the results of an exploratory factor analysis showed that there was one factor (Freeborn et al., 1990a). An exploratory factor analysis showed that there was one factor for the performance review scale. The coefficient alpha was .91 (Freeborn et al., 1990a). The reliability and validity of the views about the organization scale have not been assessed.

\section{MODEL BUILDING}

Exploring the described constructs and their relationships required an attempt to take complicated theories and practical knowledge and integrate them into a coherent and integrative framework that was manageable and useful. The selected starting point was the basic equation formulated by Kurt Lewin (1951): $B=f[P, E]$. That is human 
behavior (B) is a function of individual characteristics of the person (P) and of the characteristics of her surrounding environment (E). Understanding employee behavior thus has two basic elements, person and environment. Efforts to change employee behavior can focus on either, but understanding employee behavior must come from both.

A general model of work behavior was adopted as the framework for understanding the constructs of interest in this study. Figure 1 is a portable model useful for understanding, predicting, and changing employee behavior (Skinner, 1953; Shortell \& Kaluzny, 1988). Behavior refers to any work related activity of interest to the manager. The model has three primary components: the antecedents, behavior, and consequences of behavior.

All behavior takes place in some context. There are always environmental events or characteristics that exist prior to the onset of behavior. Environmental characteristics can stimulate or depress, facilitate or decrease desired behaviors such as performance.

The next step in the model and in understanding behavior is the environmental consequences of behavior. Thorndike's (1911) law of effect states that behavior that is followed by positive consequence is more likely to recur. Conversely, behavior followed by negative consequences is less likely to recur. 


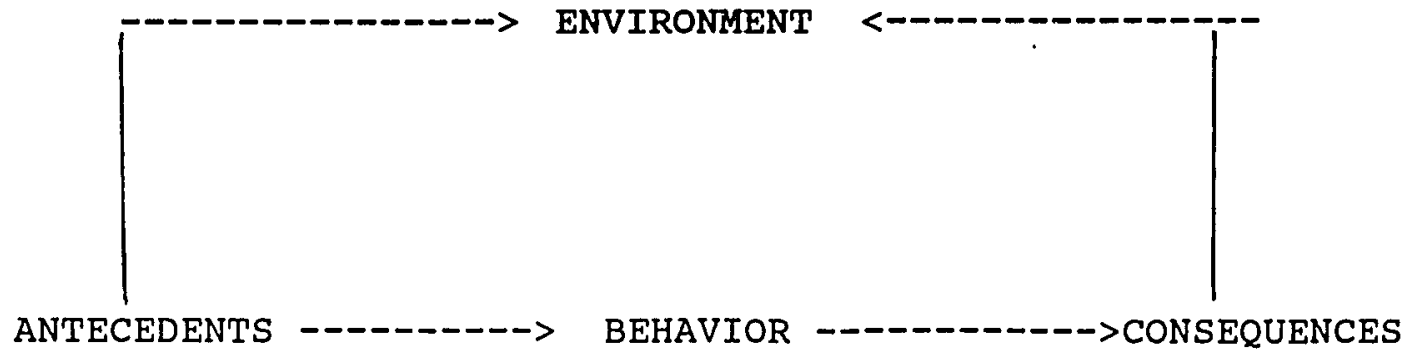

Figure 1. A general model of work behavior. 
Figure 1 is a static model. Behavior is not static. The model is presented here as a framework for understanding behavior in organizations. What needs to be understood about the model is that the consequences of behavior at Time 1 can be the antecedents of behavior at Time 2 . The elements of the model are fluid. For example, at Time 1 organizational rewards may be antecedent to performance which may result in increased satisfaction; at Time 2 satisfied employees may increase their performance which may result in increased rewards.

The model is useful for framing the constructs of interest in this study. Education, job demands, age, tenure, rewards, and organizational characteristics are antecedent variables. These variables form the environment in which commitment occurs or fails to occur. Professional and organizational commitments are the primary behaviors of interest. Performance, satisfaction, and withdrawal are the consequences of professional and organizational commitment.

The variables of interest in this study were selected from the results and recommendations of past studies (see Tables VIII, IX and $X)$. An attempt was made in this study to sample multiple variables from each category of antecedents and outcomes. Confirmatory factor analysis was used to assess the measurement properties of the variables and structural modeling was used to assess the causal 
structure. This methodology is a departure from past research efforts.

\section{Confirmatory Factor Analysis}

First and second-order confirmatory factor analyses were used to assess the fit of the measurement model. The number of individual items, first-order factors and secondorder factors are listed in Table XVII. The individual items as they appeared in the Employee Survey are listed in Appendix A. The first-order confirmatory factor analysis is diagrammed in Figure 2 .

The second-order confirmatory factor model is diagrammed in Figure 3. Five second-order factors were modeled and tested. Professional commitment, organizational commitment, organizational characteristics, rewards, and performance were the second-order factors modeled and tested.

\section{Structural Model}

A chart of the causal and correlational paths is provided in Table XVIII. The initial structural model is diagrammed in Figure 4. Correlational and causal paths are both depicted. Causal paths have a single headed arrow. Correlational paths have double headed arrows.

Causal Paths. Reading from right to left in Figure 4, satisfaction and performance have negative causal affects on turnover. Increased satisfaction and performance are 
TABLE XVII

INITIAL MEASUREMENT MODEL ITEMS AND FACTORS

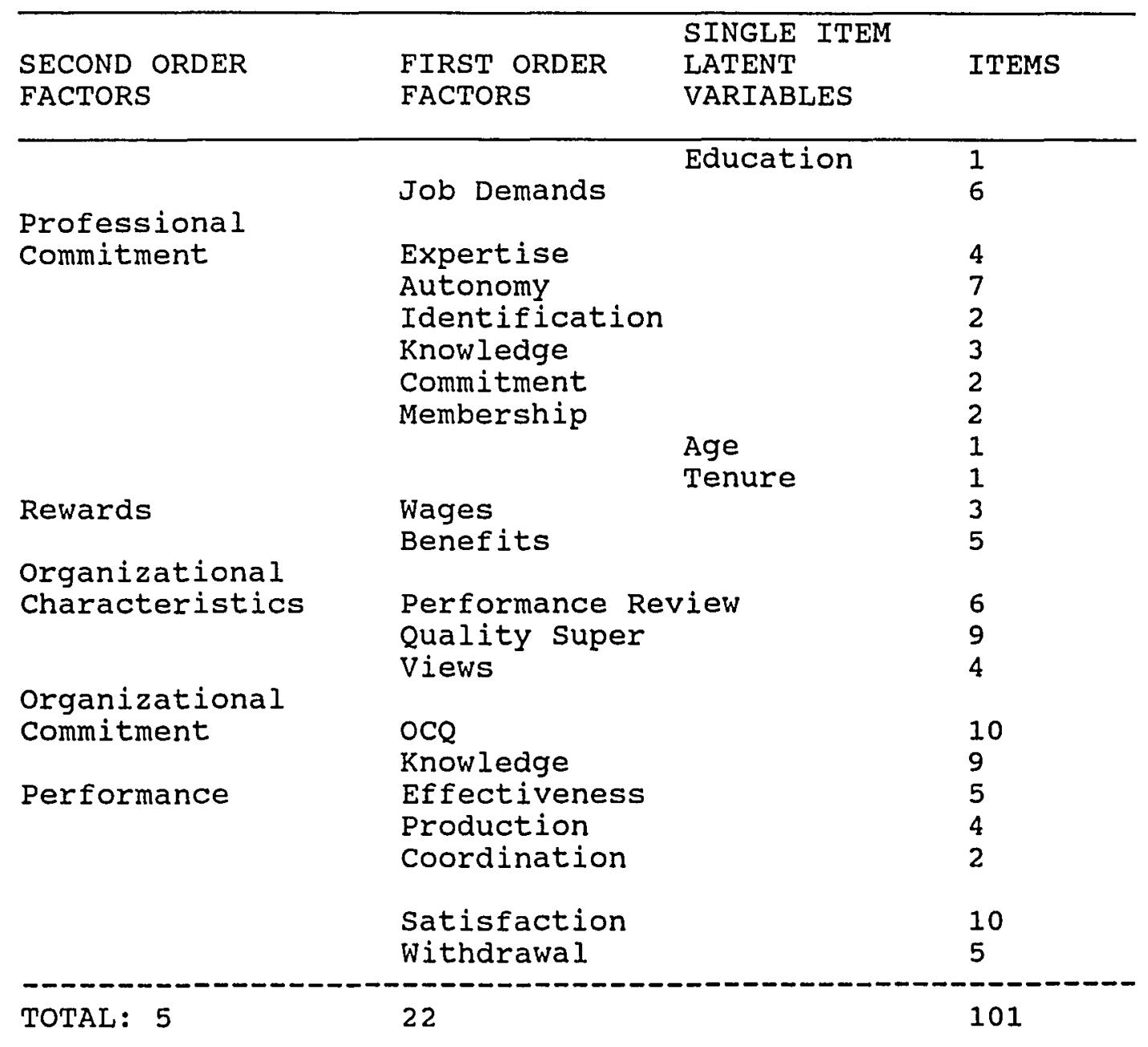




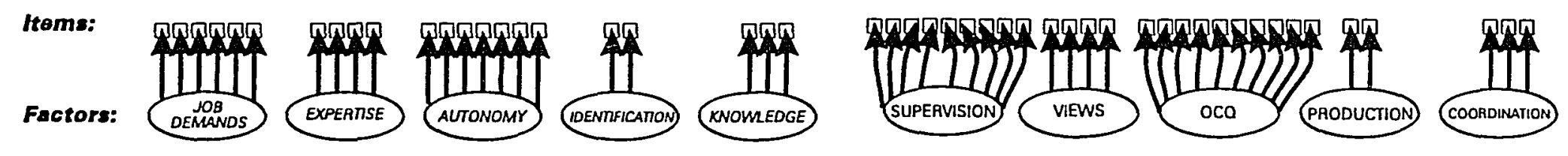

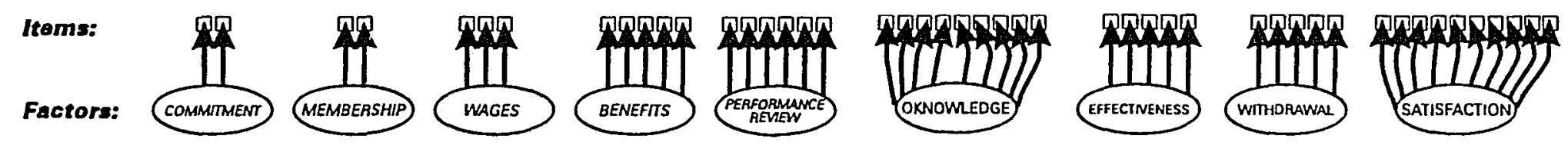

Figure 2. First-Order Factor Analysis Structure. 
First-Order

Factors:

Second-Order Factors:

\section{First-Order} Factors:

\section{Second-Order} Factors:
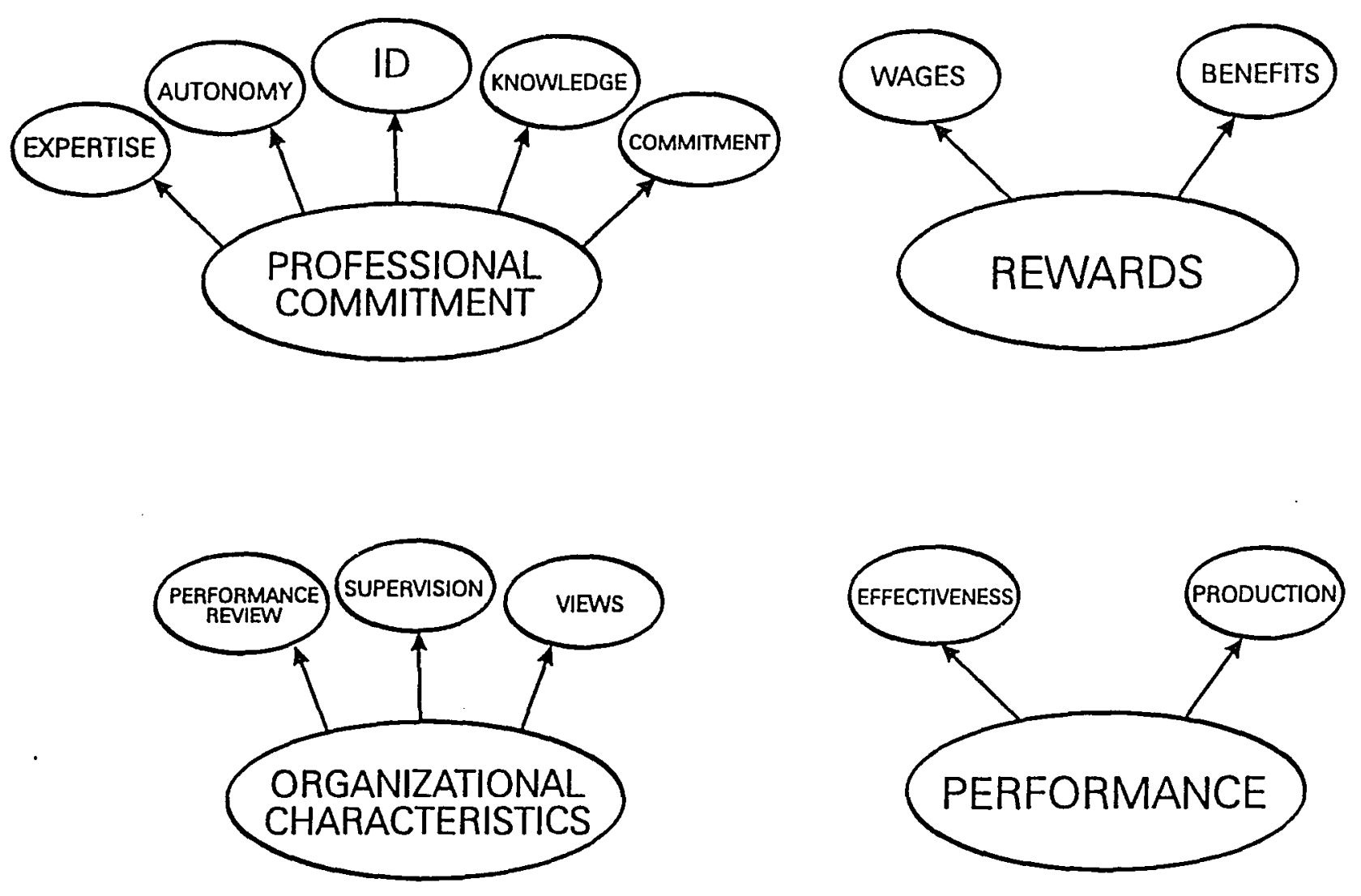

Figure 3. Second-Order Factor Analysis Structure. 
TABLE XVIII

HYPOTHESIZED CAUSAL RELATIONSHIPS AMONG STUDY VARIABLES

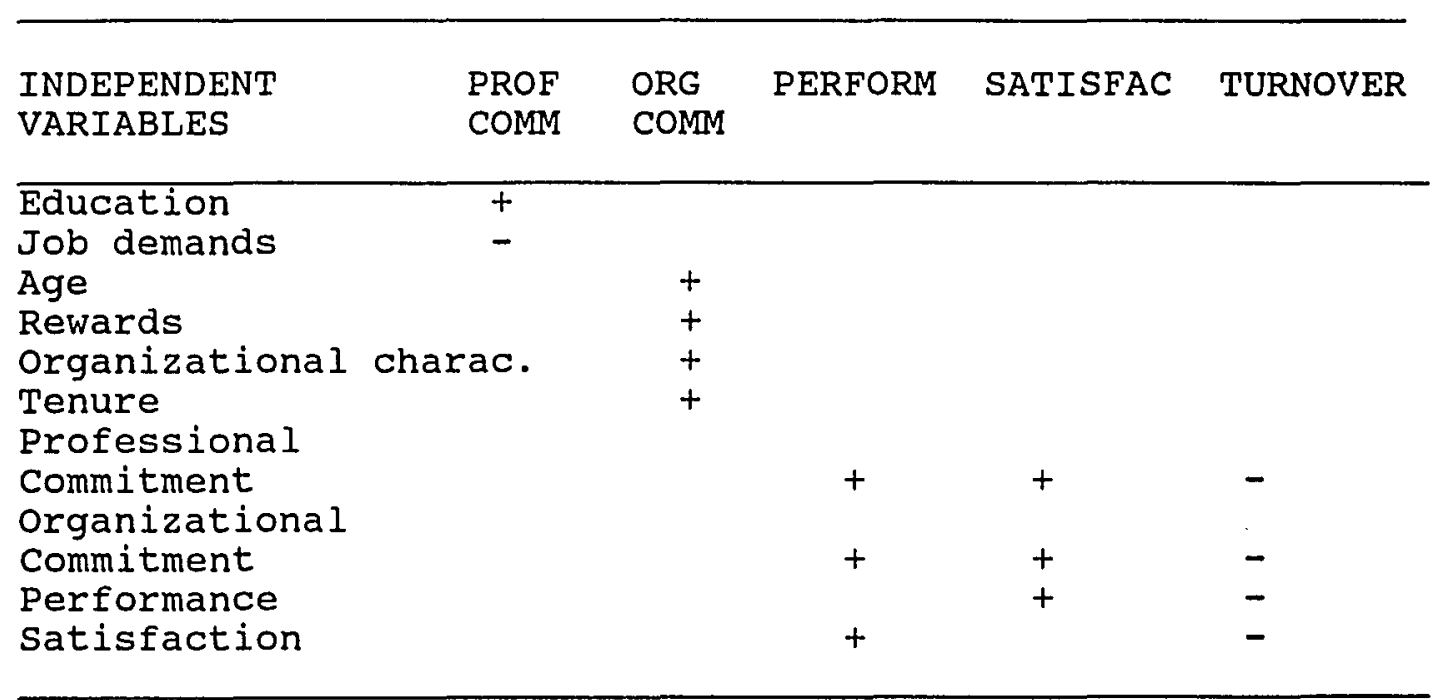

KEY: [+] INDICATES A POSITIVE CAUSAL RELATIONSHIP [-] INDICATES A NEGATIVE CAUSAL RELATIONSHIP 


\section{—EXOGENOUS — VARIABLES}

\section{ENDOGENOUS}

VARIABLES

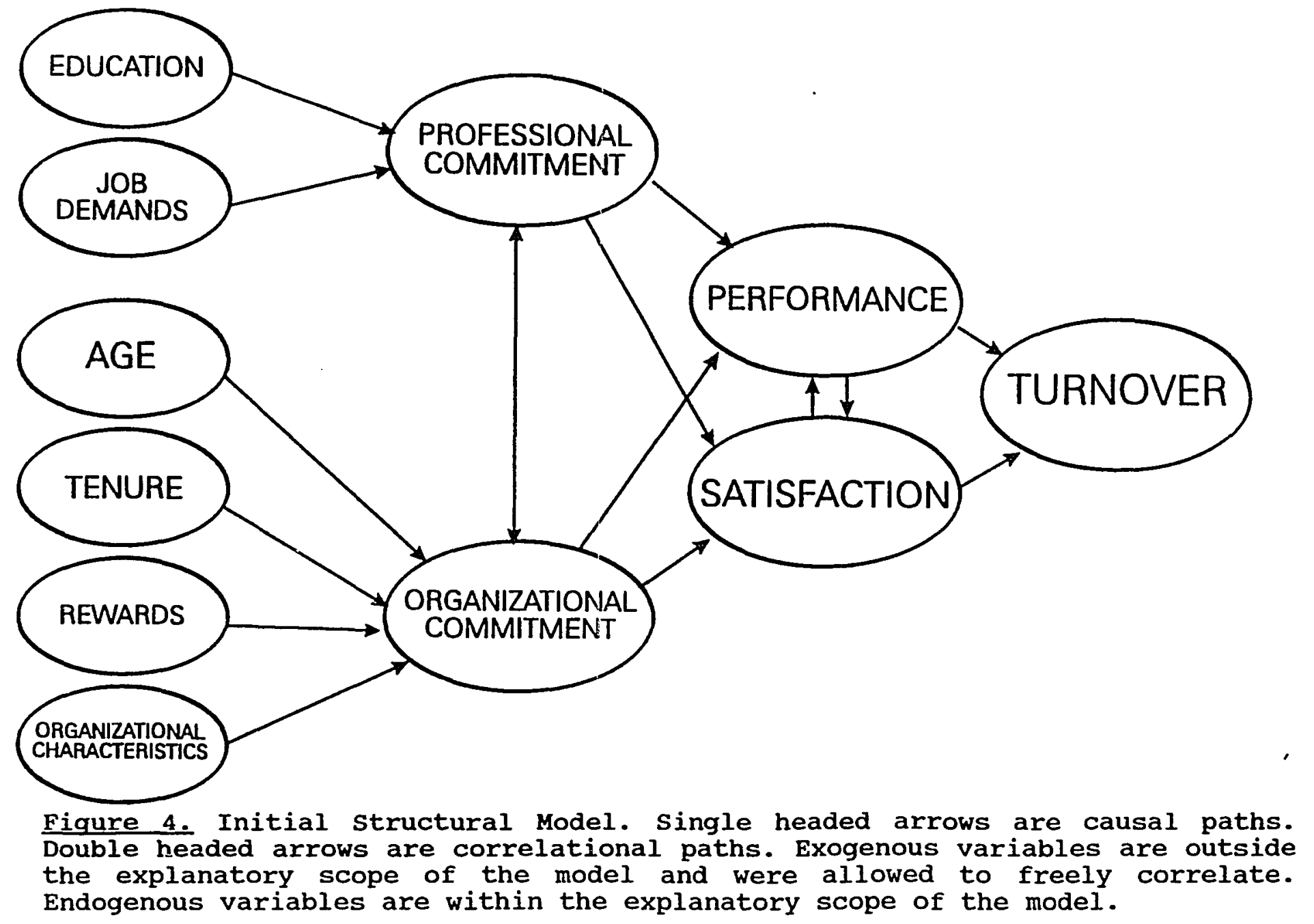


associated with a decrease in turnover. Satisfaction and performance are mutually causal. Professional and organizational commitment have positive direct effects on satisfaction and performance and indirect effects on turnover. Education and job demands have positive direct effects on professional commitment and indirect effects on satisfaction, performance, and turnover. Age, tenure, organizational characteristics, and rewards have positive direct effects on organizational commitment and indirect effects on satisfaction, performance, and turnover.

Correlational Paths. Education, job demands, age, tenure, organizational characteristics, and rewards are exogenous variables. The exogenous variables in Figure 4 are outside the explanatory scope of the system. The exogenous variables are used to explain the other variables, but are not themselves explained. The causal nature of the exogenous variables are unknown and hence, are modeled as unanalyzed relationships and were allowed to freely correlate.

Hypotheses. In structural modeling, there is only one hypothesis. The hypothesis tested was the entire network of relationships. The hypothesis tested in this study is outlined in Table XIX.

One additional hypothesis, separate from the structural and measurement models, was tested. The second hypothesis was: 
TABLE XIX

HYPOTHESIS OF STRUCTURAL RELATIONSHIPS

A: Professional and organizational commitment are distinct constructs.

B: a) Age, b) tenure, c) rewards, and d) organizational characteristics have a positive impact on organizational commitment.

c: a) Education and b) job demands have a positive impact on professional commitment.

D: a) Professional commitment has a positive causal relationship with satisfaction and b) with Performance.

E: a) organizational commitment has a positive causal relationship with performance and b) satisfaction

F: There are mutual causal paths between satisfaction and performance. Satisfaction causes performance and performance causes satisfaction.

G: Performance has a negative causal relationships with withdrawal. Increased performance causes a decrease in withdrawal.

H: Satisfaction has a negative causal relationship with withdrawal. Increased satisfaction causes a decrease in withdrawal. 
The construct professional commitment is not occupation specific. Occupational groups will not differ in their responses related to professional commitment. 
CHAPTER IV

RESULTS

HOLD-OUT SAMPLE DATA

The sample data was divided into two random samples of $50 \%$ each. The first sample was used for data analysis for both the measurement and structural models. The hold-out sample was used to confirm modified measurement and structural models. There were 4,331 subjects in the entire sample, 2166 subjects in the first sample, and 2165 subjects in the hold-out sample.

MEASUREMENT MODEL

First and second-order confirmatory factor analyses were used to assess the fit of the measurement model. The number of individual items, first-order factors and secondorder factors are listed in Table XX. The individual items as they appeared in the Employee Survey are listed in Appendix A. Items that were dropped are noted in Appendix A.

First-order Confirmatory Factor Analysis

The first-order confirmatory factor analysis model is diagrammed in Figure 5. Three computer programs were used 
TABLE XX

PROPOSED MEASUREMENT MODEL ITEMS AND FACTORS

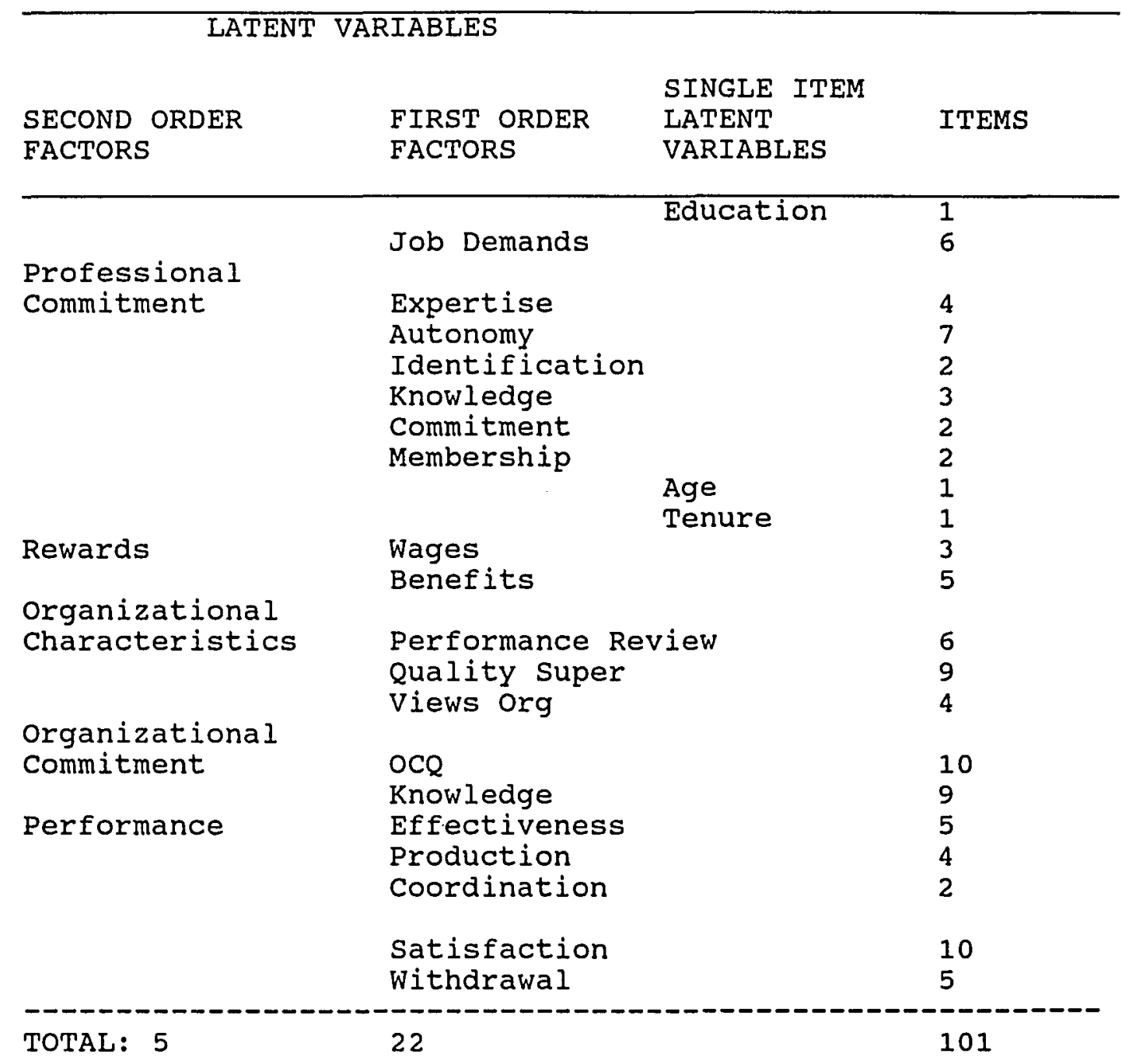



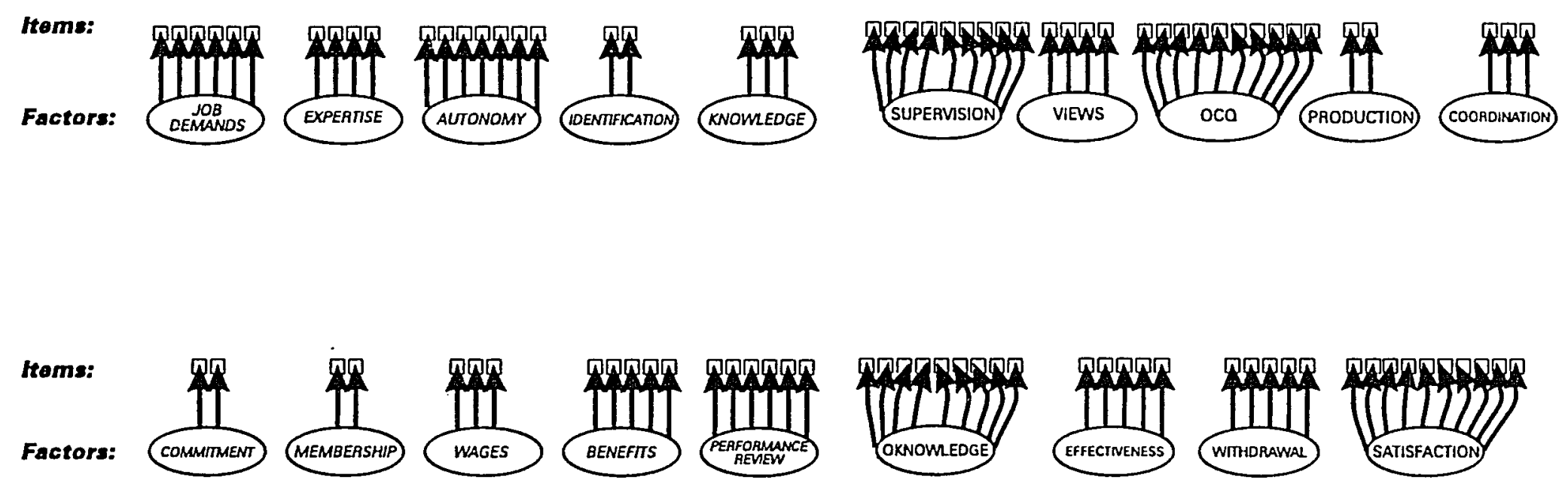

Figure 6. Proposed First-Order Factor Analysis Structure. 
to assess the first-order factor structure. The initial first-order confirmatory factor analysis was computed with the ITAN program (Gerbing \& Hunter, 1986) which is an extended subset of the correlational analysis program PACKAGE (Hunter \& Cohen, 1969). ITAN utilizes a centroid method of factor extraction such that the weights of the factors are defined a priori as 1 . ITAN was selected as the initial program and method because the computations are much easier to accomplish as compared to maximum likelihood. Anderson and Gerbing (1982) recommend the use of ITAN for preliminary evaluation of models.

The 101 items partitioned into 22 factors were submitted to a confirmatory factor analysis using ITAN. All reverse scored items were reflected, so that they would properly load on their respective factors. The $101 \times 101$ inter-item correlation matrix among the measured variables was the input data.

Based on the ITAN analysis, 91 variables and 22 factors were retained. The withdrawal factor was split into two separate factors. The first factor had two items and was labeled turnover. The second factor had three items and was labeled absenteeism. The decision to split the withdrawal factor into two separate factors was based on the pattern of relationships among the five items. The results showed that the 5 items did not covary, but it appeared that two groups 
of items did covary. The two separate factors were tested and supported.

The coordination factor was dropped. The decision was based on the relationship between the two items. The items did not covary. The pattern of relationships between the coordination items across the other factors was not proportional.

Individual items were dropped from the various factors either because they loaded highly on other factors or because they did not load significantly on the specified factor. Two items were dropped from the views and job demands factors. A single item was dropped from the satisfaction, performance review, *quantity/quality of production, and organizational knowledge factors. A revised list of the factors and items based on the results of the ITAN analysis are listed in Table XXI.

LISREL. Additional confirmatory factor analyses were conducted with maximum likelihood estimates as in the program LISREL (Joreskog \& Sorbom, 1984). The 91 variables and 22 factors listed in Table XXI were submitted to a confirmatory factor analysis with maximum likelihood estimates. This analysis resulted in the retention of 65 variables and 19 factors.

* Quantity/quality of production will be referred to as production in the remainder of the paper. 
TABLE XXI

ITAN MEASUREMENT MODEL ITEMS AND FACTORS

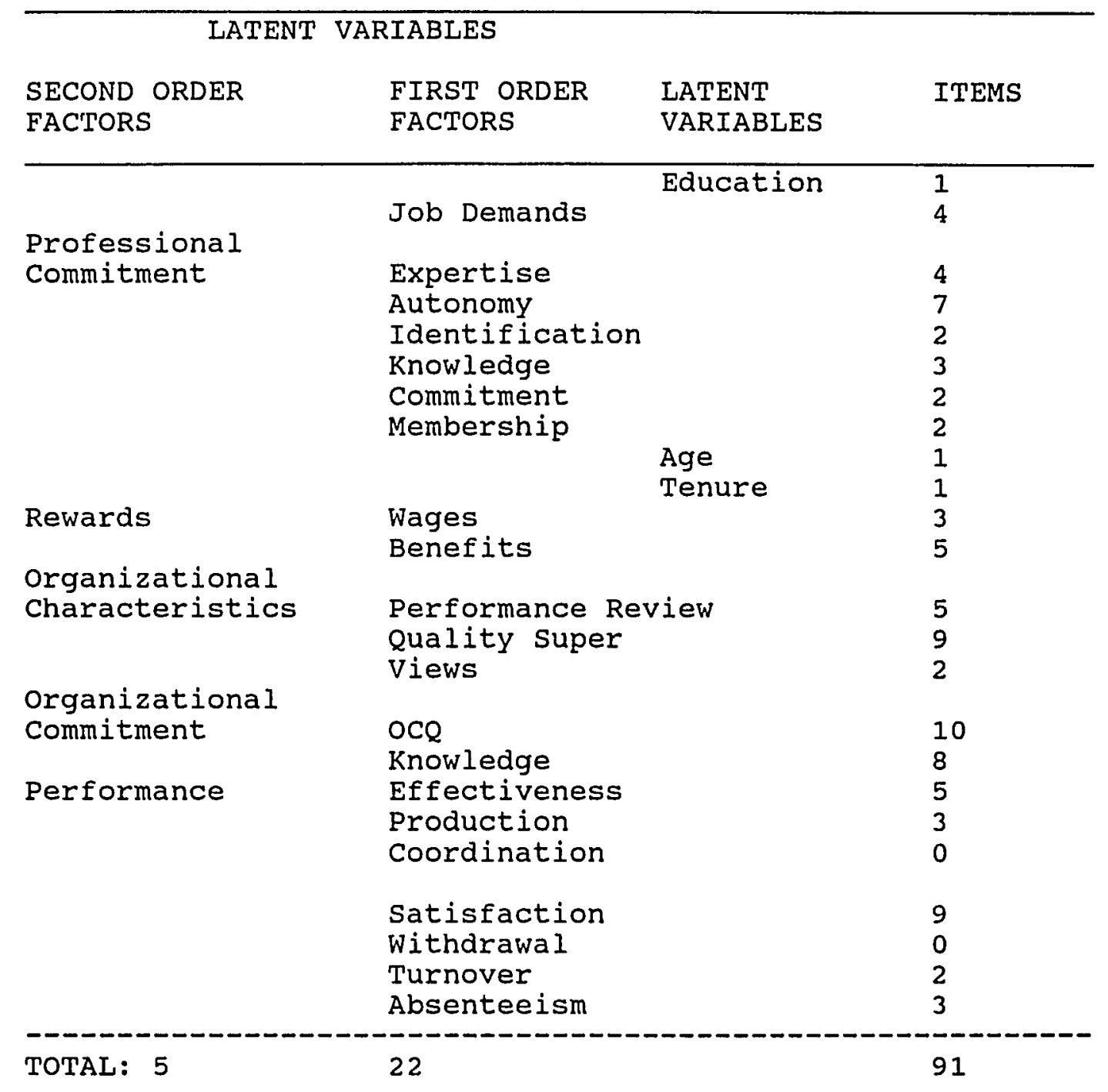


Membership, absenteeism, and organizational knowledge factors were dropped. Organizational knowledge was dropped because it created a linear dependency problem that caused the Phi matrix to be "not positive definite." Membership and absenteeism were dropped because the squared multiple correlations of their items were very small. This indicated that the items were not adequately measuring the specified construct. Therefore, 13 variables were dropped from the model.

High residuals accompanied with significant modification indices supported the removal of 13 additional variables. No items were allowed to load on more than one factor. The items were dropped in order to constrain the factors to be unidimensional. Supervision, satisfaction, and autonomy factors each had two items dropped. A single item was dropped from each of the benefits, performance review, expertise, job demands, professional knowledge, production, and effectiveness factors. The final factors and items are listed in Table XXII.

Measures of goodness of fit of the defined first-order factor analysis model support the model. The final designated model had a Chi-square of 9491.16 with 1850 degrees of freedom and a probability level of 0.000 . This compares favorably with the null model Chi-square of $75,913.24$ with 2,080 degrees of freedom. The Goodness of Fit index was .87 . The Adjusted Goodness of Fit Index was 
TABLE XXII

LISREL MEASUREMENT MODEL ITEMS AND FACTORS

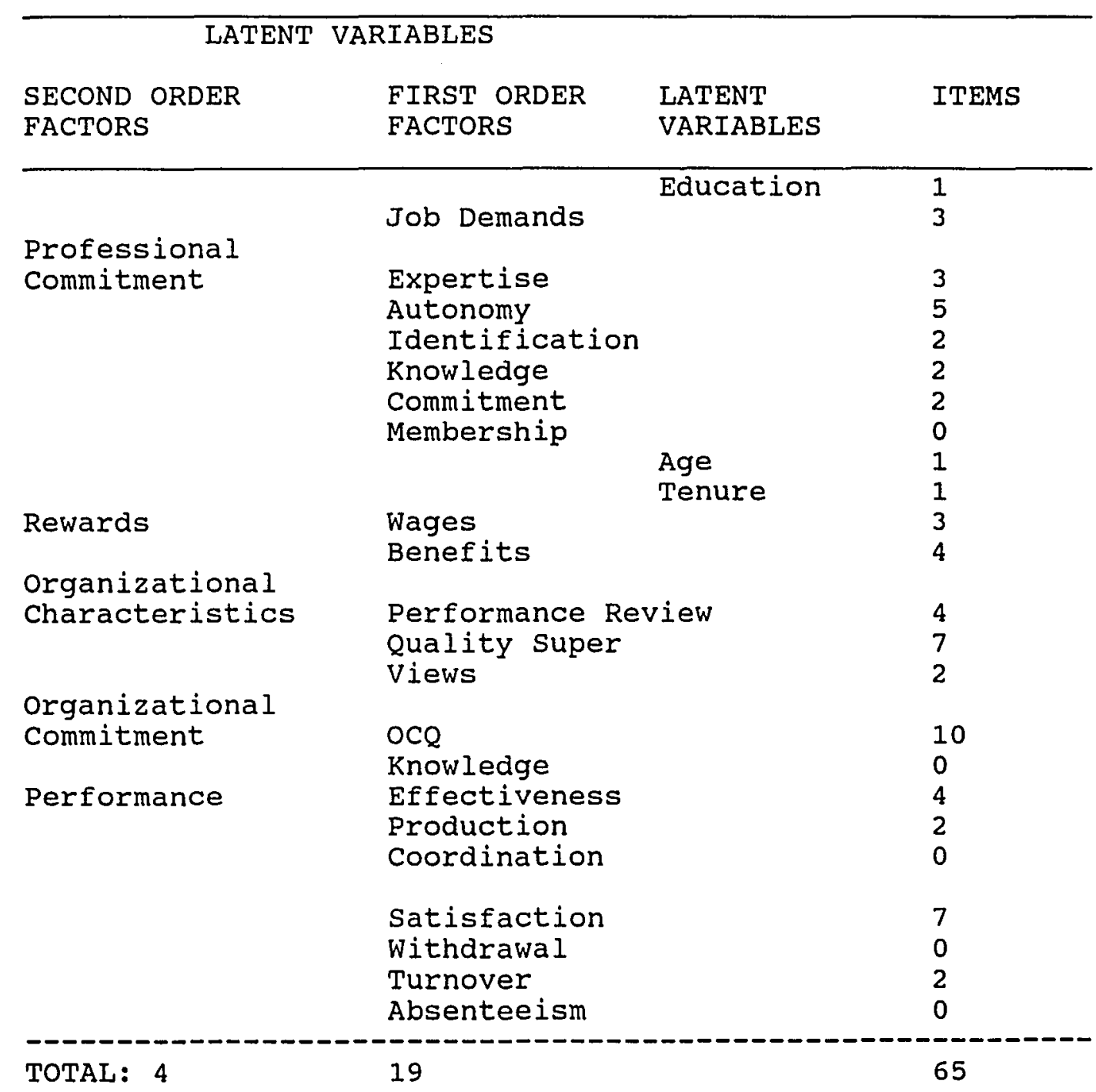


.85 and Root Mean Square Residual was .04. Together these indicators support a good fit of the first-order model. SAS. Because of ease of programming, further analyses were conducted with the structural modeling procedure CALIS in SAS Version 6 (1989). The final 65 variables and 19 factors resulting from the LISREL program were the starting point. The correlation matrix of the 65 items is provided in Appendix $B$.

The results of the first-order confirmatory factor analysis generated by SAS replicated the results found by LISREL. Following the confirmation of results one additional variable was dropped. An organizational commitment item was dropped because of the pattern of relationships with other variables and its high residual. This reduced the final model to 19 factors and 64 variables. The results listed in Table XXIII indicate strong support for the first-order confirmatory factor analysis. The combined fit indices reached an acceptable .90 level of fit. Additionally, the first-order model Chi-squared to degrees of freedom ratio was superior to the null model. The estimates of the specified 64 items by 19 factors matrix is provided in Appendix $C$.

\section{Second-order Confirmatory Factor Analysis}

The second-order confirmatory factor model is diagrammed in Figure 6. Four second-order factors were 
TABLE XXIII

FIRST-ORDER FACTOR ANALYSIS RESULTS

\begin{tabular}{llrc}
\hline MODEL & FIT INDEX & RESULT & $\begin{array}{c}\text { DEGREES OF } \\
\text { FREEDOM } \\
\text { (P-VALUE) }\end{array}$ \\
\hline \multirow{2}{*}{ Null } & & & \\
First-Order & Chi-square & $74,697.45$ & 2016 \\
& Chi-square & 8993.54 & $1784 \quad(.0001)$ \\
& GFI & .88 & \\
& CFI & .90 & \\
& DELTA2 & .90 & \\
& RHO1 & .86 & \\
& & & \\
GFI=Goodness Of Fit Index, CFI=Comparative Fit Index and \\
DELTA2=Bollen's Non-Normed Index.
\end{tabular}




\section{First-Order Factors:}

\section{Second-Order}

Factors:
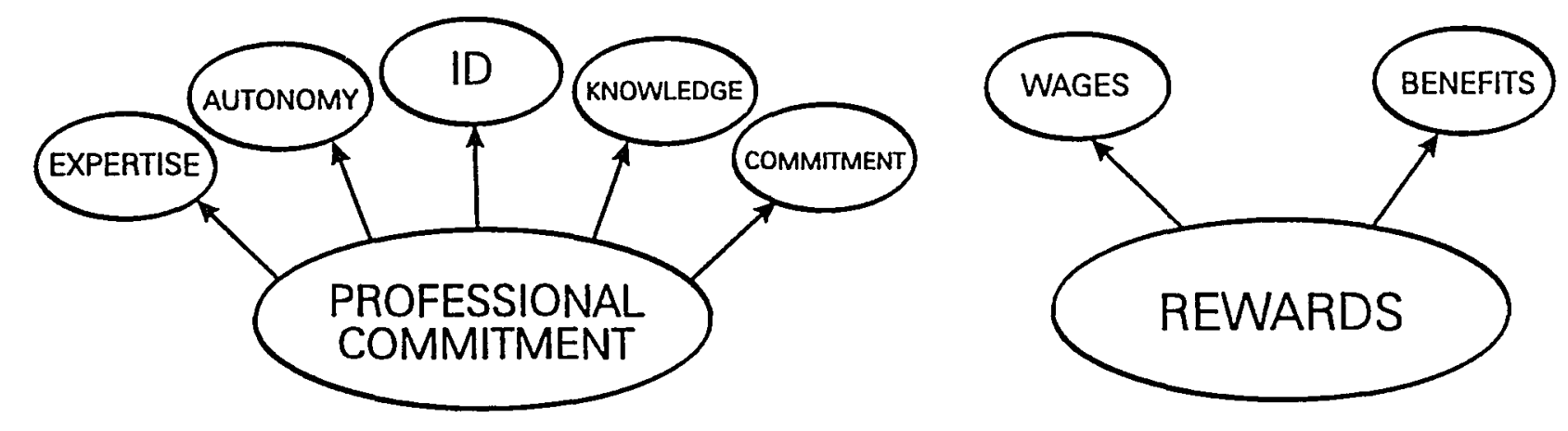

\section{First-Order} Factors:

\section{Second-Order Factors:}
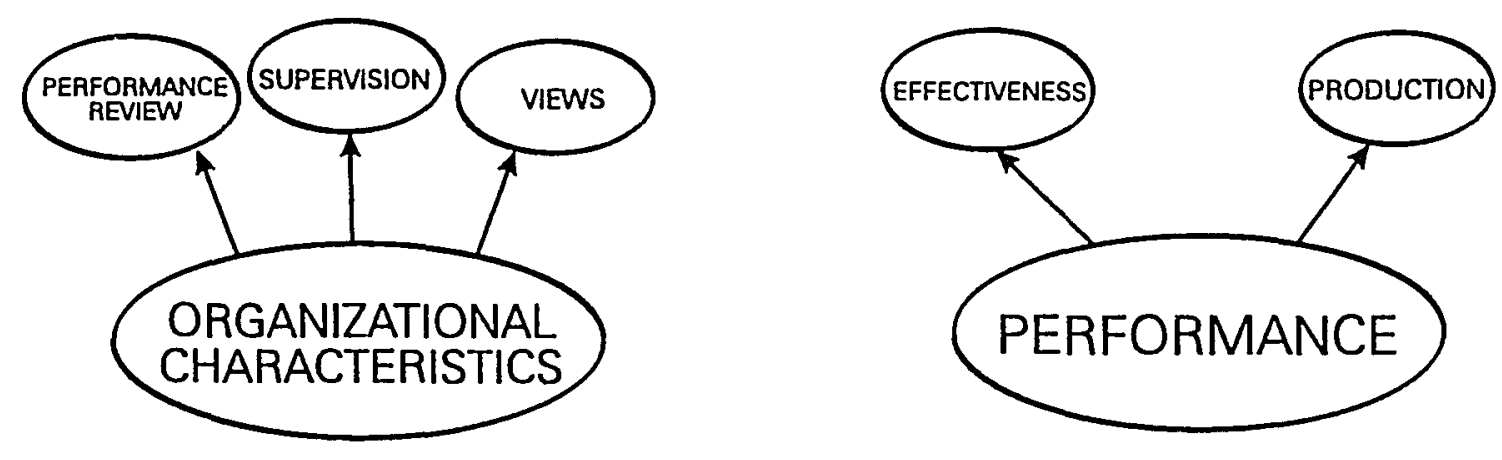

Figure 6. Proposed Second-Order Factor Analysis Structure. 
modeled and tested. Professional commitment, organizational characteristics, rewards, and performance were the secondorder factors modeled and tested. See Table XXII for a listing of the items, the first-order, and the second-order factors.

Initially, the second-order CFA was conducted separately from the first-order factor analysis. In this analysis only first-order factors that loaded on secondorder factors were tested. First-order only factors were not in the model. In a second analysis the second-order CFA was stacked with the first-order CFA. Separate analyses were used initially to reduce complexity. The results of the second-order CFA alone, and stacked with the first-order factor analysis, are listed in Table XXIV.

The fit indexes for the stand alone model reached the .90 level of fit. This indicated strong support for the second-order factor model. Additionally, the second-order model compared favorably to the null model Chi-square and degrees of freedom. These findings support the identified second-order structure.

The fit indexes for the stacked second and first-order model were attenuated. The first and second-order models separately reached the .90 level of $\mathrm{fit}$, but together they reached a smaller, but acceptable level of .88. The estimates of specified 12 first-order factors by four second-order factor matrix is provided Appendix D. 
TABLE XXIV

SECOND-ORDER FACTOR ANALYSIS RESULTS

\begin{tabular}{|c|c|c|c|}
\hline MODEL & FIT INDEX & RESULT & $\begin{array}{l}\text { DEGREES OF } \\
\text { FREEDOM } \\
\text { (P-VALUE) }\end{array}$ \\
\hline \multicolumn{4}{|l|}{ SECOND-ORDER ALONE: } \\
\hline & Chi-square & $44,317.94$ & 780 \\
\hline \multirow{5}{*}{ SECOND-ORDER } & Chi-square & $4,472.94$ & $710(.0001)$ \\
\hline & GFI & .90 & \\
\hline & CFI & .91 & \\
\hline & DELTA2 & .91 & \\
\hline & RHO1 & .89 & \\
\hline \multicolumn{4}{|c|}{ SECOND-ORDER STACKED WITH FIRST-ORDER: } \\
\hline NULL & Chi-square & $74,697.45$ & 2016 \\
\hline \multirow[t]{5}{*}{ SECOND-ORDER } & Chi-square & $10,691.40$ & $1888(.0001)$ \\
\hline & GFI & .85 & \\
\hline & CFI & .88 & \\
\hline & DELTA2 & .88 & \\
\hline & RHO1 & .85 & \\
\hline
\end{tabular}

GFI $=$ Goodness of Fit Index, CFI=Comparative Fit Index and DELTA2=Bollen's Non-Normed Index. 


\section{Reliability}

To assess the reliability of the proposed scales standardized coefficient alpha was calculated for each of the remaining first order factors: Job demands, expertise, autonomy, knowledge of profession, commitment to profession, wages, benefits, performance review, quality of supervision, views about the organization, organizational commitment Questionnaire, effectiveness, production, satisfaction and turnover. The reliability coefficients are listed in Table $\mathrm{XXV}$.

With the exception of professional knowledge and commitment, each of the proposed scales reached an acceptable reliability level. The professional commitment and knowledge scales were comprised of two items each. This accounts for the lower coefficient alpha.

\section{STRUCTURAL MODEL}

The validity of the proposed model in Figure 7 was tested using the general maximum likelihood procedures in SAS Version 6 (1989). The input data for the structural model was the second-order factor-factor matrix. Stand alone first order factors were included in the factor-factor matrix. The input data for the simultaneous estimation of the measurement and structural model was the $65 \times 65$ interitem matrix. 
TABLE XXV

RELIABILITY COEFFICIENTS

\begin{tabular}{|c|c|c|}
\hline FACTOR NAME & COEFFICIENT ALPHA & ITEMS \\
\hline$\overline{A G E}$ & - & \\
\hline EDUCATION & - & \\
\hline TENURE & - & \\
\hline WAGES & .72 & 3 \\
\hline BENEFITS & .80 & 4 \\
\hline VIEWS & .64 & 2 \\
\hline TURNOVER & .60 & 2 \\
\hline SUPERVISION & .93 & 7 \\
\hline SATISFACTION & .78 & 7 \\
\hline PERFORMANCE REVIEW & .91 & 4 \\
\hline EXPERTISE & .79 & 3 \\
\hline AUTONOMY & .84 & 5 \\
\hline JOB DEMANDS & .77 & 3 \\
\hline IDENTIFICATION & .68 & 2 \\
\hline PROFESSIONAL KNOWLEDGE & .53 & 2 \\
\hline PROFESSIONAL COMMITMENT & .51 & 2 \\
\hline ORGANIZATIONAL COMMITMENT & .93 & 9 \\
\hline PRODUCTION & .66 & 2 \\
\hline EFFECTIVENESS & .82 & 4 \\
\hline
\end{tabular}




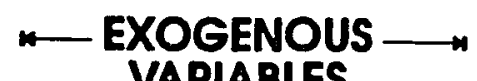

VARIABLES

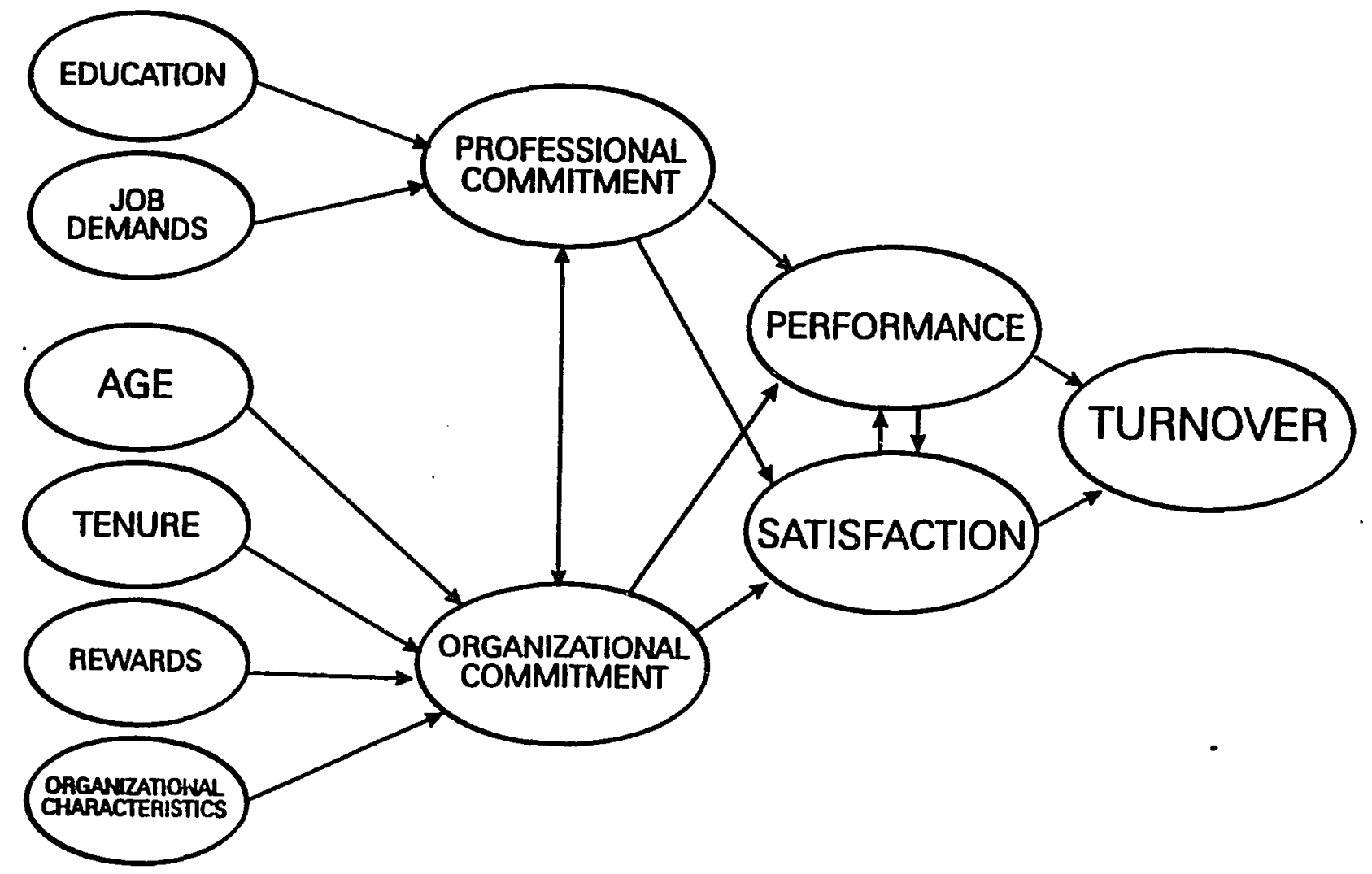

Fiqure 7. Proposed Structural Model. Single headed arrows are causal paths. Double headed arrows are correlational paths. Exogenous variables are outside the explanatory scope of the model and were allowed to freely correlate. Endogenous variables are within the explanatory scope of the model. 


\section{Initial Findings}

Education, job demands, age, tenure, organizational characteristics, and rewards are exogenous variables in the model. The exogenous variables in Figure 7 are outside the explanatory scope of the system. The exogenous variables were used to explain the other variables, but were not themselves explained. The causal nature of the exogenous variables is unknown and hence were modeled as unanalyzed relationships and were allowed to freely correlate.

The fit of the initial model was poor. The goodness of fit indices for the initial model are listed in Table XXVI. None of the fit indexes reached an acceptable level of $\mathrm{fit}$. This indicated that the model required modification.

\section{Structural Model Modifications}

Model modifications were based on empirical and theoretical information. The causal paths between performance and satisfaction were dropped in the first model modification because the error parameter for performance was not identified. This indicated that the nonrecursive path between satisfaction and performance was unstable. Because neither causal path alone was theoretically justifiable satisfaction and performance were correlated in the first model modification.

Further examination of the factor-factor matrix revealed that turnover was highly correlated to numerous 
TABLE XXVI

INITIAL STRUCTURAL MODEL RESULTS

\begin{tabular}{llrc}
\hline MODEL & FIT INDEX & RESULTS & $\begin{array}{c}\text { DEGREES OF } \\
\text { FREEDOM } \\
\text { (P-VALUE) }\end{array}$ \\
\hline NULL & Chi-square & $13,129.55$ & 55 \\
STRUCTURAL & Chi-square & $5,325.20$ & $25(.0001)$ \\
& GFI & .80 & \\
& CFI & .60 & \\
& DELTA2 & .60 & \\
& RHO1 & .11 & \\
& & & \\
\hline
\end{tabular}


other factors. The goal of the proposed structural model was to examine the antecedents and outcomes of organizational and professional commitment. The goal of the proposed structural model was not to explain turnover. The proposed structural model could not account for the high correlations with turnover. For this reason turnover was dropped from the structural model.

The results of the first model modification are listed in Table XXVII. The model is diagrammed in Figure 8 . The fit indices show an improvement of fit over the initial model, but did not reach an acceptable level of overall fit. This indicated that the model could be further improved. The second model modification was the freeing of the path from organizational characteristics to professional commitment. The correlation between these two factors was .81. The relationship between these factors could not be accounted for indirectly through the unanalyzed correlations and paths between organizational and professional commitment.

Theoretically, the freeing of the path was justified. Professional commitment as measured in this study was related to the individual's identification with their work. The design of the work and characteristics of the organization may also have influenced commitment. Organizational characteristics included quality of supervision, views about the organization and performance 
TABLE XXVII

STRUCTURAL MODEL MODIFICATIONS

\begin{tabular}{|c|c|c|c|c|}
\hline MODEL & & IT INDEX & RESULTS & $\begin{array}{l}\text { DEGREES OF } \\
\text { FREEDOM } \\
\text { (P-VALUE) }\end{array}$ \\
\hline $\begin{array}{l}\text { MODIFICATION } \\
\text { NULL MODEL }\end{array}$ & 1 & $\begin{array}{l}\text { Chi-square } \\
\text { Chi-square }\end{array}$ & $\begin{array}{r}3,986.12 \\
11,006.14\end{array}$ & $\begin{array}{l}18(.0001) \\
45\end{array}$ \\
\hline & & $\begin{array}{l}\text { GFI } \\
\text { CFI } \\
\text { DELTA2 } \\
\text { RHO1 }\end{array}$ & $\begin{array}{l}.84 \\
.64 \\
.64 \\
.09\end{array}$ & \\
\hline MODIFICATION & 2 & Chi-square & 1252.39 & $17(.0001)$ \\
\hline & & $\begin{array}{l}\text { GFI } \\
\text { CFI } \\
\text { DELTA2 } \\
\text { RHO1 }\end{array}$ & $\begin{array}{l}.91 \\
.89 \\
.89 \\
.70\end{array}$ & \\
\hline MODIFICATION & 3 & Chi-square & 1253.19 & $18(.0001)$ \\
\hline & & $\begin{array}{l}\text { GFI } \\
\text { CFI } \\
\text { DELTA2 } \\
\text { RHO1 }\end{array}$ & $\begin{array}{l}.91 \\
.89 \\
.89 \\
.72\end{array}$ & \\
\hline MODIFICATION & 4 & $\begin{array}{l}\text { Chi-square } \\
\text { GFI } \\
\text { CFI } \\
\text { DELTA2 } \\
\text { RHOI }\end{array}$ & $\begin{array}{r}1254.19 \\
.91 \\
.89 \\
.89 \\
.73\end{array}$ & $19(.0001)$ \\
\hline
\end{tabular}




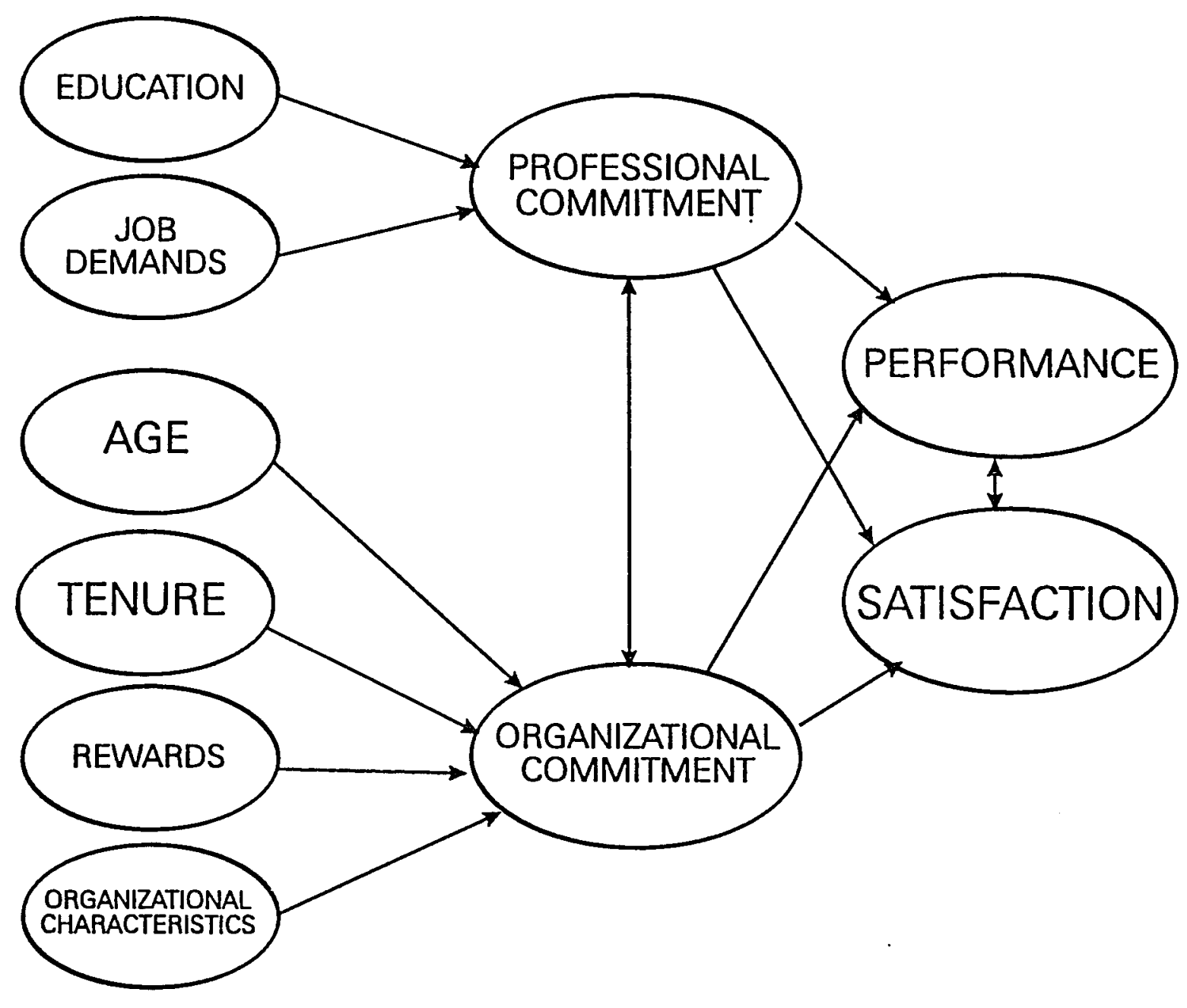

Figure 8. Structural Model Modification 1. 
appraisal process. Each of these factors may affect the nature of the work and hence individual commitment.

The results of the second model modification are listed in Table XXVII. The model is diagrammed in Figure 9. The overall fit indices show an improvement of fit over the first modification. The fit indices reached an acceptable .89 level of fit.

Three paths were found to be insignificant in the examination of the detailed fit of the model which suggested that the model could be further improved. The path from tenure to organizational commitment and the paths from organizational commitment to satisfaction and performance were not significant.

The third modification was the elimination of tenure from the model. The results of the third model modification are listed in Table XXVII. The model is diagrammed in Figure 10. The fit indices remained the same. This finding supported the elimination of tenure.

The paths from organizational commitment to satisfaction and performance were still not significant following the third modification. The path from organizational commitment to performance was dropped in the fourth modification because it had the smallest estimate and associated $t$-value.

The results of the fourth and final modification are listed in Table XXVII. The fit of the model was unchanged. 


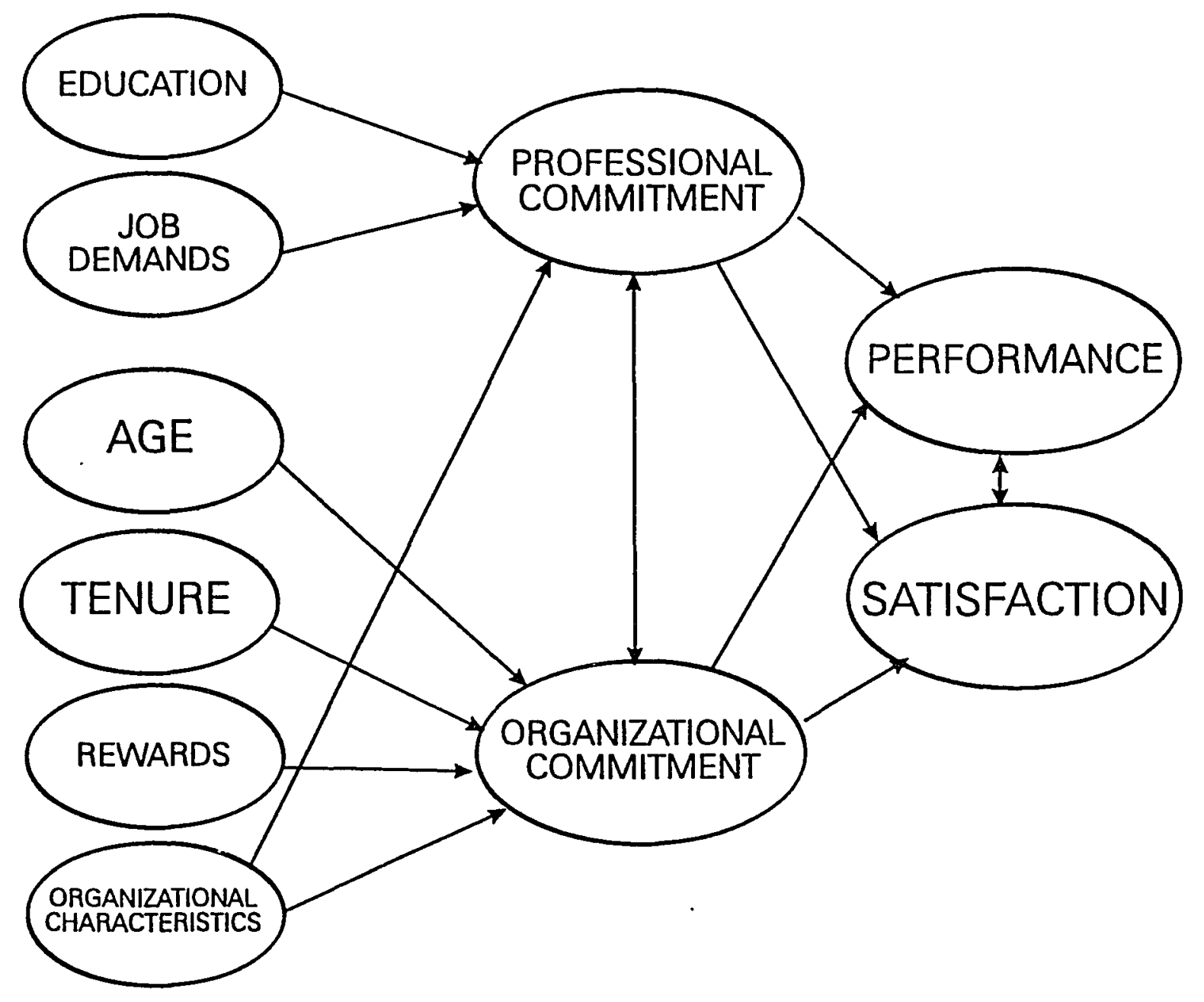

Figure 9. Structural Model Modification 2. 


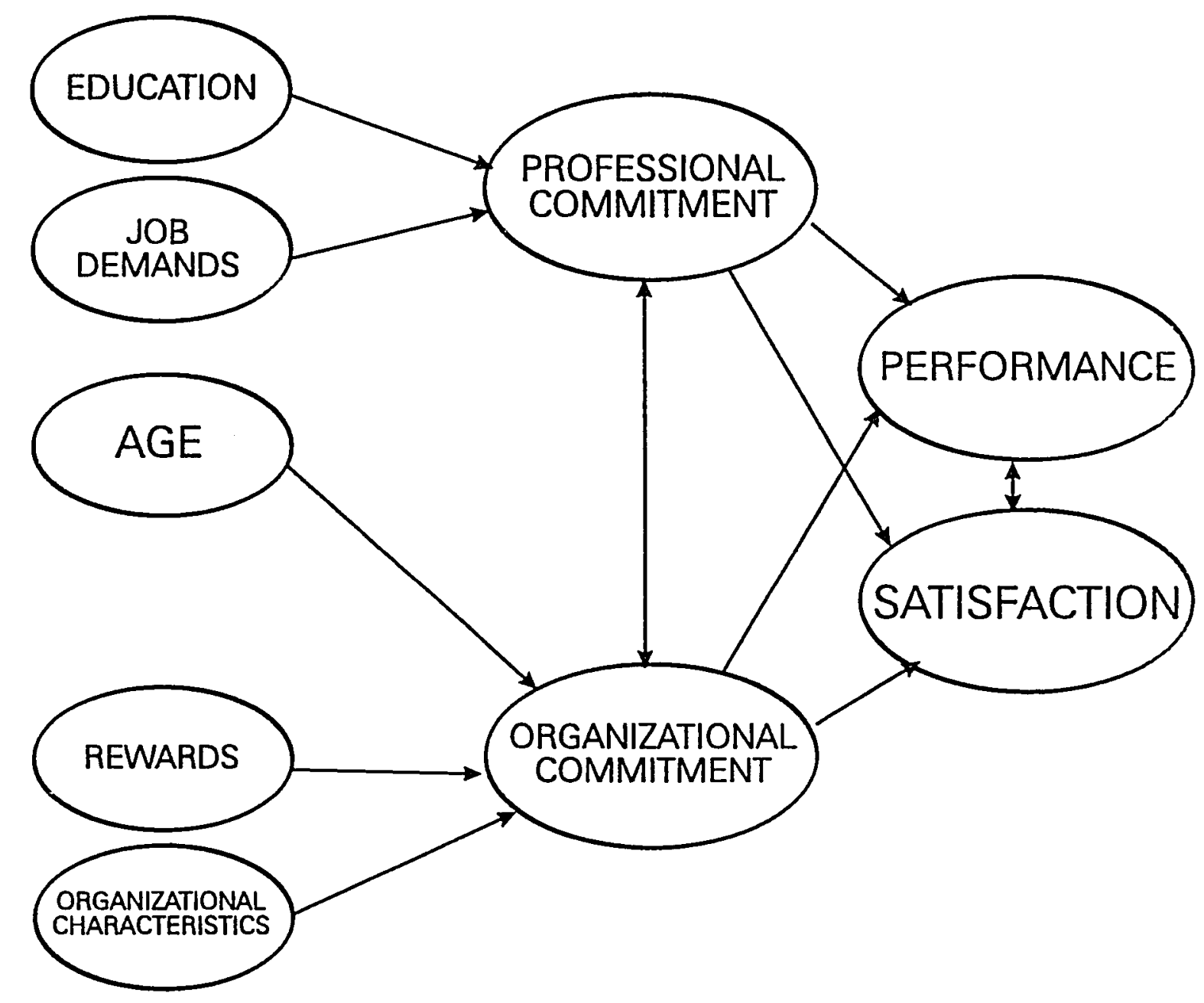

Figure 10. Structural Model Modification 3. 
All remaining paths were significant.

Many of largest modification indices were relationships with the errors. None were meaningful. The modification of error relationships in this study made no theoretical sense and were not freed.

Modification indices of additional paths between variables were then examined. The largest modification index was the path from organizational commitment to professional commitment. The freeing of this path resulted in an overidentification problem. The evidence for the overidentification problem was negative variance accounted for in the endogenous variables.

The freeing of additional paths did not improve the overall fit of the model and caused a deterioration of the structural model. No further modifications were completed. The fourth model modification results are diagrammed in Figure 11. Path equations, T-values and standard errors of the estimates are listed in Table XXVIII. Variance accounted for in each endogenous variable is listed in Table XXIX.

The path coefficients in the fourth model modification were standardized and can be interpreted in terms of standard units i.e., a unit measure change in education leads to a .15 increase in professional commitment holding all other variables in the model constant. The final model had an acceptable level of fit of .89 . All paths in the 


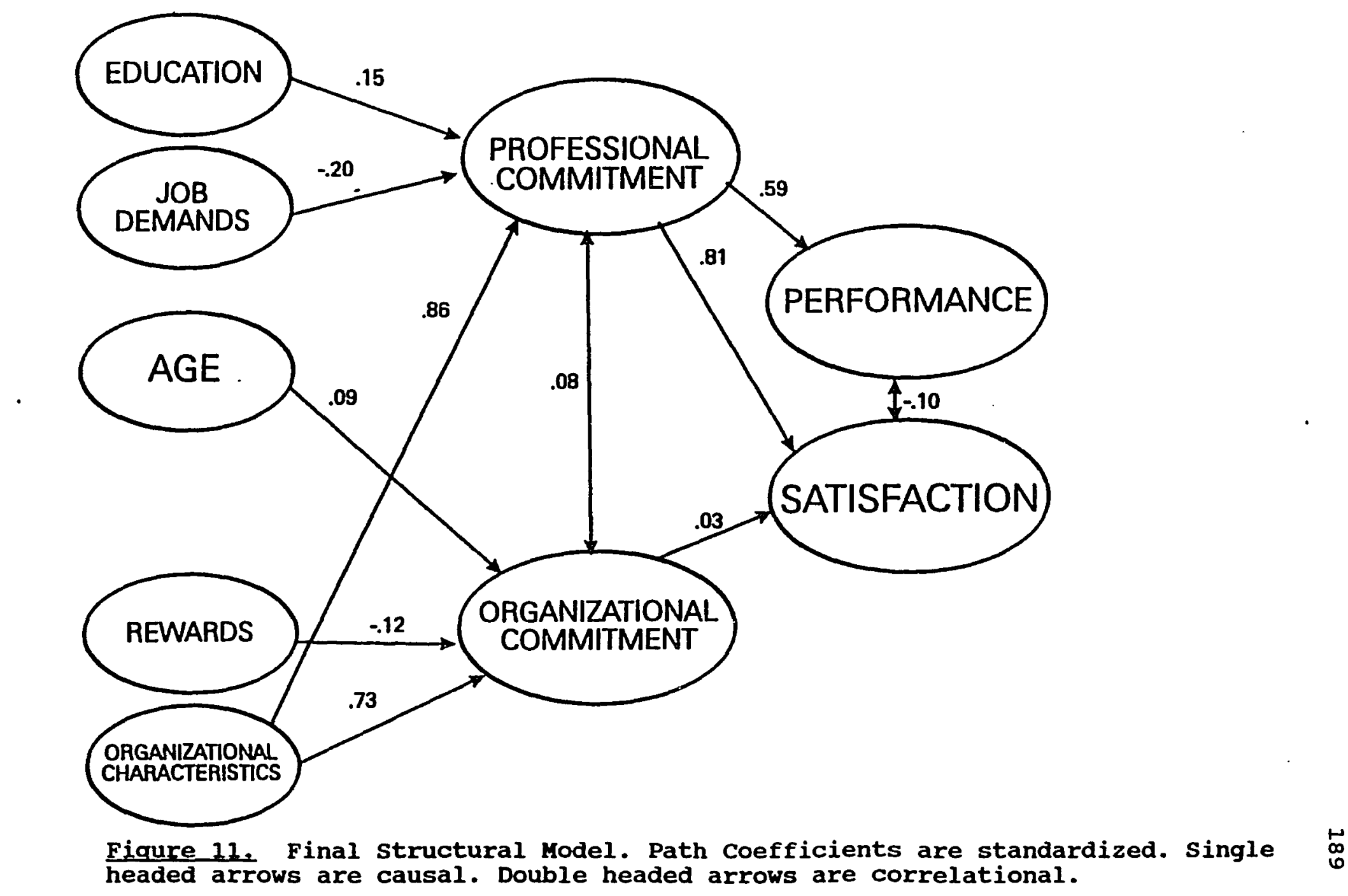


TABLE XXVIII

SUMMARY OF STRUCTURAL EQUATIONS

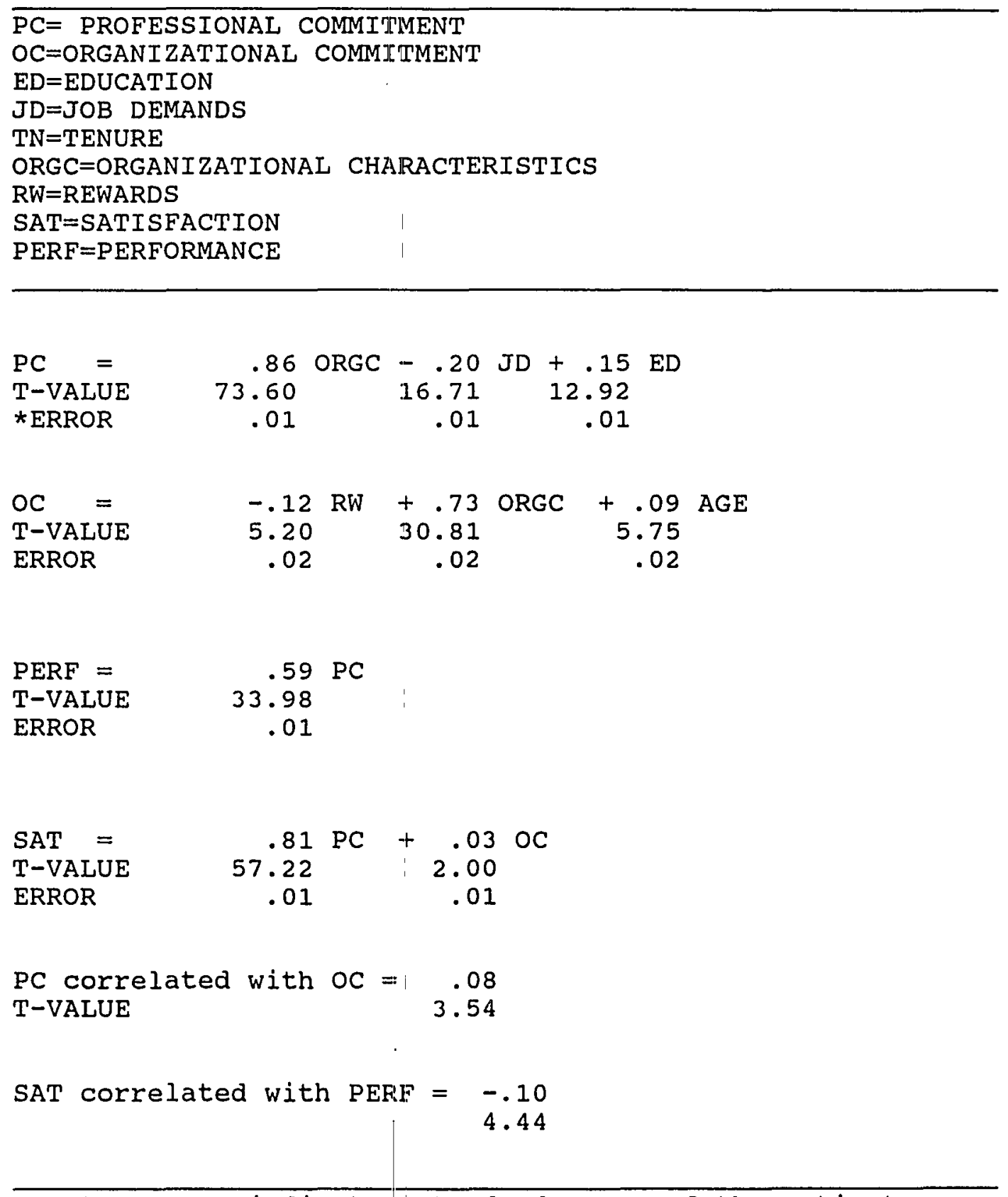

* Note: error indicates / standard error of the estimate. 
TABLE XXIX

VARIANCE ACCOUNTED FOR IN ENDOGENOUS VARIABLES

\begin{tabular}{ll}
\hline VARIABLE & R-SQUARED \\
\hline PROFESSIONAL COMMITMENT & .72 \\
PERFORMANCE & .35 \\
SATISFACTION & .67 \\
ORGANIZATIONAL COMMITMENT & .42 \\
\hline
\end{tabular}


model were significant as demonstrated by their associated $t$-values. The standard errors in the paths were small relative to their estimates. The level of overall fit and significance of the detailed fit measures indicated that the final model was strongly supported by the data.

\section{Simultaneous Measurement and structural Model}

The measurement and structural models were tested simultaneously. Overall fit of the stacked measurement and structural model was .86 as indicated by the Delta2 and Comparative Fit indices. The Goodness of Fit Index and Rho1 indicated a fit of .83 . The fit of the simultaneous model was reduced by .02 . The simultaneous estimation of the measurement and structural models strongly support the specified model.

\section{CROSS VALIDATION}

The results of the cross validation of the measurement and structural models were based on a hold-out sample of 2165 respondents. The entire sample was randomly divided in half to establish the initial and hold-out sample of data.

\section{Measurement Model}

The first and second-order confirmatory factor analyses were cross validated with the hold-out sample. The cross validation confirmed the initial results. The goodness of fit indices reached an acceptable .88 level. This finding 
was identical to the first sample. While the estimates differed slightly from the first sample, all of the indicator-factor loadings were significant.

\section{Structural Model}

The results of the final structural model were cross validated with the hold-out sample of data. The goodness of fit indices reached an acceptable .88 level of fit. A summary of the cross validated structural equations, errors and $t$-values is provided in Table XXX.

All paths were significant and the estimates approximated the original findings. The associated errors were replatively small.

Amount of variance accounted for in each endogenous variable is listed in Table XXXI. The variance accounted for in the endogenous variables values were all positive. This indicated that there were no identification problems.

The amount of variance accounted for in professional commitment shrunk .04 in the cross validation. The amount of variance accounted for in performance was unchanged. The amount of variance accounted for in satisfaction increased .22 in the cross validation. The amount of variance accounted for in performance increased .20 in the cross validation. These results support the fit and stability of the final model.

The cross validated results contributed additional 
TABLE XXX

SUMMARY OF CROSS VALIDATED STRUCTURAL EQUATIONS

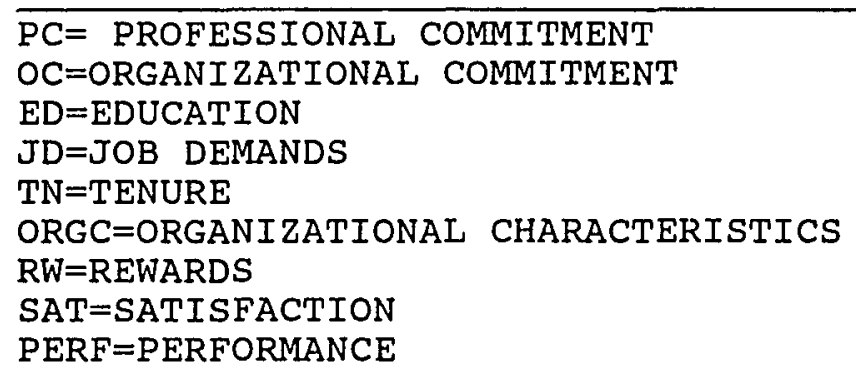

PC $=$

T-VALUE

*ERROR

$O C=$

T-VALUE

ERROR

PERF =

T-VALUE

ERROR

SAT =

T-VALUE

ERROR

.84 ORGC
67.00
.01
$-.14 \mathrm{RW}$
7.56
.02

$.59 \mathrm{PC}$
33.91
.02

14.73

$\mathrm{JD}+.11 \mathrm{ED}$

.01

9.37

.01

$+.88$

ORGC
+.09 AGE
7.22

.01

PC correlated with $O C=$

.08

T-VALUE

3.54

SAT correlated with PERF $=-.10$

4.44

* Note: error is the standard error of the estimate. 
TABLE XXXI

CROSS VALIDATED VARIANCE ACCOUNTED FOR

\begin{tabular}{ll}
\hline VARIABLE & R-SQUARED \\
\hline PROFESSIONAL COMMITMENT & .68 \\
PERFORMANCE & .35 \\
SATISFACTION & .89 \\
ORGANIZATIONAL COMMITMENT & .62 \\
& \\
\hline
\end{tabular}


evidence and support for the relationship between the antecedents, commitments, and outcomes. The overall fit of the model reached an acceptable cross validated fit of .88 . This was a .01 decrease in fit. All paths were significant and the proportion of variance accounted for in the endogenous variables was large.

\section{MULTIPLE REGRESSION}

The proposed structural model could not account for the relationship between turnover and the other variables. In order to test the commitments' ability to predict turnover, a multiple regression method was used.

In the regression analysis only one indicator was used to measure turnover. The response format was yes or no for the second indicator of turnover. Regression is not the appropriate analysis for a two choice response format. If the responses are dummy coded, discriminant analysis can be used.

The data for turnover were subject responses to the questionnaire item: Do you plan to be working for KP five years from now. The response categories ranged from definitely (1) to definitely not (5). Individuals who planned to retire were excluded from the analysis. Summary scores were computed for each individual for each of the first-order factor scales listed in Table XXII. Wages, benefits, views, supervision, satisfaction, 
performance appraisal process, expertise, autonomy, job demands, identification, professional knowledge, professional commitment, organizational commitment Questionnaire, production, age, tenure, education, and effectiveness were the independent variables.

Scale ranges, means, standard deviations, minimum and maximum scores for each of the scales are listed in Table XXXII. The response categories were 1-5 for most of the scales. Age, education, tenure, performance review, identification and organizational commitment had different response categories.

The mean responses on most of the scales were around the midrange of the response scales. Exceptions to this observation were education, tenure, work commitment, organizational commitment, and production. The means on these scales were greater than the midrange of the response scales.

The standard deviations with the exception of age, tenure and organizational commitment were less than one. Professional commitment, views about the organization and performance appraisal processes had the smallest standard deviations.

The minimum scores on most of the scales was one. Age, satisfaction and professional commitment had minimum scores greater than one. 
TABLE XXXII

SCALE SCORE SUMMARY INFORMATION

\begin{tabular}{lllrrr}
\hline VARIABLE & RESPONSE & MEAN & SD & MIN & MAX \\
& CATEGORY & & & & \\
\hline AGE & FREE & 39.34 & 9.36 & 18 & 75 \\
EDUCATION & $1-6$ & 4.36 & .90 & 1 & 6 \\
TENURE & $1-6$ & 4.26 & 1.53 & 1 & 6 \\
WAGES & $1-5$ & 3.67 & .67 & 1 & 5 \\
BENEFITS & $1-5$ & 3.67 & .73 & 1 & 5 \\
VIEWS & $1-5 / 1-4$ & 2.58 & .59 & 1 & 4 \\
TURNOVER & $1-5$ & 3.90 & 1.05 & 1 & 5 \\
SUPERVISION & $1-5$ & 3.58 & .89 & 1 & 5 \\
SATISFACTION & $1-5$ & 3.59 & .57 & 1.43 & 5 \\
APPRAISAL & $1-4 / 1-5$ & 3.59 & .86 & 1 & 5 \\
EXPERTISE & $1-5$ & 3.83 & .83 & 1 & 5 \\
AUTONOMY & $1-5$ & 3.77 & .83 & 1 & 5 \\
JOB DEMANDS & $1-5$ & 3.04 & .83 & 1 & 5 \\
IDENTIFICATION & $1-5 / 1-4$ & 2.65 & .88 & 1 & 4.5 \\
KNOWLEDGE & $1-5$ & 3.02 & .72 & 1 & 4 \\
COMMITMENT & $1-5$ & 4.41 & .76 & 1 & 5 \\
ORG COMMITMENT & $1-7$ & 5.20 & 1.19 & 1 & 7 \\
PRODUCTION & $1-5$ & 4.27 & .63 & 1 & 5 \\
EFFECTIVENESS & $1-5$ & 3.78 & .71 & 1 & 5 \\
PRO COMMITMENT & $1-5 / 1-4$ & 3.4 & .58 & 1.29 & 4.79 \\
& & & & & \\
\hline
\end{tabular}


The maximum scores on most of the scales was five. Age, education, tenure, and organizational commitment had maximum scores that exceeded five. Views about the organization, identification, professional knowledge and professional commitment had maximum scores less than five. All independent variables were included in the analysis. The results of the initial regression model are listed in Table XXXIII. The $F(18,2256)$ Value was 37.37. The model was significant at the .0001 level. The independent variables accounted for 23 percent of the variance in turnover. Wage, views about the organization, identification, professional/occupational knowledge, organizational commitment, age, tenure, and education were significant predictors of turnover.

To further test the model, a second multiple regression was conducted using stepwise inclusion of variables. The results of the analysis are listed in Table XXXIII. The variables were included in the following order with the first factor contributing the most: organizational Commitment, identification, education, views about the organization, age, tenure, knowledge about profession/occupation, wage, job demands, and autonomy. No other variables met the .15 significance level for entry into the model. A summary of the stepwise procedure is listed in Table XXXIII. Note that organizational commitment accounted for 17 percent of the variance in turnover. 
TABLE XXXIII

REGRESSION RESULTS

INITIAL FINDINGS:

\begin{tabular}{lccl} 
VARIABLE & ESTIMATE & T-VALUE & PROB \\
\hline WAGE & .11 & 2.88 & .004 \\
BENE & -.05 & -1.42 & .16 \\
VIEW & .19 & 4.44 & .0001 \\
SUPR & -.02 & -.62 & .53 \\
SAT & -.02 & -.46 & .65 \\
PRFR & .02 & .60 & .55 \\
EXP & .03 & 1.01 & .32 \\
AUT & -.05 & -1.56 & .12 \\
JOBD & -.03 & 1.69 & .09 \\
ID & .25 & 6.64 & .0001 \\
PKNOW & -.09 & -2.90 & .004 \\
COMM & .04 & 1.41 & .16 \\
OCQ & .26 & 12.32 & .0001 \\
PRODUCTION & .001 & .02 & .99 \\
EFF & -.03 & -.85 & .39 \\
AGE & -.01 & -4.92 & .0001 \\
TENURE & .05 & 3.43 & .0006 \\
ED & -.08 & -3.68 & .0002 \\
\hline
\end{tabular}

STEPWISE FINDINGS:

\begin{tabular}{lllrl} 
STEP & VARIABLE & PARTIAL R2 & FVALUE & PROB \\
\hline 1 & OCQ & .17 & 466.9 & .0001 \\
2 & ID & .02 & 65.5 & .0001 \\
3 & ED & .01 & 30.8 & .0001 \\
4 & VIEW & .007 & 19.4 & .0001 \\
5 & AGE & .004 & 10.5 & .001 \\
6 & TENURE & .005 & 13.3 & .0003 \\
7 & KNOWLEDGE & .004 & 11.7 & .0006 \\
8 & WAGE & .002 & 5.4 & .02 \\
9 & JOB DEMANDS & .001 & 3.1 & .08 \\
10 & AUT & .001 & 3.4 & .06 \\
\hline
\end{tabular}


Identification was the second largest contributor and accounted for only 2 percent of the variance in turnover.

\section{ANALYSIS OF VARIANCE}

An Analysis of Variance (ANOVA) was performed to test the second hypothesis: that there were no occupational differences on the professional commitment measure. In order to conduct the ANOVA summary scores were calculated for each individual for the second-order factor professional commitment. There were six occupational groups: 1) professionals, 2) managers, 3) skilled technicians, 4) registered nurses, 5) aides and licensed practical nurses, and 6) support service staff.

The results of the ANOVA are listed in Table XXXIV. The F $(5,3750)$ Value for the model was 131.43. The model was significant at the .0001 level. Group differences accounted for 15 percent of the variance.

The Waller-Duncan K-ratio and Duncan Multiple Range Test showed that five of the six groups had significantly different means. There was no difference between support staff and aides. In descending order, the managers had the highest mean followed by professionals, skilled technicians, nurses, support staff, and aides.

occupational differences on the professional commitment scale were found. Mangers had the highest level of 
TABLE XXXIV

OCCUPATIONAL GROUP MEAN DIFFERENCES

\begin{tabular}{lll}
\hline OCCUPATION & MEAN & N \\
\hline MANAGERS & 3.96 & 514 \\
PROFESSIONALS & 3.67 & 287 \\
SKILLED TECHS & 3.51 & 718 \\
NURSES & 3.43 & 558 \\
AIDES/SUPPORT & 3.30 & $463 / 1216$ \\
\hline
\end{tabular}


professional commitment. Support staff and aides had the lowest level of professional commitment. The mean

difference between the highest and lowest committed groups was .66. Group differences accounted for 15 percent of the variance in professional commitment. 
CHAPTER V

DISCUSSION

This study had four main purposes. The first purpose was to evaluate the definition and measurement properties of organizational and professional commitment. The second purpose was to investigate the relationship between organizational and professional commitment in order to evaluate the effects of multiple commitments. The third purpose was to model and test a system of antecedents and outcomes of organizational and professional commitment. The final purpose was to investigate how individuals across different occupations varied in their commitment to profession/occupation.

These purposes formed the basis for the investigated measurement and structural models in this study. The use of cross validation on hold-out sample data allowed for a thorough examination of these issues.

The preceding literature review and empirical research outlined problems with the definition, measure, and study of organizational and professional commitment. The nature of these shortcomings and the results of this study have strong implications for research and application. The following is 
a discussion of the results, applications, and recommendations for future research.

\section{DEFINITION AND MEASUREMENT OF COMMITMENTS}

Conceptual definition and measurement are primary issues in commitment research. Different definitions and measures can lead to conflicting results. The conflicting results should not be interpreted negatively, but should highlight the need for clearly stating the definition and measurement of the constructs under study.

The definition and measurement of the commitments in this study were based on the evaluation of evidence in the available research. The adoption of the conceptual definitions of the commitments was based on the object of the commitment and identification of the elements of commitment. The criteria for adopting the measurements of the commitments were strong evidence of validity and reliability.

Organizational commitment was defined as individual identification and attitudinal alignment of goals with the organization. The organizational commitment Questionnaire (Porter et al., 1974) was used to measure organizational commitment.

Professional/Occupational commitment was defined as individual identification and alignment of goals with the profession/occupation. The professional commitment scale 
proposed and tested in this study was used to measure professional commitment. The elements of professional commitment were autonomy, expertise, knowledge, commitment, identification. The scale was designed to measure commitment across occupations.

\section{MEASUREMENT MODEL}

There were several reasons for conducting the confirmatory factor analysis (CFA). These included establishing unidimensionality of measurement, controlling for redundancy, estimating errors in measurement, and linking the results to the structural model.

The first reason was to establish the unidimensionality of each of the constructs. Unidimensionality is important for assigning meaning to the constructs. By restricting items to load on only one factor, unidimensional measurement of job demands, wages, benefits, quality of supervision, views about the organization, performance appraisal process, expertise, autonomy, identification, knowledge, commitment, organizational commitment, satisfaction, production and effectiveness was accomplished in this study. The interpretation and assignment of meaning to each of these constructs are not dependent on any of the other scales. Furthermore, the examination of the causal relationships among these constructs are independent in the sense that no item measures more than one construct. 
The second reason for conducting the CFA was to determine whether conceptual overlap existed among the constructs. Conceptual redundancy is an important and persistent problem in work related attitude research. This issue was addressed extensively by Morrow (1983). It is important to establish that measurement by different scales truly measure different constructs.

Conceptual redundancies were identified by examining the pattern of interfactor relationships. Factors that were highly correlated and showed the same pattern of relationships with other factors were eliminated. The measures of job demands, age, tenure, education, wages, benefits, quality of supervision, performance appraisal process, expertise, autonomy, identification, commitment, knowledge, organizational commitment, satisfaction, production and effectiveness were not redundant. Each of the scales measured a distinct construct. This was demonstrated by the fit of the simple structure. The third reason for conducting the CFA was to allow for measurement error in each of the indicators. Survey research rarely, if ever, measures attitudes or behaviors without error. The capability of CFA to include error is an important quality for determining the true relationships among the measures of attitudes and behaviors.

The final reason for conducting the CFA was to link the results to the structural model. Before the causal 
structures among the variables could be assessed the measurement properties of each construct had to be established.

The purposes for assessing the second-order CFA were similar to the first-order CFA. The second-order CFA assessed dimensionality, redundancy, and error. The secondorder CFA assessed the multidimensional nature of the second-order factors.

The second-order confirmatory factor analysis supported the proposed second-order factor structure. Professional commitment, rewards, organizational characteristics and performance were the second-order factors.

Professional commitment was comprised of the firstorder factors: expertise, autonomy, identification, knowledge, and commitment. The factor loadings ranged from .61 to .47 . Expertise had the highest factor loading followed by identification, autonomy, knowledge and commitment. The factor loadings indicate that expertise carries more weight in explaining professional commitment.

Rewards included the first-order factors wages and benefits. The benefits factor had a factor loading of .62 and the wage factor had a loading of .53. This finding shows that the benefits factor contributed more than the wages factor.

Quality of supervision, performance review processes and views about the organization constituted the second- 
order factor labeled organizational characteristics. Supervision, performance review processes, and views about the organization had factor loadings of $.58, .54$, and .50 respectively. The factor loadings indicate the importance of each first-order factor.

The performance factor included the first-order factors production and effectiveness. Effectiveness had a factor loading of .70. Production had a factor loading of .47 . Effectiveness should be weighted more heavily than production in terms of the second-order factor performance.

Complex constructs like professional commitment encompass multiple behaviors and attitudes. For measurement and applied purposes it must be established that the measured behaviors and attitudes tap into the identified construct and that they covary. The second-order CFA tested and supported the measurement properties of professional commitment, rewards, organizational characteristics, and performance.

\section{STRUCTURAL MODEL}

The purpose of the structural model was to assess the relationships among the constructs simultaneously taking into account their measurement properties. In each section the effects of individual variables were addressed first followed by the joint effects. Recommendations are listed 
at the end of each section. Recommendations based on specific results are listed in this section as R1, R2, etc.

\section{Antecedents of Professional Commitment}

Education had a positive causal effect on professional commitment, such that an increase in individual education leads to an increase in professional commitment. The more education an individual invests in the more likely she is to be committed to her profession/occupation.

R1: Organizations should support and encourage employees to continue their education.

R2: Organizations should build value around the continuing development of employees. One way to accomplish this is to adapt the mission and goals of the organization to facilitate continued education.

Building organizational value and support for the educational efforts of its employees may foster commitment. Through increased commitment, organizations may reap the benefits of increased performance and satisfaction of employees.

Job demands had a negative causal effect on professional commitment. An increase in perceived job demands leads to a decrease in professional commitment. In this study job demands included responses to: amount of work, satisfying everyone at the same time, and sufficient time to do the work. To the degree individuals are unable to handle the amount of work they are given, have inadequate 
time to complete their work, and are not able to satisfy coworkers and superiors they will be less committed to their profession/occupation.

R3: Mangers should use appropriate techniques to assure that job demands are reasonable.

When job demands are excessive employees are unable to accomplish the required work. This leads employees to become less committed and as a result their satisfaction and performance are negatively affected.

Organizational characteristics had a positive causal impact on professional commitment. Increased quality of supervision, views about the organization, and performance appraisal processes positively affected professional commitment.

R4: Managers should develop and support the training and education of supervisors.

R5: In order to foster commitment organizations should be receptive to new ideas and methods that are generated from employees' experiences and needs.

R6: Organizations should develop performance appraisal systems that are fair, based on specific objectives, recognize individual contributions, help job performance, and are administered on a regular basis.

The development of quality supervisors, openness of the organization, and performance appraisal systems affect directly the commitment of employees. Developing and supporting mechanisms that improve these organizational 
characteristics may directly affect commitment and indirectly affect satisfaction and performance.

An examination of the joint effects of education, job demands and organizational characteristics on professional commitment revealed that organizational characteristics was the most important predictor of commitment followed by job demands and education. Although all three variables in concert were statistically significant predictors of commitment, their relative importance was not equal. Organizational characteristics had the largest path coefficient $(.86)$ and explained most of what was going on in terms of professional commitment. Job demands and education had path coefficients of -.20 and .15 , respectively. The effects of job demands and education on professional commitment relative to organizational characteristics were very small. It may be that organizational characteristics are all that is needed to predict professional commitment. Further studies are required to examine this issue more fully.

\section{Antecedents of organizational commitment}

Age had a positive causal effect on organizational commitment, such that as employees age they become more committed to the organization. It is useful to understand that older employees are more likely to be committed to the organization. 
R7: Managers can use information about the relationship between age and commitment to target age groups that are less likely to be committed for programs to increase organizational commitment.

organizational characteristics had a positive causal effect on organizational commitment. Increases in quality of supervision, perceived fairness and quality of performance review, and views about the organization lead to an increase in organizational commitment. No new recommendations come from this finding. What is interesting about this finding is the importance of organization characteristics in predicting both organizational and professional commitments. Additional weight and importance should be given to recommendations 4,5 , and 6 .

Rewards had a negative causal effect on organizational commitment. The degree to which employees perceive their wages and benefits to be good, the lower their commitment to the organization. This finding was puzzling. Increased rewards were hypothesized to cause increased organizational commitment. While increased rewards may lead to increased retention of the individual, it does not appear to increase their commitment. This suggests that individual identification and alignment of values and goals with the organization are more important than rewards in terms of increasing overall commitment.

This finding was contrary to most past research. The work of Katz and Kahn (1978) support the findings in this 
study. They found that pay and rewards were important for attracting and recruiting employees, but were not factors for increasing performance. These findings were congruent with the results of this study.

It may be that increased rewards lock the individual into the organization, but the mechanism is not commitment to the organization, but rather commitment to investments. Hrebiniak and Alutto (1972) have measured the effects of individual investments in the organization. Additional studies are needed to investiglate these relationships.

The joint effects of age, organizational characteristics, and rewards indicate that organizational characteristics was the best predictor of organizational commitment followed by rewards and age. Although all three variables in concert were statistically significant predictors of organizational commitment, their relative importance was not equal. Organizational characteristics had the largest path coefficient $\mid(.73)$ and explained most of what was going on in terms of organizational commitment. Age and rewards had path coefficients of .09 and -.12, respectively. The effects of age and rewards on organizational commitment relative to organizational characteristics were very small. It may be that organizational characteristics are all that is needed to predict organizational commitment. Further studies are required to examine this issue more fully. 
The finding that organizational characteristics was the best predictor of organizational and professional commitment was striking. This finding emphasized the importance of developing quality supervisors, organizational openness to new ideas and methods, and fair performance appraisal systems in developing commitment.

The finding that rewards did not have a direct causal effect on professional commitment, satisfaction, or performance was interesting. It appears that when modeled jointly with the other constructs, rewards has its effect on satisfaction, performance and professional commitment only indirectly through organizational commitment.

\section{Relationship Between the commitments}

organizational and professional commitment were positively related, but not causally related. No causal relationship was supported by the results. A longitudinal examination of the commitments may be a better test of their causal relationship.

R8: Managers should recognize the existence of multiple commitments and develop programs to support both types of commitments.

\section{Outcomes of organizational commitment}

organizational commitment directly affected satisfaction. Although this path was significant, the finding was weak. The path coefficient was .03. This study provides preliminary evidence of the ability of commitment 
to predict satisfaction. This finding contradicts the curry et al. study (1986) where no evidence of a causal relationship was found in either direction between commitment and satisfaction.

The path from satisfaction to commitment was not specified in the structural model. The modification indices did not indicate that the path should be freed. This provides some evidence that satisfaction does not cause organizational commitment.

An alternate causal model may better explain the relationship. Further studies are needed to examine the relationship between satisfaction and commitment.

R9: In order to improve the satisfaction of employees, managers should consider the institution of techniques that encourage organizational commitment.

Managers may use the information about the positive relationship between organizational commitment and satisfaction as a means for dealing with satisfaction problems that occur in human service organizations (Solomon, 1986). By facilitating employee commitment to the organizations, managers may positively affect employee satisfaction.

organizational commitment had no direct effect on performance. Organizational commitment affects performance indirectly through its relationship with professional commitment and satisfaction. By developing organizational 
commitment in employees managers may bolster employee satisfaction and indirectly performance.

outcomes of Professional commitment

Professional commitment directly affected both satisfaction and performance. Increases in professional commitment lead to increases in performance and satisfaction. This finding provides information about how to improve satisfaction and performance through commitment.

R10: Managers should institute programs to support professional commitment in order to facilitate increased satisfaction and performance. Examples include sabbaticals, funding for education and workshops, and flexibility in allowing new methods to be tried out on the job.

Knowledge about both organizational and professional commitment may be useful in dealing with satisfaction problems in human service organizations. The recognition that individuals possess multiple commitments and the use of organizational resources to facilitate commitment, may lead to increased satisfaction and performance.

The joint effects of the commitments on satisfaction and performance embedded within the structure of the entire model are interesting. Both commitments had effects on satisfaction, but only professional commitment had an effect on performance. No other variables had direct effects on satisfaction or performance. Organizational characteristics, rewards and job demands had their effects on satisfaction and performance modified through the 
commitments. These findings indicate that the commitments play an important role in developing satisfaction and performance and lend support for further investigating and understanding the relationship between the commitments.

\section{Performance and satisfaction}

The cyclical relationship between performance and satisfaction was not supported by the data. Furthermore, no causal relationship was supported between performance and satisfaction. Performance and satisfaction were positively correlated.

The initial structural model weakly supported the cyclical relationship, but the cross validation results contradicted this observed relationship. There are several explanations for the contradictory findings. The relationship may not be cyclical. The relationship may not be properly assessed with data collected at the same time. A final explanation is that nonrecursive models are not capable of assessing nonrecursive relationships. Further studies are needed to address this issue.

\section{Overall Model}

The structural model in this study was developed in order to test the antecedents and outcomes of both organizational and professional commitment. Based on the results of this study, organizational characteristics is the best predictor of both commitments. While other factors are 
statistically significant predictors of each of the commitments their path coefficients are small relative to organizational commitment and may be negligible.

The commitments affected the outcomes differently. Based on the size of the path coefficients, professional commitment is the best predictor of satisfaction and the only predictor of performance. When both commitments are taken into consideration, organizational commitment does not play a significant role. Since no one has examined both professional commitment and organizational commitment together in a system of antecedents and outcomes this has not previously been seen. Organizational commitment may not be needed when professional commitment is considered in predicting satisfaction and performance.

Alternately, a minimum level of organizational commitment may have to be present for high satisfaction and performance to occur. Very low levels or total lack of organizational commitment may negatively affect satisfaction and performance. Organizational commitment above some minimally acceptable standard may not improve satisfaction or performance. Further studies are needed to examine this issue.

\section{Conclusion}

This study demonstrated that organizational and professional commitment have different antecedents and 
affect outcomes differentially. The results support the importance of studying multiple commitments in the workplace. The results of the cross validation support the relationships among the antecedents, commitments, and outcomes.

\section{CROSS VALIDATION}

Cross validation is rarely completed primarily because of limited resources and small sample size. This study was unique in that the sample size was very large and permitted a large hold-out sample of data.

The measurement model results were fully confirmed by the hold-out sample data. The goodness of fit was identical to the original sample. All items loaded on their proposed factors and did not load highly on other factors. This demonstrated the unidimensionality of the scales. The constructs were significant and sufficiently unrelated. This result indicates support that the constructs were not redundant and provided evidence for the discriminant validity of each of the constructs with all of the other constructs.

The relationships among the antecedents, commitments, and outcomes were strongly supported by the cross validation results. The fit of the structural model was reduced by only one percent. This testifies to the stability of the model. 
The hold-out sample confirmation indicated that the structural and measurement model results were stable. Sampling errors that may have been maximized in the first sample were eliminated in the cross validation. The replication of the initial findings supports the strength of the model.

\section{MULTIPLE REGRESSION}

In the initial structural model turnover was modeled as an outcome variable. The structural model was unable to account for the relationship between the antecedents, commitments and turnover. Turnover is an important organizational variable and warranted further investigation. The data allowed for the first-order factors to be used in a regression analysis to predict turnover.

The stepwise regression analysis demonstrated that organizational commitment was the most important variable for predicting turnover. Other less important predictors of turnover were identification, education, views about the organization, age, tenure, knowledge about occupation/profession, wage, job demands, and autonomy.

The combined independent variables accounted for 22 percent of the variance in turnover. Organizational commitment accounted for 17 percent of the variance in turnover. The remaining variables play only a minor role in predicting turnover. 
Some of the regression results differ from the findings of the structural model. In the structural model the affects of professional and organizational commitment were examined simultaneously. In the regression analysis only the first-order factor elements of professional commitment were used. The regression results indicate that organizational commitment played a more important role in predicting turnover than the elements of professional commitment.

Some of the regression results agree with structural model findings. Both analyses indicate that commitment is the best predictor of the outcomes. The other predictors play at best, only a minor role.

The regression results in this study are complementary to the findings of Mowday et al. (1982), Steers (1977), Porter et al. (1974). Organizational commitment is better than satisfaction at predicting turnover.

\section{ANALYSIS OF VARIANCE}

The ANOVA results indicate that statistically there are significant occupational differences on the professional commitment measure. Managers and professionals possess the highest levels of professional commitment followed by skilled technicians, registered nurses, support staff and aides. The group differences accounted for $15 \%$ of the variance in professional commitment. 
This finding was contrary to the hypothesis in this study, but was not completely unexpected. The work of Freidson (1970a), Lichtenstein (1984), Gouldner (1957), and Hall (1968) suggested that different occupations would have different levels of professional commitment. The results of this study are in the direction these researchers might have predicted.

The finding of occupational differences on the professional commitment scale may be useful in developing programs for fostering commitment. It may also be helpful in understanding the nature of dissatisfaction within health care organizations.

R11: Mangers should find out what the occupational differences are in professional commitment and build on those to develop commitment. For example what are the environmental or job factors that cause one occupation to be more committed than another.

The findings of this study indicate that there are occupational differences in professional commitment. Researchers and managers need to determine what the differences are and what the different occupations require for commitment. organizations may need to develop different programs for different occupational groups.

\section{ADDITIONAL APPLICATIONS AND RECOMMENDATIONS}

This research is important for researchers for several reasons. It was a first attempt at modeling and testing 
multiple organizationally relevant behaviors simultaneously. This approach approximates reality in a superior fashion. Professional and organizational commitment, education, job demands, age, tenure, supervision, performance appraisal, satisfaction and performance are dynamic variables. They occur throughout the organization and within individuals at different rates at different times. This study reflected the dynamics of this reality and provided initial evidence about the simultaneous relationships among the constructs. Complexity and uncertainty are apparent in every organization. This study attempted to provide organizations with a tool for understanding complexity and reducing uncertainty. This study combined multiple indicators of multiple constructs of interest to organizations into a comparatively simple model of their relationships. The test of the relationships and replication provided evidence for the strength of the model.

A clear and concise model is important for managers. Demands on their time limit their ability to interpret detailed information. The final model supported in this study requires minimum interpretation. The manager does not need extensive information about the confirmatory factor analysis process of item and factor selection or structural modeling in order to understand the model. Mangers need information about the nature of the constructs and a basic 
understanding of the network of relationships tested and supported in the model.

This research provides preliminary information for, but did not test for modeling a distribution of employees with tendencies toward organizational or professional commitment within an organization. Insight into the development of differential career paths and benefit plans for differentially committed employees from this research may bolster retention and performance. Furthermore, this research may provide organizations with a foundation on which to build better support systems for differentially committed employees.

Individuals possess varying levels of multiple commitments that affect their satisfaction and performance. One way to develop greater performance and satisfaction is to acknowledge the presence of multiple commitments and support both types of commitment.

\section{Recommendations for Researchers}

The primary recommendation to researchers is to continue the use of model building and evaluation in commitment research. Over the years researchers have correlated or used regression to predict commitment with various individual characteristics, organizational characteristics, and job characteristics. Covariance structural modeling provides the researcher with the 
opportunity to examine the causal relationships among multiple constructs simultaneously.

R12: Researchers should use covariance structural modeling techniques to build and evaluate models of commitment.

The models tested in this study were a starting point. other variables of interest to organizations such as leadership, group cohesion, organizational structure and size, gender differences and union presence may be added to the general commitment model and evaluated.

Researchers may want to examine the performancesatisfaction relationship with a different approach. The performance measures in this study were self-reported. The use of actual performance ratings by superiors and others may be a better reflection of actual performance and lead to different results. Researchers could design and test a multi-rater multi-trait method for analyzing the relationship. This approach would take into account different types of measures from different sources. The use of longitudinal data collection and analysis may better assess the actual relationship between satisfaction and commitment over time.

R13: Researchers should use and compare different research methods and analyses for assessing the performance-satisfaction relationship.

One reason turnover may not have been accounted for in the structural model was because actual turnover was not measured. The measurement of actual turnover over a period 
of time and the use of a longitudinal structural equation model may better estimate the effect of commitment on turnover.

R14: Researchers should measure actual turnover in assessing the relationship between turnover and commitment and compare this method with turnover intentions.

The structural model in this study did not take into account occupational differences. There is some evidence to suggest that occupational groups differ in their professional commitment. Future studies should develop and test different causal structures for different occupations.

\section{Recommendations for Management}

The recommendations for management were distributed throughout the discussion section of this dissertation. The primary suggestion was that managers recognize multiple commitments in the work place and begin to investigate how these commitments operate in their organization. A second recommendation was to develop support systems for facilitating increased commitment.

\section{Conclusion}

Overall the support for the unidimensional interpretation of the $O C Q$ was strong. The initial evidence for the Professional commitment scale is encouraging. Professional commitment was sufficiently measured and distinct from the other constructs in the study. Future 
research is needed to establish its generalizability across occupations not tested in this study.

The structural model in this study supported a network of relationships between education, job demands, age, tenure, organizational characteristics, rewards, professional and organizational commitment, satisfaction and performance. The best predictor of both commitments was organizational characteristics. When professional and organizational commitment were modeled together, professional commitment played the dominant role in predicting satisfaction and performance. Organizational commitment did not predict performance and contributed little in predicting satisfaction. Future research is needed to assess the relationship between satisfaction and performance and to evaluate the importance of other organizationally relevant behaviors and attitudes.

The regression analysis indicated that organizational commitment was the most important predictor of turnover and that elements of professional commitment also contributed significantly to predicting turnover. The structural model was not able to account for the relationships among the antecedents, commitments, and turnover.

The findings presented in this dissertation represent an increase in knowledge because of the modeling techniques used and the questions addressed. When professional and organizational commitment are modeled together it appears 
that professional commitment plays the more important role in predicting outcomes.

Professional commitment within organizations and across occupations has not been studied extensively. This approach is concerned with how an individual's commitment to his or her profession or occupation affects his or her behavior in the work place. This approach is not concerned with whether a particular occupation qualifies as a profession or not.

How individuals behave "professionally" in the work place may be more important than their occupational status in understanding "professionals" in organizations. This study not only supported occupational differences in professional commitment, but also showed that professional commitment crosses the boundaries of occupational groups. Members across the occupational groups demonstrate varying levels of professional commitment.

Hopefully, others will be stimulated to continue research on the structural relationships between organizational, professional, and other commitments relevant to organizations. 
REFERENCES

Allen, N. \& Meyer, J. (1990). The measurement and antecedents of affective, continuance and normative commitment to the organization. Journal of occupational Psychology, 63, 1-18.

Abramson, E., Cutter, H., Kautz, R. \& Mendelson, M. (1958). Social power and commitment: A theoretical statement. American Sociological Review, 23, 15-22.

Alutto, J., Hrebiniak, L., \& Alonso, R. (1973) on operationalizing the concept of commitment. Academy of Management Review, 2, 217-230.

American Psychological Association, American Educational Research Association, \& National Council on Measurement in Education (Joint Committee). (1985). Standards for Educational and Psychological Testing. Washington, DC: American Psychological Association.

Anderson, J. \& Gerbing, D. (1982). Some methods for respecifying measurement models to obtain unidimensional construct measurement. Journal of Marketing Research, 19, $453-460$.

Anderson, J. \& Gerbing, D. (1984). The effect of sampling error on convergence, improper solutions, and goodnessof-fit indices for maximum likelihood confirmatory factor analysis. Psychometrika, 49, 155-173.

Anderson, J. \& Gerbing, D. (1988). Structural equation modeling in practice: A review and recommended two-step approach. Psychological Bulletin, 103, 3, 411-423.

Angle, H. \& Perry, J. (1981). An empirical assessment of organizational commitment and organizational effectiveness. Administrative science Quarterly, 26, 114 .

Angle, H. \& Perry, J. (1983) Organizational commitment: Individual and organizational influences. Work and occupations, 10, 2, 123-146. 
Aranya, N. \& Ferris, K. (1983). Organizational-professional conflict among U.S. and Israeli professional accountants. The Journal of Social Psychology, 119, 153-161.

Aranya, N., Lachman, R. \& Amernic, J. (1982). Accountants' job satisfaction: A path analysis. Accounting, organizations and Society, 7, 3, 201-215.

Aranya, N., Pollock, J., \& Amernic, J. (1981). An examination of professional commitment in public accounting. Accounting, organizations and Society, 6, 4, 271-280.

Arnold, H. \& Feldman, D. (1982). A multivariate analysis of the determinants of job turnover. Journal of Applied Psychology, 67, 3, 350-360.

Barling, J. \& Wade, B. (1990). Predicting employee commitment to company and union: Divergent models. Journal of Occupational Psychology, 63, 49-61.

Bartol, K. (1979a) Professionalism as a predictor of organizational commitment, role stress, and turnover: A multidimensional approach. Academy of Management Journal, $22,815-821$.

Bartol, K. (1979b) Individual versus organizational predictors of job satisfaction and turnover among professionals. Journal of Vocational Behavior, 15, 55-67.

Bateman, T. \& Strasser, S. (1984). A longitudinal analysis of the antecedents of organizational commitment. Academy of Management Journal, 22, 815-821.

Beauvais, L., Scholl, R. \& Cooper, E. (1991). Dual commitment among unionized faculty: A longitudinal investigation. Human Relations, 44,2 .

Becker, H. (1960). Notes on the concept of commitment. American Journal of Sociology, 66, 32-40.

Bentler, P. \& Bonnet, D. (1980). Significance tests and goodness of fit in the analysis of covariance structures. Psychological Bulletin, 88, 588-606.

Bentz, V. (1950). A study of leadership in a liberal arts college. Columbus, $\mathrm{OH}$ : Ohio State University Press.

Berger, P., \& Grimes A. (1973). Cosmopolitan-Local: A factor analysis of the construct. Administrative Science Quarterly, 18, 223-235. 
Blalock, H. (1968). The measurement problem: A gap between the languages of theory and research. In H. M. Blalock, Jr. and A. B. Blalock (Eds.), Methodology in Social Research (pp. 5-27). New York: McGraw-Hill.

Blau, G. (1986). Job involvement and organizational commitment as interactive predictors of tardiness and absenteeism. Journal of Management, 12, 4, 577-584.

Blau, G. \& Boal, K. (1987). Using job involvement and organizational commitment interactively to predict turnover and withdrawal cognitions. Paper presented at the meeting of the Academy of Management, New Orleans, August.

Blau, G. \& Boal, K. (1989). Using job involvement and organizational commitment interactively to predict turnover. Journal of Management, 15, 1, 115-127.

Blau, G. \& Scott, R. (1962). Formal organizations. San Francisco, CA: Chandler.

Bluedorn, A. (1982). A unified model of turnover from organizations. Human Relations, 35, 2, 135-153.

Bollen, K. (1990) overall fit in covariance structure models: Two types of sample size effects. Psychological Bulletin, 107, 2, 256-259.

Brayfield, A. \& Crockett, (1955). Employee attitudes and employee performance. Psychological Bulletin, 52, 396424 .

Boomsma, A. (1982). The robustness of LISREL against small sample sizes in factor analysis models. In K.G. Joreskog \& H. Wold (Eds.), Systems Under Indirect Observation: Causality, structure, prediction (Part 1, pp. 149-173). Amsterdam: North Holland.

Brayfield, A. \& Rothe, H. (1951). An index of job satisfaction. Journal of Applied Psychology, 35, 307-311.

Brickman, P. (1987). Commitment, Conflict, and Caring. Englewood Cliffs, N.J.: Prentice-Hall Inc.

Brooke, P., Russell, D. \& Price, J. (1988). Discriminant validation of measures of job satisfaction, job involvement, and organizational commitment. Journal of Applied Psychology, 73, 2, 139-145. 
Buchanan, B. (1974). Building organizational commitment: The socialization of managers in work organizations. Administrative Science Quarterly, 19, 533-546.

Burke, R. \& Wilcox, D. (1972). Absenteeism and turnover among female telephone operators. Personnel Psychology, $25,639-48$.

Cohen, A. \& Lowenberg, G. (1990). A re-examination of the side-bet theory as applied to organizational commitment: A meta-analysis. Human Relations, 43, 10, 1-15-1050.

Colarelli, S. \& Bishop, R. (1990). Career commitment: Functions, correlates and management. Group \& organizational Studies, 15, 2, 158-176.

Cole, D. (1987). Methodological contributions to clinical research: Utility of confirmatory factor analysis in test validation research. Journal of consulting and clinical Psychology, 53, 4, 584-594.

Cook, J. \& Wall, T. (1980). New work attitude measures of trust, organizational commitment and personal need nonfulfillment. Journal of Occupational Psychology, 53, 3952 .

Cooke, D. (1989). The validity of the organizational commitment construct: Investigating the dimensionality and discriminant validity of the organizational Commitment Questionnaire. Unpublished Doctoral Dissertation, University of Miami, Florida.

Cotton, J. \& Tuttle, J. (1986). Employee turnover: A metaanalysis and review with implications for research. Academy of Management Review, 11, 1, 55-70.

Csikszentmihalyi, M. (1975). Beyond Boredom and Anxiety: The Experience of Play in Work and Games. San Francisco: Jossey-Bass.

Curry, J., Wakefield, D., Price, J., \& Mueller, C. (1986). on the causal ordering of job satisfaction and organizational commitment. Academy of Management Journal, $29,847-858$.

Darden, W. , Hampton, R. \& Howell, R. (1989). Career versus organizational commitment: Antecedents and consequences of retail salespeoples' commitment. Journal of Retailing, $65,1,80-106$. 
Davis, J. (1961). Locals and cosmopolitans in American graduate schools. International Journal of Sociology, 72, $1-16$.

Decotiis, T. \& Summers, T. (1987). A path analysis of a model of the antecedents and consequences of

organizational commitment. Human Relations, 40, 7, 445470 .

Dornstein, M. \& Matalon, Y. (1989). A comprehensive analysis of the predictors of organizational commitment: A study

of voluntary army personnel in Israel. Journal of Vocational Behavior, 34, 192-203.

Dougherty, T., Bluedorn, A., \& Keon, T. (1985). Precursors of employee turnover: A multi-sample analysis. Journal of Occupational Behavior, 6, 259-271.

Etzioni, A. (1964). Modern Organizations. Englewood Cliffs, NJ.: Prentice-Hall.

Ferris, K. \& Aranya, N. (1983) A comparison of two organizational commitment scales. Personnel Psychology, $36,87-98$.

Festinger, L. (1957). A Theory of Cognitive Dissonance. Stanford, CA: Stanford University Press.

Flamholtz, E. (1974). Human Resource Accounting. Encino, CA: Dickenson Publishing.

Flango, V. \& Brumbaugh, R. (1974). The dimensionality of the Cosmopolitan-Local construct. Administrative Science Quarterly, 19, 2, 198-210.

Freeborn, D., Schrager, L. \& Lamb, S. (1990a). Satisfaction and effectiveness. (unpublished) center for Health Research. Kaiser Permanente, Northwest Region.

Freeborn, D., Schrager, L. \& Lamb, S. (1990b). Satisfaction by job category and by year. (unpublished) center for Health Research. Kaiser Permanente, Northwest Region.

Freidson, E. (1970a). Professional Dominance: The Social Structure of Medical Care. New York, NY: Atherton Press, Inc.

Freidson, E. (1970b). Profession of Medicine. New York, NY: Dodd, Mead \& Company. 
Friedlander, F. (1971). Performance and orientation structures of research scientists. Organization 169-183.

Gerard, H. (1965). Deviation, conformity, and commitment. In I.D. Steiner \& M. Fishbein (Eds.), Current Studies in Social Psychology. New York: Holt, Rinehart, \& Winston.

Gerbing, D. \& Anderson, J. (1988). An updated paradigm for scale development incorporating unidimensionality and its assessment. Journal of Marketing Research, 25, 186-192.

Gerbing, D. \& Hunter, J. (1986). ITAN: A Statistical Package for Item Analysis. (Available from D. Gerbing, Department of Management, Portland State University, Portland, or 97207).

Geyer, P. \& Pond, S. (1988). Validation of measures of job commitment, organizational commitment, and turnover intentions. Paper presented at the 96th Annual Convention of the American Psychological Association, Atlanta, GA.

Glisson C. \& Durick, M. (1988). Predictors of job satisfaction and organizational commitment in human service organizations. Administrative Science Quarterly, $33,61-81$.

Goldberg, L., Baker, F. \& Rubenstein, A. (1965). Localcosmopolitan: Unidimensional or multidimensional? American Journal of Sociology, 70, 704-710.

Goldberger, A. (1972). Structural equation methods in the social sciences. Econometrica, 40, 979-109.

Gouldner, A. (1954). Patterns of Industrial Bureaucracy. Glencoe, Ill: Free Press.

Gouldner, A. (1957). Cosmopolitans and locals: Toward an analysis of latent social roles, I. Administrative Science Quarterly, 2, 281-306.

Gouldner, A, (1958). Cosmopolitans and locals: Toward an analysis of latent social roles, II. Administrative Science quarterly, 2, 444-480.

Gray, D. (1989). Gender and organizational commitment among hospital nurses. Human Relations, 42, 9, 801-813.

Greenlick, M., Freeborn, D., \& Pope, C. (1988). Health Care Research in an HMO. Maryland: The Johns Hopkins University Press. 
Grimes, A. \& Berger, P. (1970). Cosmopolitan-local: Evaluation of the construct. Administrative Science Quarterly, 15, 407-416.

Hall, D. (1968). Professionalization and bureaucratization. American Sociological Review, 92-104.

Hayduk, I. (1987). Structural Equation Modeling with LISREL: Essentials and Advances. Baltimore, MA: John Hopkins University Press.

Heneman, H. (1974). Comparisons of self and superior ratings of managerial performance. Journal of Applied Psychology, $59,638-642$.

Herman, J., Dunham, R., \& Hulin, C. (1975). Organizational structure, demographic characteristics, and employee responses. Organizational Behavior and Human Performance, $13,206-232$.

Herman, J. \& Hulin, C. (1972). Studying organizational attitudes from individual and organizational frames of reference. Organizational Behavior and Human Performance, $8,84-108$.

Hom, P., Katerberg, R. \& Hulin, C. (1979). Comparative examination of three approaches to the prediction of turnover. Journal of Applied Psychology, 64, 3, 280-290.

Hrebiniak, I. \& Alutto, J. (1972). Personal and role related factors in the development of organizational commitments. Administrative Science Quarterly, 17, 555-572.

Huff, C., Sproull, L., \& Kiesler, S. (1989). Computer communication and organizational commitment: Tracing the relationship in a city government. Journal of Applied Social Psychology, 19, 16, 1371-1391.

Hunter, J. \& Cohen, S. (1969). PACKAGE: A system of computer routines for the analysis of correlational data. Educational and Psychological Measurement, 29, 697-700.

Hunter, J. \& Gerbing, D. (1982). Unidimensional measurement, second order factor analysis, and causal models. Research in Organizational Behavior, 4, 267-320.

Iaffoldino, M. \& Muchinsky, R. (1985). Job satisfaction and job performance: A meta analysis. Psychological Bulletin, $97,2,251-273$. 
Institute for Social Research, University of Michigan (1978). Survey of Organizations. Ann Arbor, MI: University of Michigan Press.

Jackofsky, E. \& Peters, L. (1983). Job turnover versus company turnover: Reassessment of the March and Simon participation hypothesis. Journal of Applied Psychology, $68,3,490-495$.

Jamal, M. (1990). Relationship of job stress and type-a behavior to employees' job satisfaction, organizational commitment, psychosomatic health problems, and turnover motivation. Human Relations, 43, 8, 727-738.

Jauch. L., Glueck, W. \& Osborn, R. (1978). Organizational loyalty, professional commitment, and academic research productivity. Academy of Management Journal, 21, 1, 8492 .

Jermier, J. \& Berkes, L. (1979). Leader behavior in a police command bureaucracy: A closer look at the quasi-military model. Administrative science Quarterly, 24, 1-23.

Johnson, M. (1973). Commitment: A conceptual structure and empirical application. The Sociological Quarterly, 14, 395-406.

Joreskog, K. \& Sorbom, D. (1978) . LISREL IV. Chicago: National Educational Resources.

Joreskog, K. \& Sorbom, D. (1984). LISREL: Analysis of Linear Structural Relationships by the Method of Maximum Likelihood. Mooresville, Indiana: Scientific Software, Inc.

Joreskog, K. \& Wold, H. (1982). Systems Under Indirect Observation: Causality, Structure, Prediction. Amsterdam: North Holland.

Kanter, R. (1972). Commitment and Community: Communes and Utopias in Social Perspective. Cambridge, MA: Harvard University Press.

Kanungo, R. (1982). Work Alienation. New York: Praeger.

Karasek, R. (1979). Job demands, job decision latitude, and mental strain: Implications for job redesign.

Administrative Science Quarterly, 24, 285-306. 
Karasek, R. \& Theorell, T. (1990). Healthy Work. New York, NY: Basic Books.

Katz, D. \& Kahn, R. (1978). The Social Psychology of organizations, Second Edition. New York, NY: John Wiley \& Sons.

Kerr, S., Von Glinow, M. \& Schriesheim, J. (1977). Issues in the study of professionals organizations: The case of scientists and engineers. Organizational Behavior and Human Performance, 18, 329-345.

Kidron, A. (1978). Work values and organizational commitment. Academy of Management Review, 21, 2, 239-247.

Kiesler, C. (1971). The Psychology of Commitment: Experiments Linking Behavior to Belief. New York, NY: Academic Press.

Kleingartner, A. \& Anderson, C. (1987). Human Resource Management in High Technology Firms. Lexington, MA: Lexington Books.

Koslowsky, M. (1990). Staff/line distinction in job and organizational commitment. Journal of Occupational Psychology, 167-173.

Lachman, R. \& Aranya, N. (1986). Evaluation of alternative models of commitments and job attitudes of professionals. Journal of Occupational Behaviour, 7, 227-243.

Landy, J. \& Farr, L. (1983). The Measurement of Work Performance. New York, NY: Academic Press.

Landy, J. (1989). Psychology of Work Behavior. Belmont, Ca: Wadsworth, Inc.

Laporte, T. (1965). Conditions of strain and accommodation in industrial research organizations. Administrative Science Quarterly, 10, 21-38.

Larson, E. \& Fukami, C. (1984). Relationships between worker behavior and commitment to the organization and union. Proceedings of the Acaldemy of Management, 222-226.

Lewin, K. (1951). Field Theory in Social Science. New York, NY: Harper.

Lichtenstein, R. (1984). The job satisfaction and retention of physicians in organized settings: A literature review. Medical Care Review, 41, 3, 139-179. 
Locke, E. (1970). Job satisfaction and job performance: A theoretical analysis. Organizational Behavior and Human Performance, 5, 484-500.

Locke, E. (1975). Personal attitudes and motivation. Annual Review of Psychology, 25, 457-480.

Locke, E. (1976). The Nature and Causes of Job Satisfaction. In M.D. Dunnette (ed.) The Handbook of Industrial and Organizational Psychology. Chicago, Ill.: Rand McNally.

Luthans, F., McCaul, H., \& Dodd, N. (1985). Organizational commitment: A comparison of American, Japanese, and Korean employees. Academy of Management Journal, 28, 1, 213-219.

Luthans, F., Baack, D. \& Taylor, L. (1987). Organizational commitment: Analysis of antecedents. Human Relations, 40, $4,219-236$.

Marcson, S. (1960). The Scientist in American Industry Research. Princeton, N.J.: Industrial Relations.

Marsh, R. \& Mannari, H. (1977). Organizational commitment and turnover: A predictive study. Administrative Science Quarterly, 22, 57-75.

Martin, T. \& O'Laughlin, M. (1984). Predictors of organizational commitment: The study of part-time Army reservists. Journal of Vocational Behavior, 25, 270-283.

Martin, T., Price, J. \& Mueller, C. (1981). Job performance and turnover. Journal of Applied Psychology, $66,1,116-$ 19.

Masters, W. \& Johnson, V. (1974). The Pleasure Bond: A New Look as Sexuality and commitment. Boston, MA: Little, Brown.

Mathieu, J. (1988). A causal model of organizational commitment in a military training environment. Journal of Vocational Behavior, 32, 321-335.

Mathieu, J. \& Farr, J. (1991). Further evidence for the discriminant validity of measures of organizational commitment, job involvement, and job satisfaction. Journal of Applied Psychology, 76, 1, 127-133. 
Mathieu, J. \& Hamel, K. (1989). A causal model of the antecedents of organizational commitment among professional and nonprofessionals. Journal of Vocational Behavior, 34, 299-317.

Mathieu, J. \& Kohler, S. (1990). A test of the interactive effects of organizational commitment and job involvement on various types of absence. Journal of Vocational Behavior, 36, 33-44.

Mathieu, J. \& Zajac, D. (1990). A review and meta-analysis of the antecedent, correlates, and consequences of organizational commitment. Psychological Bulletin, 108, $2,171-194$.

McGee, G. \& Ford, R. (1987). Two or more dimensions of organizational commitment: Reexamination of the Affective and Continuance Commitment Scales. Journal of Applied Psychology, 72, 4, 638-642.

Merton, R. (1957). Social Theory and Social structure. Glencoe, IL.: Free Press.

Meyer, J. \& Allen, N, (1984). Testing the "side-bet theory" of organizational commitment: Some methodological considerations. Journal of Applied Psychology, 69, 372378 .

Meyer, J. \& Allen, N. (1987). A longitudinal analysis of the early development and consequences of organizational commitment. Canadian Journal of Behavioral Science, 19, 2 , 199-215.

Meyer, J., Paunonen, S., Gellatly, I., Goffin, R. \& Jackson, D. (1989). Organizational commitment and job performance: Its's the nature of the commitment that counts. Journal of Applied Psychology, 74, 1, 152-156.

Michaels, C. \& Spector, P. (1982). Causes of employee turnover: A test of the Mobley, Griffeth, Hand and Meglino model. Journal of Applied Psychology, 67, 1, 5359 .

Miller, D. (1986). Managing PRofessionals in Research and Development. San Francisco, CA: Jossey-Bass.

Miller, G. \& Wagner, L. (1971). Adult socialization, organizational structure, and role orientations. Administrative Science Quarterly, 16, 151-163. 
Mirvis, P. \& Lawler, E. (1977). Measuring the financial impact of employee attitudes. Journal of Applied Psychology, 62, 1-18.

Mobley, W. (1977). Intermediate linkages in the relationship between satisfaction and employee turnover. Journal of Applied Psychology, 62, 237-240.

Mobley, W. (1982). Employee Turnover: Causes, Consequences, and Control. Philippines: Addison-Wesley Publishing Company, Inc.

Mobley, W., Griffeth, R., Hand, H. \& Meglino, B. (1979). Review and conceptual analysis of the employee turnover process. Psychological Bulletin, 86, 493-522.

Mohrman, A., Resnick-West, S. \& Lawler, E. (1989). Designing Performance Appraisal Systems. San Francisco, CA: JosseyBass Publishers.

Morris, J. \& Sherman, J. (1981). Generalizability of an organizational commitment model. Academy of Management Journal, 24, 512-526.

Morris, J. \& Steers, R. (1980). Structural influences on organizational commitment. Journal of Vocational Behavior, 17, 50-57.

Morrow, P. (1983). Concept redundancy in organizational research: The case of work commitment. Academy of Management Review, 8, 486-500.

Morrow, P. \& MCElroy, J. (1986). On assessing measures of work commitment. Journal of Occupational Behavior, 7, 139-145.

Mott, P. (1972). The Characteristics of Effective organizations. New York, NY: Harper and Row.

Mottaz, C. (1986). An analysis of the relationship between educational and organizational commitment in a variety of occupational groups. Journal of Vocational Behavior, 28, 214-228.

Mottaz, C. (1988). Determinants of organizational commitment. Human Relations, 41, 6, 467-482.

Mowday, R., Porter, L. \& steers, R. (1982). Employeeorganization Linkages: The Psychology of Commitment, Absenteeism, and Turnover. New York, NY: Academic Press. 
Mowday, R., steers, R. \& Porter, L. (1979). The measurement of organizational commitment. Journal of Vocational Behavior, 14, 224-247.

Muliak, S. (1972) The Foundatins of Factor Analysis. New York, NY: McGraw-Hill.

Nunnally, J. (1978). Psychometric Theory, 2nd ed. New York, NY: McGraw-Hill.

O'Reilly, C. \& Caldwell, D. (1980). Job choice: The impact of intrinsic and extrinsic factors on subsequent satisfaction and commitment. Journal of Applied Psychology, 65, 5, 559-565.

O'Reilly, C. \& Chatman, J. (1986). Organizational commitment and psychological attachment: The effects of compliance, identification, and internalization on prosocial behavior. Journal of Applied Psychology, 71, 3, 492-499.

Ormsby, J. \& Watts, L. (1989). The effect of unionization on organizational commitment: A longitudinal study of a university faculty. Journal of Collective Negotiations, $18,4,327-336$.

Parasuraman, S. \& Nachman, S. (1987). Correlates of organizational and professional commitment. Group \& organizational studies, 12, 3, 287-303.

Pedhazur, E. (1982). Multiple Regression in Behavioral Research. New York, NY: CBS College Publishing.

Penley, L. \& Gould, S. (1988). Etzioni's model of organizational involvement: A perspective for understanding commitment to organizations. Journal of organizational Behavior, 9, 43-59.

Podsakoff, P., Williams, L.m \& Todor, W. (1986). Effects of organizational formalization on alienation among professionals and nonprofessionals. Academy of Management Journal, 29, 4, 820-831.

Porter, L., Crampon, W. \& Smith, F. (1976). Organizational commitment and managerial turnover: A longitudinal study. organizational Behavior and Human Performance, 15, 87-98.

Porter, L. \& Lawler, E. (1968). Managerial Attitudes and Performance. Homewood, ILL: Dorsey. 
Porter, L. \& Steers, R. (1973). Organizational, work, and personal factors in employee turnover and absenteeism. Psychological Bulletin, 80, 151-76.

Porter, L., Steers, R., Mowday, R. \& Boulian, P. (1974). organizational commitment, job satisfaction, and turnover among psychiatric technicians. Journal of Applied Psychology, 59, 603-609.

Price, J. (1977). The Study of Turnover. Ames, Iowa: Iowa State University Press.

Price, J. \& Mueller, C. (1981). Professional Turnover: The Case of Nurses. New York: Spectrum.

Putti, J., Aryee, A. \& Liang, T. (1989). Work values and organizational commitment: A study in an Asian context. Human Relations, 42,3 .

Raelin, J. (1985). The basis for the professional's resistance to managerial control. Human Resource Management, 24, 2, 147-175.

Randal1, D. (1987). Commitment and the organization: The organizational man revisited. Academy of Management Review, 12, 3, 460-471.

Randall, D. (1988). Multiple roles and organizational commitment. Journal of Organizational Behavior, 9, 309317 .

Randall, D., Fedor, D. \& Longenecker, C. (1990). The behavioral expression of organizational commitment. Journal of Vocational Behavior, 36, 2, 210-224.

Reichers, A. (1985). A review and reconceptualization of organizational commitment. Academy of Management Review, $10,3,465-476$.

Reichers, A. (1986). Conflict and organizational conflicts. Journal of Applied Psychology, 71, 3, 508-514.

Reissman, I. (1949). A study of role conceptions in bureaucracy. Social Forces, 22, 305-310.

Rhodes, S. \& Steers, R. (1990). Managing Employee Absenteeism. Reading, MA: Addison-Wesley.

Ritzer, G. \& Trice, H. (1969). An empirical study of Howard Becker's side-bet theory. Social Forces, 47, 475-478. 
Rotondi, T. (1980). Commitment to organization and profession: A review. Journal of General Management 6, 1, 15-21.

Rousseau, D. (1978). Characteristics of departments, positions, and individuals: Contexts for attitudes and behavior. Administrative Science Quarterly, 23, 521-540.

Rupp, M. \& Segal, R. (1989). Confirmatory factor analysis of a professionalism scale in pharmacy. Journal of Social and Administrative Pharmacy, 6, 1, 31-38.

SAS Institute Inc. (1989) SAS/STAT User's Guide, Version 6, Fourth Edition, Volume 1, Cary, NC: SAS Institute Inc.

Schack, D. \& Hepler, C. (1979). Modification's of Hall's Professionalism Scale for use with pharmacists. American Journal of Pharmacy Education, 43, 98-104.

Schmitt, N. \& Stults, D. (1985). Factor defined by negatively keyed items: The result of careless respondents? Applied Psychological Measurement, 8, 367373 .

Scholl, R. (1981). Differentiating organizational commitment from expectancy as a motivating force. Academy of Management Review, 6, 4, 589-599.

Schriesheim, J., Von Glinow, M. \& Kerr, S. (1977). Professionals in bureaucracies: A structural alternative. In Prescriptive Models of Organizations, North-Holland TIMS studies in the Management Sciences, 5. Amsterdam: North-Holland.

Shepard, H. (1956). Nine dilemmas in industrial research. Administrative Science Quarterly, 1, 340-360.

Shore, L. \& Martin, H. (1989). Job satisfaction and organizational commitment in relation to work performance and turnover intentions. Human Relations, 42 , $7,625-638$.

Shortell, S. \& Kaluzny, A. (1988). Health Care Management: A Text in Organizational Theory and Behavior. New York, NY: John Wiley \& Sons.

Skinner, B. (1953). Science and Human Behavior. New York, NY: Macmillan Publishing Company. 
Smith, P., Kendall, L., \& Hulin, C. (1969). The Measurement of Satisfaction in Work and Retirement: A strategy for the Study of Attitudes. Chicago, Ill: Rand McNally.

Snizek, W. (1972). Hall's professionalism scale: An empirical reassessment. American Sociological Review, 37, 109-113.

Solomon, E. (1986). Private and publj.c sector managers: an empirical investigation of job characteristics and organizational climate. Journal of Applied Psychology, $71,247-259$.

Sorenson, J. \& Sorenson, T. (1974). The conflict of professionals in bureaucratic organizations. Administrative Science Quarterly, 19, 98-106.

Staw, B. (1980). The consequences of turnover. Journal of occupational Behavior, 1, 253-73.

Staw, B. \& Ross, J. (1985). Stability in the midst of change: A dispositional approach to job attitudes. Journal of Applied Psychology, 70, 469-480.

Steers, R. (1977). Antecedents and outcomes of organizational commitment. Administrative Science Quarterly, 22, 46-56.

Steers, R. \& Mowday, R. (1981). Employee Turnover and the Post Decision Accommodation Process. In B.M. Shaw and L.L. Cummings (Eds.) Research in organizational Behavior. Greenwich: JAI Press.

Steers, R. \& Rhodes, S. (1978). Major influences on employee attendance: A process modell. Journal of Applied Psychology, 63, 391-407.

Stevens, J. Beyer, J. \& Trice, H. (1978). Assessing personal, role and organizational predictors of managerial commitment. Academy of Management Journal, 21, 380-396.

Stumpf, S. \& Hartman, K. (1984). Individual exploration to organizational commitment or withdrawal. Academy of Management Journal, 27, 308-329.

Taylor, F. (1911). Scientific Management. New York, NY: Harper Brothers.

Thorndike, E. (1911). Animal Intelligence. New York, NY: MacMillan. 
Thornton, R. (1970). Organizational involvement and commitment to organization and profession. Administrative Science Quarterly, 15, 417-426.

U.S. Bureau of Labor Statistics. (1980). Employment Earnings 27-4. Washington, D.C.: U.S. Department of Labor.

Van Maanen, J. (1975). Police socialization: A longitudinal examination of job attitudes in an urban police

department. Administrative Science Quarterly, 20, 207228 .

Von Glinow, M. (1983). Incentives for controlling the performance of high technology and professional employees. IEEE Transactions on Systems, Man and Cybernetics SMC-13, 1, 70-74.

Von Glinow, M. (1988). The New Professionals. Cambridge, MA: Ballinger Publishing Company.

Vroom, V. (1964). Work and Motivation. New York, NY: Wiley.

Wanous, J. (1980) . Organizational Entry: Recruitment, Selection and Socialization of Newcomers. Reading, MA: Addison-Wesley.

Weiss, D., Dawis, R., England, G. , \& Lofquist, L. (1967). Manual for the Minnesota Satisfaction Questionnaire. Minneapolis: Industrial Relations Center, University of Minnesota.

Welsh, H. \& LaVan, H. (1981). Inter-relationship between organizational commitment and job characteristics, satisfaction, professional behavior, and organizational climate. Human Relations, 34, 1079-1089.

Wicklund, R. \& Brehm, J. (1976). Perspectives in cognitive dissonance. Hillsdale, NJ: Erlbaum.

Wiener, Y. (1982). Commitment in organizations: A normative view. Academy of Management Review, 7, 3, 418-428.

Wiener, Y., Vardi, Y. \& Muczyk, J. (1980). Antecedents of employee mental health the role of career and work satisfaction. Journal of Vocational Behavior, 19, 1, 5060 . 
Williams, L. \& Hazer, J. (1986). Antecedents and consequences of satisfaction and commitment in turnover models: A reanalysis using latent variable structural equations methods. Journal of Applied Psychology, 71, $219-231$.

Zaccaro, S. \& Dobbins, G. (1989). Contrasting group and organizational commitment: Evidence for differences among multilevel attachments. Journal of organizational Behavior, 10, 267-273.

Zahra, S. (1984). Antecedents and consequences of organizational commitment: An integrative approach. Akron Business and Economic Review, 15, 26-32. 
APPENDIX A

QUESTIONNAIRE ITEMS 
MEASURES

OUTCOME VARIABLES

** Indicates items or factors that were dropped

Job Satisfaction

Please indicate below how satisfied or dissatisfied you are with each of the following: (Very satisfied, Satisfied, Neutral, Somewhat Dissatisfied, Very Dissatisfied)

1. Degree of control over the pace/quality of your work**

2. Degree of variety in your work

3. Degree of job security you have

4. How you and your fellow workers get along**

5. Physical surroundings at work

6. Your job overall

7. Opportunities for advancement

8. Availability of continuing education and training at $\mathrm{KP}$

9. Amount of responsibility you have

10. Taking all things into consideration, how satisfied are you with your immediate supervisor**

\section{Performance}

Effectiveness.

In your opinion, how well do the people in your department do at each of the following: (Extremely well, very well, Fair, Not Very Well, Not at all Well)

1. Getting the most from the resources available

2. Identifying and discussing work related problems

3. Keeping up with changes in equipment and techniques

4. Coping with temporary work overloads** 
5. Pulling together to get the work done

\section{Production Quality/Quantity.}

1. Thinking now of the various things produced by the people you know in your department, how much are they producing (their production is very high, it is fairly high, it is neither high nor low, it is fairly low, it is very low)

2. How good would you say is the quality of the products or services produced by the persons you know in your department (their products or services are of excellent quality, good quality, fair quality, their quality is not too good, their quality is poor)

3. In your opinion, how has the quality of the work in your department changed in the past year (improved, remained about the same, declined, I haven't worked in this department for 1 year yet)

4. In your opinion, have the services provided to our Kaiser Permanente members generally improved, become worse, or remained the same, no opinion during the past year**

\section{Coordination of work activity. **}

1. From time to time problems of coordinating the work of people who must work together arise. When they arise in your department, how well are these problems handled (these problems are extremely well handled, very well handled, fairly well handled, not so well handled, they are not handled well at all)**

2. How well coordinated are your department objectives with the Regional Strategies and objectives (very well coordinated, fairly well coordinated, not very well coordinated, not coordinated at all, don't know)**

\section{Withdrawal}

1. Do you plan to be working for KP five years from now (definitely, probably, not sure, probably not, definitely not, will be retiring in the next five years)

2. In the past several weeks have you thought about leaving your job at KP (frequently, sometimes, no) 
About how many days of work did you miss this past twelve months for each of the following reasons: (None, less than 1 day, $1-2$ days, 3-5 days, 6-10 days, $11+$ days)

1. My own personal illness**

2. Illness of family members**

3. Just "sick of work"**

PREDICTOR VARIABLES

\section{Education}

1. How much formal or academic education have you had (grade school, some high school, completed high school, some college (including community college), completed college degree (BA or BS), postgraduate work)

\section{Job Demands}

A. We would like to know how you feel about various aspects of your job. Do you agree or disagree that the following statements describe your job (strongly agree, agree, neutral, disagree, strongly disagree)

B. Listed below are different kinds of opportunities a job might offer. With respect to your present job, how well are each of the following met (not at all, slightly, moderately, considerably, greatly)

1. I have too much work to do everything well (A)

2. On my job I can't satisfy everyone at the same time (A)

3. I never seem to have enough time to get everything done on my job (A)

4. On my job I know exactly what is expected of me (A)**

5. Having clear objectives toward which to aim my work (B)**

6 . On the job, do you feel pressure from others to perform beyond what you think is reasonable (I feel a great deal of pressure, some pressure, a little pressure, very little pressure, no pressure at all) 
Professional Commitment

A. We would like to know how you feel about various aspects of your job. Do you agree or disagree that the following statements describe your job (strongly agree, agree, neutral, disagree, strongly disagree)

B. Listed below are different kinds of opportunities a job might offer. With respect to your present job, how well are each of the following met (not at all, slightly, moderately, considerably, greatly)

\section{Expertise/skill requirements.}

1. My job lets me use my skills and abilities (A)

2. My job requires that I keep learning new things (A)

3. My job requires a high level of skill (A)**

4. Making full use of my knowledge and skills (B)

\section{Autonomy/discretion.}

1. I am given a lot of freedom to decide how to do my own work (A)

2. I have a lot to say about what happens on my job (A)

3. I can experiment and take risks with the way I do my job (A)

4. Working on difficult and challenging problems (B)**

5. Having freedom to carry out my own ideas (B)

6. Being recognized for what I contribute (B)**

7. In general, how much say or influence do you have on what goes on in your work group (little or no influence, some, quite a bit, a great deal, a great deal of influence) 
Knowledge About standards.

1. When decisions that affect your work are made, how adequately are they explained to you (completely adequately, very adequately, adequately, somewhat inadequately, very inadequately)**

2. How informed are you about each of the following: (very well informed, somewhat informed, not very well

informed, not at all informed)

3. Goals and objectives of your department or division

4. Quality of service behavior guidelines

Identification.

1. On the whole, how well do you like the work you do (extremely well, very well, fairly well, not very well, not at all)

2. Knowing what you know now, if you had to decide all over again whether to take the specific job you now have, what would you decide (definitely take the same job, probably take the same job, probably not take the same job, definitely not take the same job)

commitment.

How much do you feel you are a part of or committed to each of the following: (very, somewhat, slightly, not very, not at all, doesn't apply to me)

1. Your immediate work group

2. Your profession or occupation

Membership. **

1. Do you hold a membership in a professional or occupational association or group (yes, no)**

2. If yes, do you attend regular meetings (yes, no)** 


\section{Rewards}

Wages.

How would you rate the following within KP: (excellent, good, adequate, poor, very poor)

1. Amount of your salary or wages

2. Vacation benefits

3. Sick leave benefits

Benefits.

1. Health plan benefits

2. Retirement program

3. Life and disability

4. Dental benefits

5. Employee education program**

\section{Tenure}

1. What is the total length of time you have worked for the KP health care program (less than 6 months, more than 6 months but less that a year, more than 1 year but less than 2 years, more than 2 years but less than 5 years, more than

5 years but less than 10 years, 10 years or more)

Age

1. In what year were you born

\section{organizational Characteristics}

Performance Review.

How would you rate your last performance review on each of the following: (excellent, good, adequate, poor, very poor) 
1. Fairness

2. Recognizing my contribution

3. Confidentiality

4. Helping job performance

5. Are you evaluated against established performance objectives (yes, no)**

6. If yes, how well coordinated are your performance evaluation objectives with the objectives of your department (extremely well, very well, fairly well, not very well, not at all)**

\section{Quality of supervision.}

How would you rate your immediate supervisor on the following: (excellent, good, adequate, poor, very poor)

1. Establishing clear work objectives

2. Delegating work

3. Providing advance notice on assignments and changes

4. Fairness in decision making

5. Handling conflict

6. Willingness to listen**

7. Letting you know when you are doing a good job

8. Taking responsibility for mistakes

9. Seeking your opinion when a problem comes up**

Views About the organization.

1. On the whole, what do you think of this organization as a place to work (excellent place, good place, fair place, poor place, very poor place)

2. How open is $\mathrm{KP}$ to new ideas and ways of doing things (extremely open, very open, somewhat open, not very open) 
3. KP does a good job of promoting employees from within (true, false, don't know)**

4. KP does a good job of training both male and female employees for higher positions (true, false, don't know)**

\section{organizational commitment}

How much do you feel you are a part of or committed to each of the following (very, somewhat, slightly, not very, not at all, doesn't apply to me)

1. The KP organization

\section{Organizational Commitment Questionnaire.}

Organizational Commitment Questionnaire: (Strongly agree, moderately agree, slightly agree, neither agree nor disagree, slightly disagree, moderately disagree, strongly disagree)

2. I am willing to put in a great deal of effort beyond that normally expected to help KP be successful

3. I "talk up" KP to my friends as a great organization to work for

4. I would accept almost any type of job assignment to keep working for $\mathrm{KP} * *$

5. I find that my values and $\mathrm{KP}$ 's values are very similar

6. I am proud to tell others that I am a part of $\mathrm{KP}$

7. KP really inspires the very best in me in the way of job performance

8. I am extremely glad that I chose KP to work for over others I was considering at the time I joined

9. I really care about the fate of $\mathrm{KP}$

10. For me this is the best of all possible organizations for which to work 
Knowledge About organization. **

How informed are you about each of the following (very well informed, somewhat informed, not very well informed, not at all informed)

1. Mission of Kaiser Permanente**

2. Regional strategies and objectives**

3. Innovation fund**

4. Procedures for performance reviews**

5. Hazard communication program**

6. Employee assistance program**

7. Horizon award program**

8. Key person program**

9. VIP program** 
APPENDIX B

$65 \times 65$ INTERITEM CORRELATION MATRIX 
CONTENTS PROCEOURE

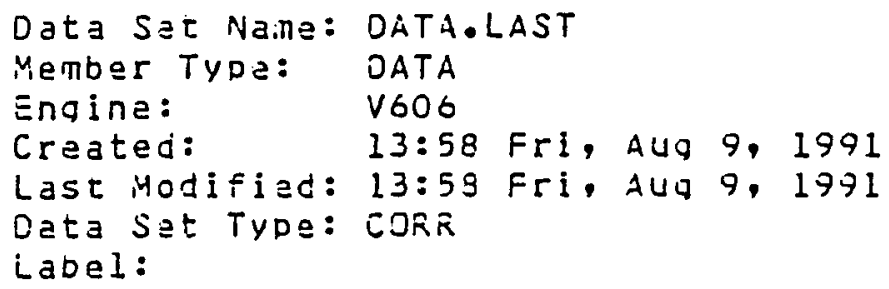




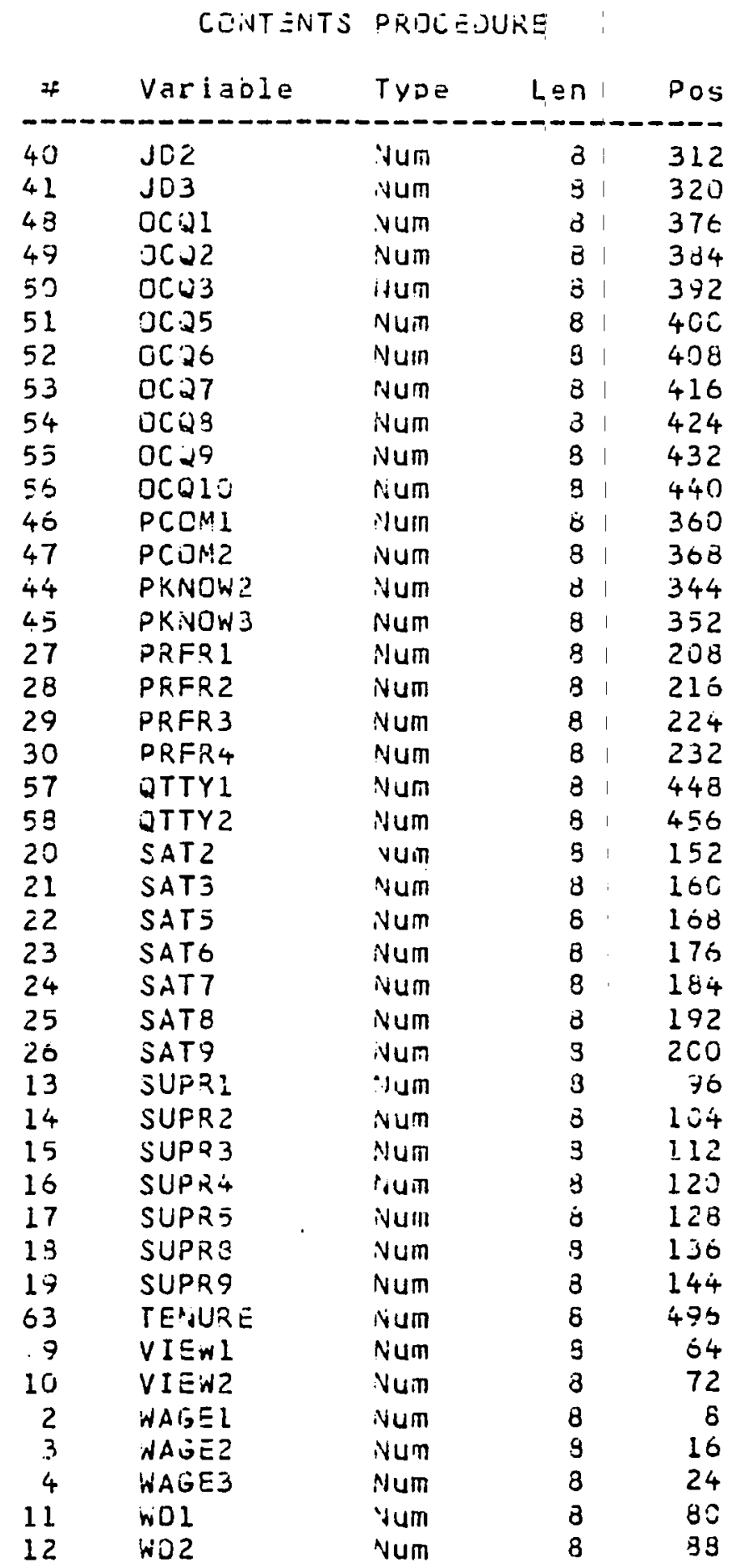




\begin{tabular}{|c|c|c|c|c|c|c|c|c|}
\hline D̈S & ABت & NATSE 1 & $\triangle A G \equiv 2$ & $W A O=3$ & $S E . V \equiv 1$ & $E \equiv M_{i E 2}$ & BEIVE3 & SECE \\
\hline 1 & 1.U00 & $C .100$ & -.3 .054 & $-[.041$ & e.cic & 0.033 & -0.024 & vels \\
\hline 2 & $\cdot 0 \cdot 103$ & 1.000 & $0.3 a c$ & 0.300 & 0.237 & $0.29 \%$ & 0.293 & \\
\hline 3 & $-0 \cdot u \bar{s}+$ & 0.300 & 1.005 & 0.052 & 5.356 & 0.256 & 0.340 & 0.28 \\
\hline 4 & $-0 . c_{41}$ & & 0.652 & 1.000 & & 0.369 & 0.411 & \\
\hline$j$ & $-c .072$ & 0.287 & 0.356 & 3.434 & 1.000 & 0.413 & 0.445 & 0.505 \\
\hline$\dot{E}$ & 0.039 & 0.279 & 0.250 & 0.359 & 0.413 & 1.000 & 0.703 & j. 36 \\
\hline 7 & -0.024 & 0.253 & 0.346 & 0.411 & 0.440 & 0.703 & 1.000 & 0.42 \\
\hline 8 & -0.100 & 0.263 & 0.287 & 0.373 & J.505 & 0.307 & 0.421 & 1.000 \\
\hline 9 & - ت & ט.?C5 & 0.275 & 0.289 & 246 & 0.215 & c. 245 & .74 \\
\hline 10 & -0.010 & 0.343 & 47 & 0.393 & & & 0.330 & 27 \\
\hline 11 & 0.205 & -0.217 & -0.277 & $-c .241$ & -3. & -0.149 & -0.155 & -0 \\
\hline 12 & C.064 & -0.177 & -0.154 & -0.155 & -0.155 & -0.150 & -0.134 & -0 \\
\hline 13 & 0.003 & 0.160 & c.135 & 0.203 & 3.109 & 0.144 & 0.183 & \\
\hline 14 & 0.009 & 0 & 0.134 & 0.147 & 3. & 0.143 & $c .152$ & \\
\hline 15 & -0.011 & 39 & 0.132 & 0.181 & 0. & 0.161 & $c .177$ & 03 \\
\hline 16 & 0.009 & & 0.132 & 0.220 & & & 0.181 & \\
\hline 17 & 0.025 & & 0.109 & 0.190 & 0 & 0. & o. & $\varepsilon$ \\
\hline 18 & 0.025 & 0 & 0.149 & 0.196 & 0. & 0.1 & 0.159 & 0 \\
\hline 19 & 0.005 & 0 & 0.154 & 0.224 & 0. & 0.1 & c. 176 & 0 \\
\hline 20 & -0.141 & & & 0. & & & 0. & \\
\hline 21 & -0.019 & & $5 c$ & 23 & 44 & 30 & C.181 & \\
\hline 22 & -0.007 & & 174 & 0.175 & 0.108 & 0.128 & 0.117 & \\
\hline 23 & -0.067 & & 7 & 0. & & & 0 & \\
\hline 24 & ذان & & & $C .250$ & & & 17 & \\
\hline 25 & -0.030 & 0 & 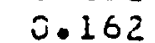 & 0.135 & 0 . & j. & 0.196 & \\
\hline 20 & $-0.00 \overline{3}$ & 0.263 & c. & 38 & 3. & 0 & $c .204$ & \\
\hline 27 & 20.00 & & & う。 & & & 0.222 & \\
\hline 29 & 0.010 & & & 26 & 34 & 98 & 213 & \\
\hline 27 & 0.009 & & & 0. & & 96 & 15 & \\
\hline 30 & 0.012 & & 1 & 0 & 0. & 0 & 75 & \\
\hline 31 & & & & 47 & & & 0.175 & \\
\hline 32 & 0.108 & -0 & & 37 & -0 & -0.195 & -0.167 & \\
\hline 33 & 0.133 & -0 & -0 . & $-\bar{v} .173$ & & -0.200 & -0.203 & -1 \\
\hline 34 & 0.117 & & $-1)$. & $-c$ & -3 & -0 & -0.100 & -0 \\
\hline 35 & c.005 & -6 & -0 & -0 & -0 & -6 & 197 & \\
\hline 36 & & & & & & & & \\
\hline 37 & & & $-\dot{u}$. & & & -3 & 1.52 & \\
\hline 39 & 5.067 & -0 & -0 & 204 & -0 & -2.223 & 204 & -0 \\
\hline 39 & $-0.12 j$ & & -3.147 & -0.127 & -0.040 & -0.000 & -0.043 & -0 \\
\hline 40 & $-10 \cdot 0+7$ & -.3 .082 & -0.075 & -9.091 & -0.037 & -0.023 & -0.0557 & \\
\hline $4 i$ & -3.079 & & & $-c \cdot 075$ & -0.013 & 0.032 & 0.013 & \\
\hline & & & & -0.177 & & -0 & & \\
\hline & & & .104 & $-v .155$ & & -0.1 & 4 & \\
\hline & ن. 255 & & -0 & -0.170 & -3.172 & -0 . & -0.185 & \\
\hline & $\theta^{2}+2$ & & 25 & +1 & -0.100 & 21 & 138 & 2 \\
\hline
\end{tabular}




\begin{tabular}{|c|c|c|c|c|c|c|c|c|}
\hline 033 & $A G E$ & WAGEI & NAUEZ & MAEミ3 & BEIVEI & BENE 2 & EENES & BENE: \\
\hline 40 & כ.ن. & -0.117 & -0.101 & -0.095 & -0.154 & -0.000 & -0.113 & -0.10 \\
\hline 47 & $3 \overline{5}$ & -0.109 & -0.287 & -0.091 & -3.070 & -0.083 & -0.059 & -0.000 \\
\hline 48 & $-0,112$ & 0.184 & 0.255 & $\therefore .247$ & 0.257 & 0.211 & 0.228 & 0.218 \\
\hline 49 & -0.051 & $\therefore .0 \varepsilon 3$ & 0.177 & 0.131 & 159 & 0.140 & 0.254 & 0.107 \\
\hline 50 & $-0.070^{\circ}$ & 0.151 & 0.227 & 0.220 & 0.250 & 0.206 & 0.215 & 170 \\
\hline 51 & -0.091 & 0.147 & 2.219 & 0.231 & 0.232 & C. 242 & 0.248 & 0.209 \\
\hline 52 & -0.0 .50 & 0.154 & 0.241 & 0.244 & 0.234 & 0.240 & 0.261 & 0.225 \\
\hline 53 & -0.050 & 0.104 & 0.252 & 0.263 & .0 .253 & c. 245 & C.250 & 0.203 \\
\hline 54 & $-c$ & & 0.273 & 0.276 & 659 & 0.221 & 0.252 & 0.187 \\
\hline 55 & -0.131 & 0.150 & 227 & 0.254 & $\$ 4$ & 0.197 & 0.222 & 0.216 \\
\hline 56 & $-0 . ؟ 78$ & 0.232 & 0.315 & C.287 & 0.271 & 0.236 & 0.260 & 0.172 \\
\hline 57 & -0.043 & 0.055 & 0.045 & 0.054 & 0.039 & 0.002 & 0.076 & 0.040 \\
\hline 50 & -0.000 & 0.105 & 0.112 & 0.113 & 0.167 & 0.039 & 0.119 & 0.109 \\
\hline 59 & -0.051 & .036 & $0.177 \varepsilon$ & 0.125 & 0.150 & 0.077 & 0.078 & 0.111 \\
\hline on & -0.035 & 0.121 & 0.089 & 0.130 & .137 & 0.053 & D. 100 & 0.111 \\
\hline 61 & -0.050 & $C .144$ & 0.130 & 0.133 & 0.150 & 1.099 & 0.114 & 0.128 \\
\hline 62 & -0.013 & 0.109 & 0.102 & 0.106 & 0.130 & 0.099 & 0.051 & 0.097 \\
\hline 63 & 0.425 & -0.042 & $-C .096$ & -0.029 & -0.005 & 0.131 & 0.094 & -0.031 \\
\hline 64 & 0.1 & & C.231 & .031 & 67 & .0108 & -0.049 & -0.073 \\
\hline
\end{tabular}




\begin{tabular}{|c|c|c|c|c|c|c|c|c|}
\hline ذj & $V$ VE., 1 & IEWL & VDI & KOD 2 & UDRI & IJPR 2 & UPR3 & U \\
\hline & טכטי & 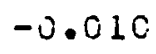 & & & & & 2 & \\
\hline & & & & & & & & \\
\hline & & & & & & & & \\
\hline & & & -1 & $-c$ & & & & \\
\hline & & & -0 & -0 & & & & \\
\hline 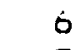 & & & . & & & & & \\
\hline 7 & & & -0 & & & & & \\
\hline 3 & & & & $-\infty$. & & & C. & \\
\hline 9 & & & & -0 & & & & \\
\hline & & & -0. & -0 & & & & \\
\hline & & & 1. & & & & & \\
\hline & & -0 & 0. & 1. & & & -0 & \\
\hline & & & $-C$ & $-C$. & & & & \\
\hline & & & $-i$ & $-\bar{v}$ & & & & \\
\hline & & & & -0 & & & & \\
\hline & & & -0 & -0 & & & & \\
\hline & & & -0 & -0 & & & & \\
\hline & & & -0. & -0 & & & & \\
\hline & & & -0 & $-c$ & & & 0 & \\
\hline & & & & & & & & \\
\hline & & & -3. & -0 & & & & \\
\hline & & & . & $-c$ & & & & \\
\hline & & & -0. & -0 & & & & \\
\hline & & & -0 & & & & & \\
\hline & & & -0. & -0 & & & & \\
\hline & & & -0 & -0 & & & & \\
\hline & & & -3 & & & & & \\
\hline & & & -0 & & & & & \\
\hline & & & -0 & -0 & & & & \\
\hline & & 8 & -10. & -0 & & & & \\
\hline & & - & $\sigma_{0}$ & & & & & \\
\hline & & & & & & & & \\
\hline & & & & & & & & \\
\hline & & & & & & & & \\
\hline & & & & & & & & \\
\hline & & -0 & 0. & & & & & \\
\hline & & & & & & & & \\
\hline & & & & & & & & \\
\hline & & & & & & & & \\
\hline & & & & & & & & \\
\hline & & & & & & & & \\
\hline & & & & & & & & \\
\hline & & & & & & & & \\
\hline & & & & & & & & \\
\hline & & & & & & & & \\
\hline
\end{tabular}


OES VIENI VIENL WDI WUL SUPRI SUPRZ SUPRZ SUPR 4

\begin{tabular}{|c|c|c|c|c|c|c|c|c|}
\hline 6 & $\begin{array}{l}0.13 \\
0.32 \\
0.23 \\
0.33\end{array}$ & $\begin{array}{l}0.22 \\
0.44 \\
0.28 \\
0.49 \\
0.50 \\
0.52 \\
0.53 \\
0.54 \\
0.44 \\
0.56 \\
0.14 \\
0.25 \\
0.21 \\
0.28 \\
0.27 \\
0.29 \\
0.03 \\
0.04\end{array}$ & $\begin{array}{l}0.2 \\
-0.3 \\
-0.2 \\
-0.40 \\
-0.40 \\
-0.4 \\
-0.42 \\
-0.4 \\
-0.40 \\
-0.5 \\
-0.1 \\
-0.1 \\
-0.1 \\
-0.1 \\
-0.1 \\
-0.1 \\
0.10 \\
-0.10\end{array}$ & $\begin{array}{r}0.2 \\
-0 . c \\
-0.1 \\
-0.2 \\
-0.3 \\
-0.3 \\
-0.3 \\
-0.3 \\
-0.2 \\
-0.3 \\
-0.0 \\
-0.1 \\
-0.0 \\
-0.1 \\
-0.1 \\
-0.1 \\
-0.0 \\
-0.0\end{array}$ & $\begin{array}{r}-0.1 \\
0.2 \\
0.1 \\
0.2\end{array}$ & $\begin{array}{l}0.234 \\
0.170 \\
0.228 \\
0.160\end{array}$ & $\begin{array}{l}0.237 \\
0.203 \\
0.298 \\
0.317 \\
0.221 \\
0.100 \\
0.077\end{array}$ & $\begin{array}{l}-0 . \\
-0 .\end{array}$ \\
\hline
\end{tabular}




\begin{tabular}{|c|c|c|c|c|c|c|c|c|}
\hline S & JPR 5 & SUPRS & SUPR? & SATZ & SAT3 & SATS & SATS & S.AT7 \\
\hline 1 & .026 & 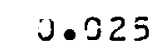 & 0 & 1 & 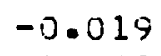 & 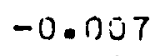 & 0.057 & 0.0 \\
\hline 6 & .133 & & & & & & & \\
\hline 3 & 169 & & & & & & & \\
\hline$\dot{4}$ & 35 & & & & & & & \\
\hline & & & & & & & & \\
\hline 6 & & & & & & & & \\
\hline 7 & & & & & & & & ن \\
\hline 0 & & & & & & & & 04 \\
\hline 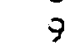 & & & & & & & & \\
\hline & & & & & & & & \\
\hline & -0 & $-i j$. & & & -0.1 & 106 & -0 & \\
\hline & -0.2 & & & & & & & 38 \\
\hline & 0.553 & & & & & & & \\
\hline & & & & & & & & \\
\hline & & & & & & & & \\
\hline & & 0.0 & & & & & & \\
\hline & 1.0 & C. & & & & & & \\
\hline & & 1 & & & & & & \\
\hline 1 & 0. & i. & 1. & & & & & \\
\hline 20 & & & & & & & & \\
\hline & & & & & & & & \\
\hline 2 & & & & & & & & \\
\hline 23 & & 0 & כ & & & & & \\
\hline 26 & & & & & & & & \\
\hline 2 & & & & & & & & \\
\hline 2 & & & & & & & & \\
\hline 2 & & & & & & & & \\
\hline & & & & & & & & \\
\hline 2 & 0 & 0. & 0 & & & 195 & 0 & \\
\hline 3 & 6 & 0. & 3 & & & 4 & & \\
\hline 31 & & -0 & 0 & & & 120 & -0 & -0 \\
\hline 32 & & & & -0 . & & & & \\
\hline 33 & & & & & & & & \\
\hline 3 & -0.2 & & & & & & -0 & \\
\hline 3 & -0. & & & -0 & & & & \\
\hline & & & & & & & & \\
\hline 3 & -0 & -0 & & -0 & & 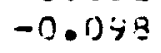 & -0 & \\
\hline 3 & -2 & $-i$. & -0 & $-i$ & -3 & -0 & ז & \\
\hline 3 & -1. & -0 & -0 & D. & & -0 & $-r_{j}$ & \\
\hline 41) & -0. & -0.0 & & 0.0 & -0 & -0 & -0 & \\
\hline 41 & -0 & & & 0.5 & & & -כ. & \\
\hline 4 & & & & & & & & \\
\hline & & & & & & & & \\
\hline & & & & & & & & \\
\hline & & & & & & & & \\
\hline
\end{tabular}




\begin{tabular}{|c|c|c|c|c|c|c|c|c|}
\hline 33 & SUPRE & SUPRO & SUPRS & SAT2 & SAT3 & SATS & SATO & SATT \\
\hline 40 & $-0.20 z$ & $-0.22 B$ & -50219 & -0.22 .5 & -0.230 & $-0.14+$ & -0.225 & -0.149 \\
\hline 47 & -0.149 & -0.115 & -0.151 & -0.227 & -0.137 & -0.114 & -0.225 & -0.090 \\
\hline & 0.236 & 0.228 & 0.236 & 0.255 & 0.219 & 0.206 & 73 & 0 \\
\hline$\uparrow$ & 06 & 173 & 0.191 & 18 & 0.137 & 175 & $0.1 \subseteq 1$ & 153 \\
\hline & 247 & 0.211 & 0.234 & 0.23 & 0.189 & 0.251 & 0.236 & \\
\hline & 41 & 05 & 0.232 & 0.241 & 0.171 & 39 & 0.315 & \\
\hline & 0.230 & 0. & 0.226 & & 0.182 & 34 & 0.300 & 0.276 \\
\hline & 0.320 & $\dot{v .276}$ & 0.305 & 0.295 & 0.219 & 0.282 & $C .380$ & 23 \\
\hline 5 & 0.290 & $0.28 \varepsilon$ & 0.295 & 0.28 & 0.244 & 0.286 & 0.301 & 10 \\
\hline 5 & 0.214 & 0.205 & 0.219 & C. 28 & 0.232 & 0.210 & 0.258 & 0.224 \\
\hline & 0.250 & 0.234 & $C .238$ & 0.25 & 0.197 & 0.275 & 0.345 & 0.290 \\
\hline 5 & $0.1 \in 6$ & 0.081 & 0.132 & .110 & 0.101 & 0.031 & 0.092 & 0.079 \\
\hline & 0.245 & 0.202 & 0.245 & 0.147 & 0.114 & 0.120 & 0.156 & 0.240 \\
\hline & 0.257 & 0.189 & 0.234 & & 0.167 & 0.111 & 0.170 & 0.123 \\
\hline & 0.320 & 0.325 & 0.325 & & 0. & 0.161 & 0.274 & 0.196 \\
\hline & $0,3-7$ & 0.261 & 0.312 & 2 & 0.1 & 0.178 & 0.240 & 0.211 \\
\hline & 0.251 & 0.223 & 0.230 & 0.217 & 0.170 & 0.133 & 0.178 & 0.145 \\
\hline $0=$ & 0.033 & 0.059 & 0.083 & -0.063 & -0.104 & 0.086 & 0.084 & 0.094 \\
\hline 04 & -0.055 & -0.053 & -0.071 & -0.050 & 0.007 & $0.05 \overline{0}$ & -0.016 & 0.031 \\
\hline
\end{tabular}




\begin{tabular}{|c|c|c|c|c|c|c|c|c|}
\hline 35 & $S \perp T E$ & SATA & PRFR.1 & PRFRZ & DRFR3 & PRFK 4 & $\ddot{E} \times \bar{P} 1$ & $E \times P 2$ \\
\hline 1 & -0.395 & $-0,0 \in 3$ & 0.002 & 0.010 & 0.057 & 0.012 & 101 & 103 \\
\hline 2 & 0.217 & 0.253 & 0.192 & $c .197$ & 0.212 & 0.170 & -0.200 & -0.140 \\
\hline 3 & 0.102 & 0.215 & 147 & $c .150$ & 0.140 & 0.141 & -0.111 & \\
\hline 4 & 0.185 & 0.238 & 226 & 0.220 & 0.233 & 0.197 & -0.147 & -0.137 \\
\hline 5 & 0.173 & 0.213 & 0.201 & 0.194 & 0.244 & 0.103 & $-c .194$ & -0.174 \\
\hline 6 & C. & & & 0.193 & 0 & 0.170 & $-C$ & -0.195 \\
\hline 7 & 0.190 & 0.2 & 22 & 0.213 & 2.2 & 0.175 & -0.175 & -0.107 \\
\hline 5 & 0.101 & 0.183 & 3 & 0.177 & J. & 0.130 & $-1)$. & -0.145 \\
\hline 9 & 0.229 & 0.305 & 33 & 0.230 & 0.227 & 0.236 & -0.230 & $-\ddot{0.199}$ \\
\hline 0 & $C .332$ & 0.509 & 317 & 0.306 & 0.335 & 0.318 & -0.301 & -0.247 \\
\hline 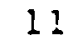 & -0.244 & -0.370 & -0.107 & -165 & -3.199 & -0.202 & 0.189 & 0.174 \\
\hline 12 & -0.253 & -0.331 & -0.200 & -3.212 & -10.200 & -2.240 & $c .214$ & $c .150$ \\
\hline 13 & C. 271 & 0.360 & 0.396 & 0.389 & 0.373 & 0.424 & $-C .272$ & -0.255 \\
\hline 14 & 0.281 & 0.3 & 70 & 0.357 & 0.367 & 0.382 & -0.24 .3 & -0 \\
\hline 15 & 2.272 & 0. & & 0.303 & 0 & C4 & -0 & 09 \\
\hline 10 & 0.277 & 0.37 & 4 & 0.402 & 0.430 & 0.400 & -0.204 & -0.239 \\
\hline 17 & 0.274 & 2.354 & & 0.559 & 0.373 & C.396 & -0.243 & -0.233 \\
\hline 18 & 0.279 & & & 0.427 & 3 & 0.433 & $-C$ & -0.245 \\
\hline 19 & 0.290 & & & $C .430$ & 0 & 443 & -0 & -0.252 \\
\hline 20 & $5.50 j$ & 0.5 & & 0.210 & 0.229 & 0.203 & $-i$ & $-\mathrm{C} .47 \mathrm{C}$ \\
\hline 21 & 0.287 & $0 \cdot 3$ & & 0.242 & 9. & 0.239 & -0 & $-0.18 j$ \\
\hline 22 & 0.218 & 0.3 & 11 & S. & U. & $0.19+$ & -j. & $-i$ \\
\hline 23 & 0.453 & 0.480 & 51 & 0.260 & 0.237 & 0.272 & בים & $-\hat{0.5554}$ \\
\hline 24 & 0.322 & 0 & & 0.228 & 9 & 0.222 & -0.221 & -0.235 \\
\hline 20 & 1.000 & & & 305 & 4 & 0.291 & $-5 \cdot 5.20$ & $-C_{0}+\alpha_{0}$ \\
\hline 26 & 0.350 & 1.000 & & 0.370 & 0.3 & 0.378 & -0.490 & -0.393 \\
\hline 27 & 0.255 & J. & 0 & 0.0 & 0. & Sü & -0. & -0.233 \\
\hline 25 & 0.305 & 0. & 31 & 1.0 & 0.6 & 0. & -2 & -0.221 \\
\hline 29 & 0.274 & 0.343 & 698 & 0.683 & 1.000 & 0.037 & -0.239 & -0.234 \\
\hline 36 & ט.291 & ר. & & 0.731 & $0 \cdot$ & 1.000 & -0.200 & $-C .19 j$ \\
\hline 31 & -0.506 & -0.490 & 45 & -2.236 & -.7 .238 & -0.206 & 1.000 & 0.574 \\
\hline 32 & -0.406 & -0.373 & & -0.221 & -0.234 & 193 & 0.574 & 1.000 \\
\hline 33 & -0.461 & -0.435 & -0 & -0.241 & -0.239 & $-17 \cdot 222$ & 0.617 & $0 .+92$ \\
\hline 2 &.+14 & $-0,43$ & & 273 & 2 & -0.220 & $c$. & ن.37 \\
\hline 35 & .4 .06 & a & & -17.270 & .290 & -0.254 & c. & U.343 \\
\hline & .253 & 22 & $9 ?$ & -0.189 & -0.18 & .116 & (1) & $0.21+$ \\
\hline 37 & 357 & 36 & & -0.238 & 323 & 243 & 6 & 254 \\
\hline 30 & 61 & 4 & 76 & -0.280 & $-0.30 ?$ & -0.234 & 21 & 0.302 \\
\hline 39 & & - & & -0.111 & & 134 & & $-C .094$ \\
\hline 40 & -0.043 & -0.130 & -0 & -0.070 & -0.059 & -0.094 & $-0.04 \overline{0}$ & -0.005 \\
\hline 1 & 0.029 & & & $C .071$ & & & $-\bar{c}$ & -3.246 \\
\hline $\mathrm{T}$ & $\begin{array}{l}83 \\
82\end{array}$ & $\begin{array}{l}-6 . \\
-13 .\end{array}$ & & $\begin{array}{l}-c .237 \\
-1.270\end{array}$ & $\begin{array}{l}-2.259 \\
-0.289\end{array}$ & $\begin{array}{l}-0.25 E \\
-0.303\end{array}$ & $\begin{array}{l}0 . \\
0 .\end{array}$ & $\begin{array}{l}345 \\
318\end{array}$ \\
\hline 44 & -0.237 & -0.257 & . & -0.258 & -0.275 & -0.243 & 0. & 61 \\
\hline 45 & 2.131 & $2014=$ & (1) & ס & -3.131 & idar & 2.143 & 1.0120 \\
\hline
\end{tabular}




\begin{tabular}{|c|c|c|c|c|c|c|c|c|}
\hline oes & SATO & SATO & PEFRI & PRFR2 & PRFA3 & PKFRY & EXP 1 & EXPZ \\
\hline 46 & -3.267 & -0.328 & -0.150 & -0.173 & -0.233 & -0.180 & $c .234$ & 0.221 \\
\hline 47 & -0.231 & -3.290 & -0.087 & -0.102 & -0.123 & $-C .136$ & 0.203 & 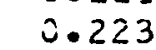 \\
\hline 4 & 204 & 0.357 & 0.179 & 0.176 & 0.171 & 0.200 & -0.210 & -1 \\
\hline 45 & 0.131 & 0.212 & 0.143 & 0.133 & 0.157 & 0.200 & -0.113 & -0.1 \\
\hline 5 & 0.195 & 0.372 & 0.202 & $0.19+$ & 0.200 & 0.250 & -0.202 & \\
\hline jl & 0.220 & 0.358 & 0.216 & 0.203 & 0.220 & 0.249 & -0.204 & \\
\hline 52 & C.23E & 0.403 & 0.215 & C.205 & 0.214 & 0.257 & -0.225 & -0.197 \\
\hline 5 & $c .316$ & 0.452 & 0.260 & 0.280 & $0.27 i$ & 0.337 & -0.258 & -0.258 \\
\hline 5 & 09 & 0.470 & $c .252$ & E. & 0.230 & 0.311 & -0 & -6 \\
\hline$\varepsilon$ & 0.210 & 0.351 & 0.173 & $0.1=$ & 0.194 & 104 & -0.231 & -0.24 \\
\hline 56 & 0.266 & 0.428 & 0.220 & 0.232 & 0.229 & 0.297 & -0.245 & -0.215 \\
\hline 57 & 0.133 & 0.182 & 0.114 & 0.090 & 0.149 & 0.079 & $-0.14 b$ & -0.163 \\
\hline $5 \pi$ & 0.197 & 0.271 & 0.201 & 0.205 & 0.233 & 0.197 & -0.205 & $-C .184$ \\
\hline & 0.231 & 0.272 & 0.197 & 0.139 & 0.221 & 0.173 & -3.217 & -0.221 \\
\hline & 0.237 & .332 & 0.254 & 0.27 & 0.265 & 0.235 & -0.285 & -0.200 \\
\hline$\dot{\theta}$ & 0.253 & 0.303 & 0.252 & C. 247 & 0.250 & 0.243 & -0.233 & -0.25 \\
\hline 62 & 0.232 & 0.315 & 0.201 & 0.202 & 0.239 & 0.170 & -0.197 & -0.193 \\
\hline 53 & -0.045 & 0.010 & 0.074 & $C .093$ & 0.059 & 0.101 & $C .000$ & 0.011 \\
\hline 04 & -0.059 & .016 & .057 & -0.034 & 0.085 & 0.042 & 0.114 & 0.174 \\
\hline
\end{tabular}




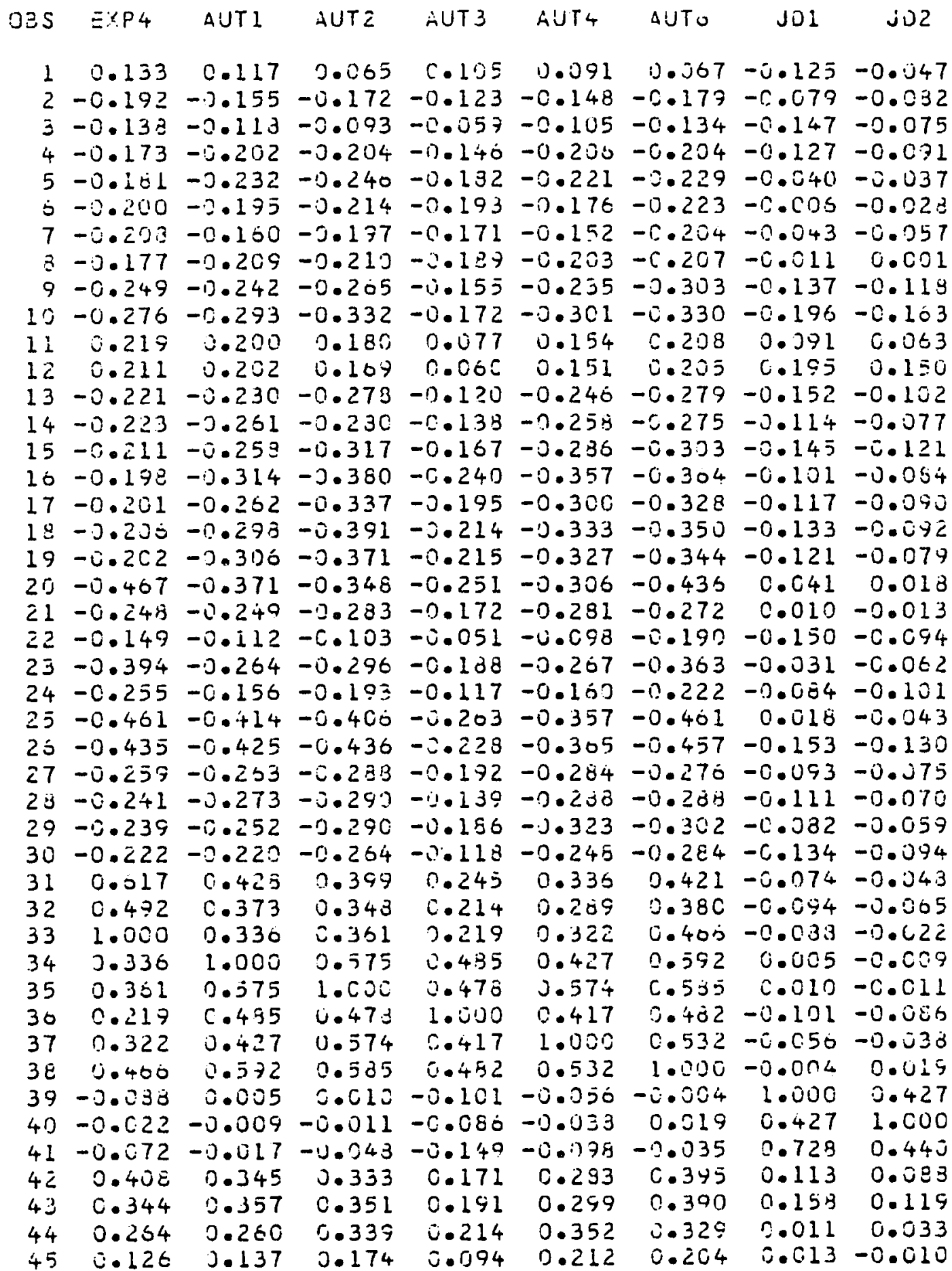




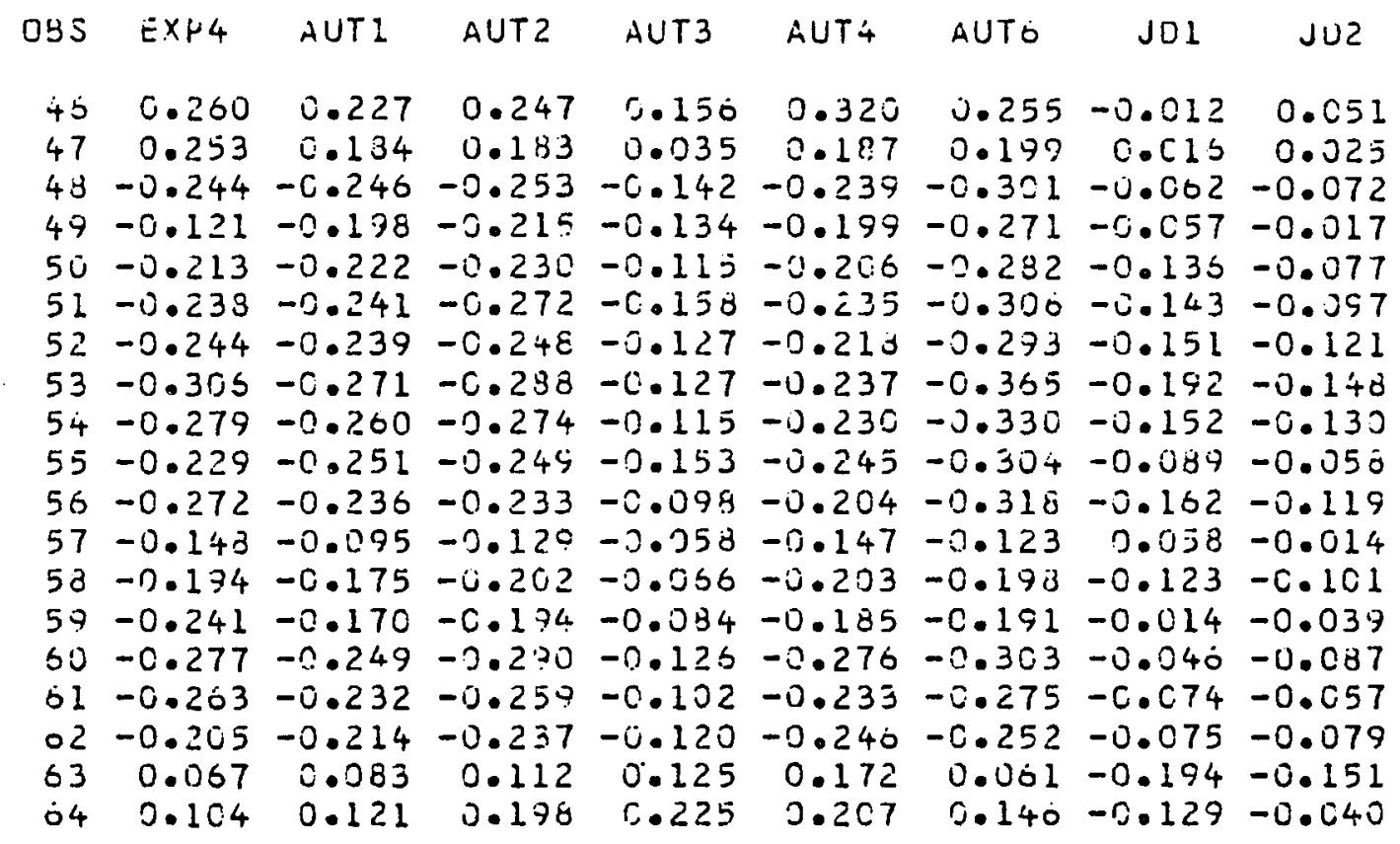




\begin{tabular}{|c|c|c|c|c|c|c|c|c|}
\hline 5 & $\mathrm{JO} 3$ & ID: & 02 & K.VO. 2 & Kivin 3 & $\cos 1$ & PCSili & DCQI \\
\hline 1 & 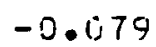 & & -604 & & & & & \\
\hline$C$ & & & & -6. & & & & \\
\hline & & - & & -0. & & & & \\
\hline+ & & -0 & & & & & & \\
\hline 5 & $-C$ & -0. & & -0 & & & & \\
\hline ó & 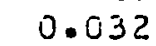 & & & -0 & & & & \\
\hline 7 & & & & & & & & \\
\hline 8 & - & & & & & & & \\
\hline 9 & -0. & & -0 . & -0. & & & & \\
\hline & -0. & -0. & 0 & $-c$. & & & & \\
\hline & 0. & $c$ & & & & & & \\
\hline & - & & & 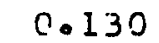 & & & & \\
\hline & 2 & 0 & $t$ & -0. & & $-c$ & & \\
\hline & 0 . & & & & & & & \\
\hline & & & -0 & -6 & & & & \\
\hline & -0 & -6 & & -0 & & & & \\
\hline 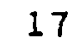 & -0. & -0 & -5 & -0 & & & & \\
\hline & c. & -0 & $-i$ & -9 & & & & \\
\hline & 65 & -8 & & & & & & \\
\hline & & -0 & -0 & -0 & -0 & -0 & $-C$ & \\
\hline & 0. & -0. & & $-c$ & & & & \\
\hline & . כ- & & & & & & & \\
\hline & -0 & -0 & -0 & -0 & $-\hat{c}$ & -0 & & \\
\hline & -0 & -0 & & -6 & & & & \\
\hline & & & & & & & & \\
\hline & -0. & & -0 & -0 & & D - & & \\
\hline & -0. & -10 & & & & & & \\
\hline & $-c$. & & & & & & & \\
\hline & . & $-C$ & -0 & -0 & & -0 & & \\
\hline & 3 & & & & & & & \\
\hline & & & & & & & & \\
\hline & & & & & & & & \\
\hline & & & & & & & & \\
\hline & & & & & & & & \\
\hline & & & & & & & & \\
\hline & & & & & & & & \\
\hline & & & & & & & & \\
\hline & -0 & & & & & & & \\
\hline & & & & & & & & \\
\hline & & & & & & & & \\
\hline & & & & & & -0. & & \\
\hline & & & & & & & & \\
\hline & & & & & & & & \\
\hline & & & & & & & 49 & -0 \\
\hline & 10 & & & & ? & 13 & $1.1 \overline{0}$ & \\
\hline
\end{tabular}




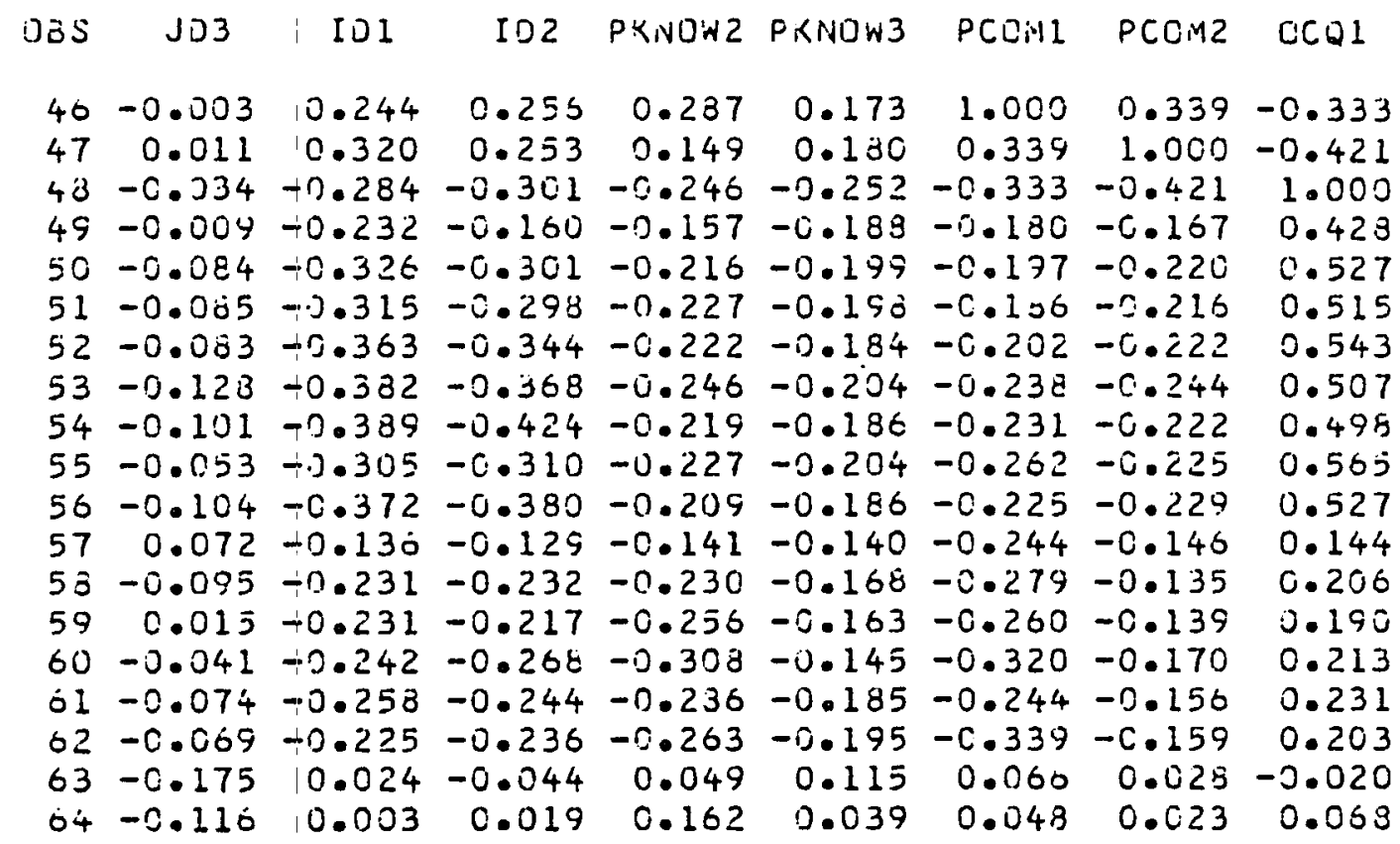




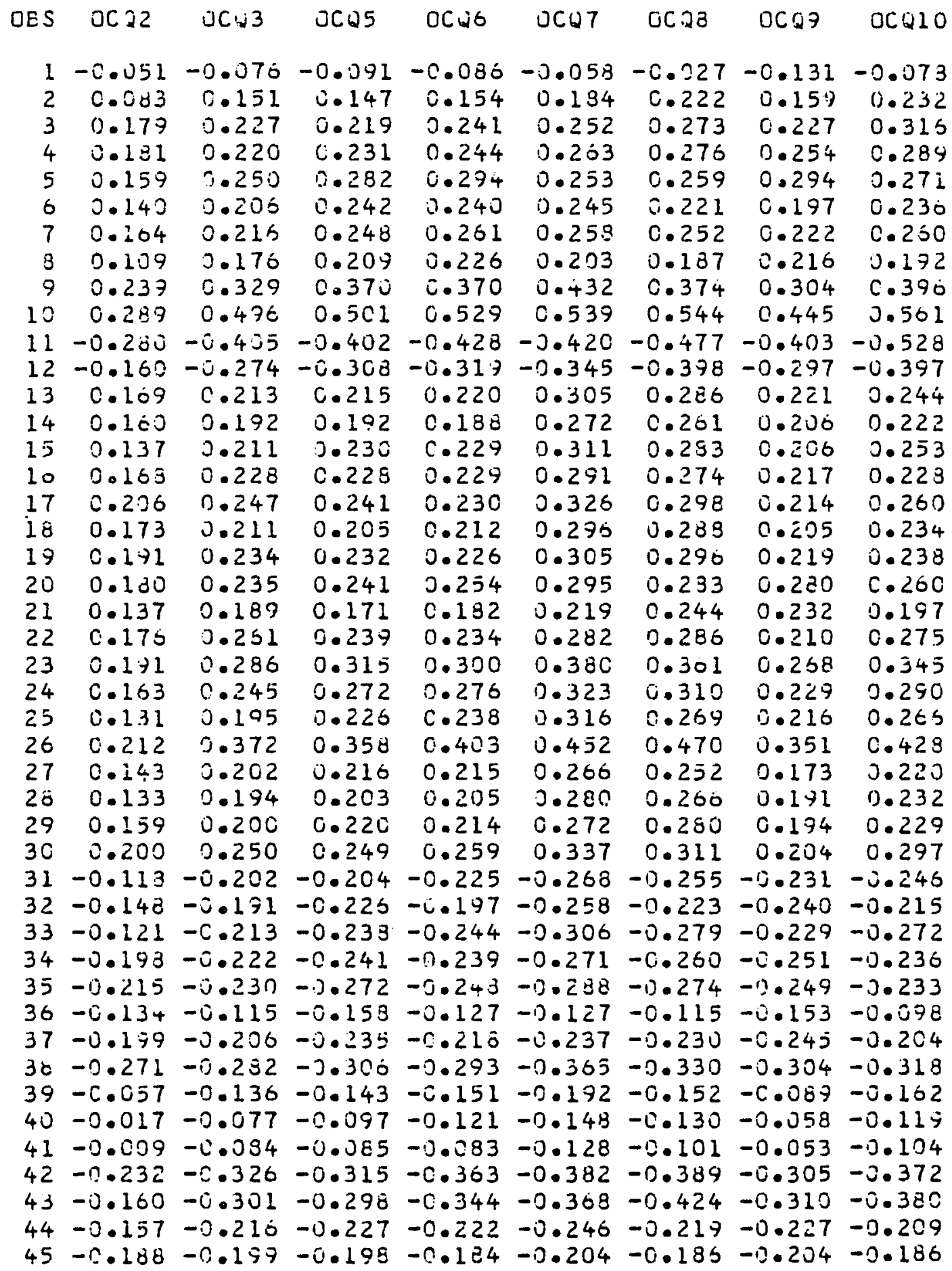




\begin{tabular}{|c|c|c|c|c|c|c|c|c|}
\hline 比 & JCQ2 & $0<23$ & $0<25$ & $0<26$ & ocin 7 & 0 Cas & 0029 & OCUIO \\
\hline 40 & -0.180 & -0.197 & -0.186 & $-C .202$ & -0.238 & $-c .231$ & -0.202 & -0.22 \\
\hline 47 & & -0.220 & -0.216 & -0.222 & 02 & & -0.225 & \\
\hline 48 & 28 & 27 & 15 & 0.543 & 0.5 & & & 0 \\
\hline 49 & 1.000 & & 4 & 0.471 & 0.480 & 4 & 0 & 0.45 \\
\hline 50 & 0.506 & 1.000 & 0.645 & 0.748 & 0.044 & 0.643 & 0.528 & 0.650 \\
\hline 51 & 0.474 & & 0 & C. & 0.691 & 595 & & 0. \\
\hline 52 & 0.471 & 0.748 & C.713 & 1.000 & 0.725 & 0.679 & 0.029 & 0.677 \\
\hline 53 & 0.480 & 0.644 & 0.691 & 0.725 & 1.000 & 0.699 & 82 & 0.702 \\
\hline 54 & 0.434 & 0.648 & 95 & c.079 & 0.699 & 1.000 & 61 & .743 \\
\hline 55 & 0.540 & 0.623 & 49 & 0.627 & 0.532 & C.601 & 1.000 & 0.651 \\
\hline 56 & 0.457 & 0.656 & 29 & 0.677 & 0.702 & 0.743 & 0.651 & 1.000 \\
\hline 57 & 0.052 & 0.091 & 0. & 0.100 & 0.121 & 124 & 0.123 & 102 \\
\hline 53 & 0.120 & 0.217 & 0.210 & 0.224 & 0.246 & 0.231 & 0.188 & 0.216 \\
\hline 59 & 0.115 & 0.157 & 71 & 0.169 & 0.218 & 0.216 & 0.207 & 0.182 \\
\hline 60 & & 0.1 & 0.209 & 0.194 & 0.272 & 270 & 0.215 & 0 \\
\hline 61 & 57 & 0.213 & 0.207 & 0.219 & 0.271 & 57 & 0.224 & 0.241 \\
\hline 62 & 0.150 & 0.198 & 0.172 & c. 194 & 0.222 & 0.236 & 0.215 & 0.216 \\
\hline 53 & 0.043 & 0.055 & 0.093 & 0.114 & 0.127 & 68 & -0 & \\
\hline 64 & .045 & 0.078 & 0.021 & 0.069 & 0.088 & 119 & 0.070 & 120 \\
\hline
\end{tabular}




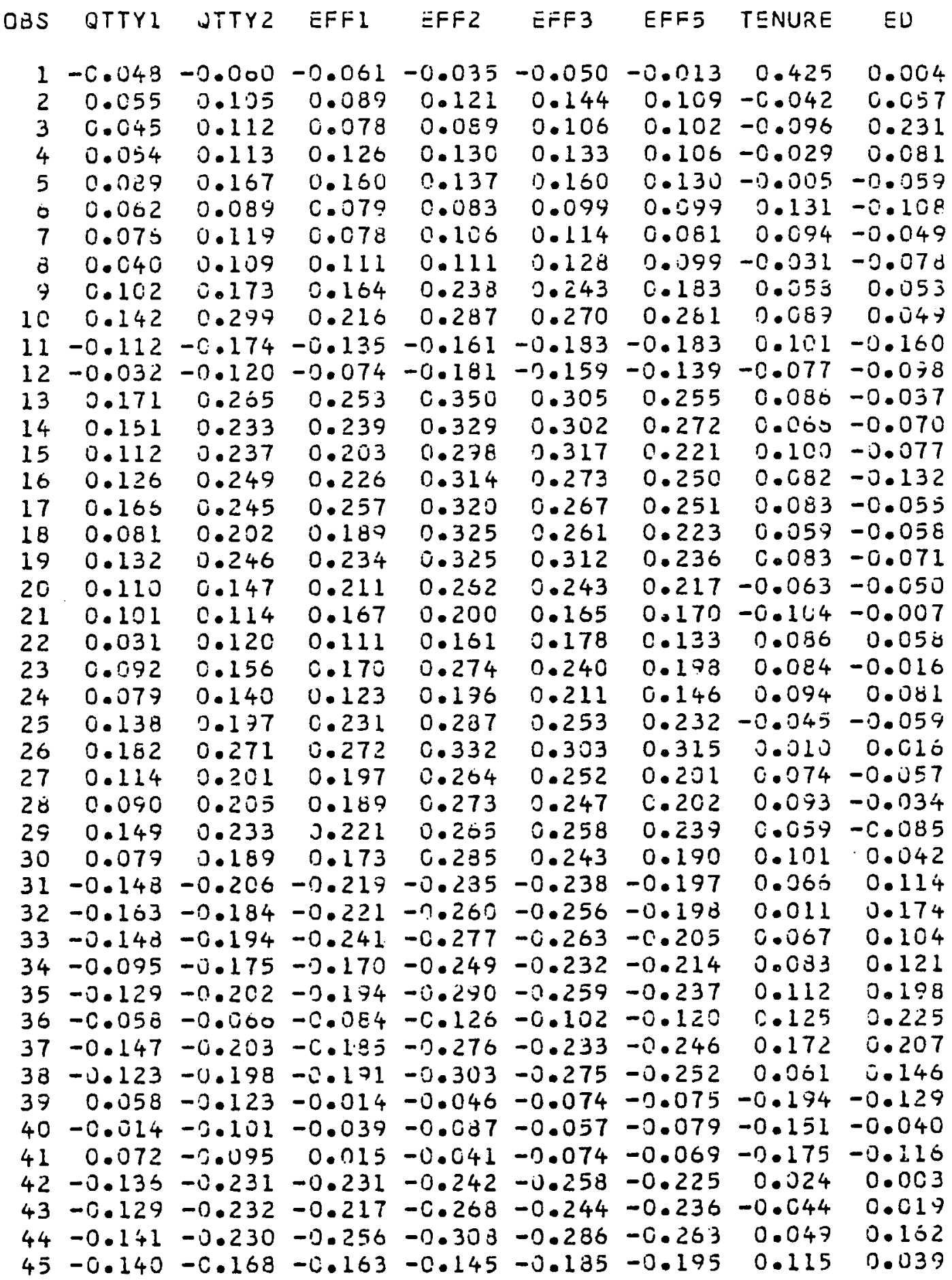




\begin{tabular}{rrrrrrrrr} 
OBS & QTTY1 & 2TTY2 & EFFI & EFF2 & EFF3 & EFF5 & TENURE & \multicolumn{1}{l}{ ED } \\
46 & -0.244 & -0.279 & -0.260 & -0.320 & -0.244 & -0.339 & 0.066 & 0.040 \\
47 & -0.146 & -0.135 & -0.139 & -0.170 & -0.156 & -0.159 & 0.028 & 0.023 \\
48 & 0.144 & 0.206 & 0.190 & 0.213 & 0.231 & 0.203 & -0.020 & 0.008 \\
47 & 0.052 & 0.120 & 0.115 & 0.162 & 0.157 & 0.150 & 0.043 & 0.045 \\
50 & 0.091 & 0.217 & 0.157 & 0.172 & 0.218 & 0.198 & 0.055 & 0.005 \\
51 & 0.087 & 0.216 & 0.171 & 0.209 & 0.207 & 0.172 & 0.093 & 0.021 \\
52 & 0.100 & 0.224 & 0.169 & 0.194 & 0.219 & 0.194 & 0.114 & 0.069 \\
53 & 0.121 & 0.246 & 0.219 & 0.272 & 0.271 & 0.222 & 0.127 & 0.083 \\
54 & 0.124 & 0.231 & 0.216 & 0.270 & 0.257 & 0.236 & 0.068 & 0.119 \\
55 & 0.123 & 0.188 & 0.207 & 0.215 & 0.224 & 0.215 & -0.003 & 0.070 \\
50 & 0.102 & 0.216 & 0.182 & 0.224 & 0.241 & 0.216 & 0.030 & 0.180 \\
57 & 1.000 & 0.488 & 0.432 & 0.324 & 0.312 & 0.410 & -0.067 & -0.063 \\
58 & 0.488 & 1.000 & 0.455 & 0.415 & 0.415 & 0.457 & 0.005 & -0.063 \\
59 & 0.432 & 0.455 & 1.000 & 0.570 & 0.502 & 0.561 & -0.017 & -0.0196 \\
60 & 0.324 & 0.415 & 0.570 & 1.000 & 0.524 & 0.569 & 0.020 & -0.057 \\
61 & 0.312 & 0.415 & 0.502 & 0.524 & 1.000 & 0.464 & -0.015 & -0.053 \\
62 & 0.410 & 0.457 & 0.501 & 0.569 & 0.464 & 1.000 & -0.003 & -0.061 \\
63 & -0.007 & 0.005 & -0.017 & 0.020 & -0.015 & -0.003 & 1.000 & -0.016 \\
64 & -0.068 & -0.063 & -0.098 & -0.057 & -0.053 & -0.061 & -0.016 & 1.000
\end{tabular}


APPENDIX C

$64 \times 19$ ITEM-FACTOR CORRELATION MATRIX 


\begin{tabular}{|c|c|c|c|c|c|c|c|}
\hline & WAGE & BENEFIT & VIEW & TURNOVER & SUPR & SAT & PRFR \\
\hline WAGE1 & .50 & & & & & & \\
\hline WAGE2 & .78 & & & & & & \\
\hline WAGE 3 & .81 & & & & & & \\
\hline BENE1 & & .65 & & & & & \\
\hline BENE2 & & .76 & & & & & \\
\hline BENE3 & & .80 & & & & & \\
\hline BENE4 & & .60 & & & & & \\
\hline VIEWI & & & .58 & & & & \\
\hline VIEW2 & & & .82 & & & & \\
\hline WD1 & & & & .73 & & & \\
\hline WD2 & & & & .58 & & & \\
\hline SUPRI & & & & & .81 & & \\
\hline SUPR2 & & & & & .76 & & \\
\hline SUPR3 & & & & & .80 & & \\
\hline SUPR4 & & & & & .87 & & \\
\hline SUPR5 & & & & & .83 & & \\
\hline SUPR8 & & & & & .75 & & \\
\hline SUPR9 & & & & & .85 & & \\
\hline SAT2 & & & & & & .65 & \\
\hline SAT3 & & & & & & .43 & \\
\hline SAT5 & & & & & & .34 & \\
\hline SAT6 & & & & & & .61 & \\
\hline SAT7 & & & & & & .45 & \\
\hline SAT8 & & & & & & .70 & \\
\hline SAT9 & & & & & & .83 & \\
\hline PRFRI & & & & & & & .90 \\
\hline PRFR2 & & & & & & & .91 \\
\hline PRFR3 & & & & & & & .77 \\
\hline PRFR4 & & & & & & & .85 \\
\hline
\end{tabular}




\begin{tabular}{|c|c|c|c|c|c|c|c|c|c|}
\hline & EXP & AUT & JD & ID & KNOW & COMM & OCQ & PROD & EFF \\
\hline$\overline{\text { EXP1 }}$ & .81 & & & & & & & & \\
\hline EXP2 & .70 & & & & & & & & \\
\hline EXP 4 & .75 & & & & & & & & \\
\hline AUTI & & .72 & & & & & & & \\
\hline AUT2 & & .78 & & & & & & & \\
\hline AUT3 & & .60 & & & & & & & \\
\hline AUT4 & & .69 & & & & & & & \\
\hline AUT6 & & .79 & & & & & & & \\
\hline JD1 & & & .88 & & & & & & \\
\hline JD2 & & & .51 & & & & & & \\
\hline JD3 & & & .83 & & & & & & \\
\hline IDI & & & & .71 & & & & & \\
\hline ID2 & & & & .72 & & & & & \\
\hline KNOW2 & & & & & .74 & & & & \\
\hline KNOW3 & & & & & .49 & & & & \\
\hline COMM1 & & & & & & .65 & & & \\
\hline COMM2 & & & & & & .52 & & & \\
\hline OCQ1 & & & & & & & .65 & & \\
\hline OCQ2 & & & & & & & .59 & & \\
\hline OCQ3 & & & & & & & .81 & & \\
\hline OCQ5 & & & & & & & .78 & & \\
\hline $0 \mathrm{CQ} 6$ & & & & & & & .85 & & \\
\hline OCQ7 & & & & & & & .83 & & \\
\hline OCQ8 & & & & & & & .82 & & \\
\hline OCQ9 & & & & & & & .76 & & \\
\hline OCQ10 & & & & & & & .84 & & \\
\hline PRÕD1 & & & & & & & & .63 & \\
\hline PROD2 & & & & & & & & .77 & \\
\hline EFF 1 & & & & & & & & & .74 \\
\hline $\mathrm{EFF} 2$ & & & & & & & & & .76 \\
\hline EFF 3 & & & & & & & & & .67 \\
\hline EFF5 & & & & & & & & & .74 \\
\hline
\end{tabular}

Note: AGE, EDUCATION, AND TENURE HAVE ESTIMATES OF 1.0 
APPENDIX D

$12 \times 4$ FACTOR-FACTOR CORRELATION MATRIX 
REWARDS ORGANIZATIONAL PROFESSIONAL PERFORMANCE CHARACTERISTICS COMMITMENT

\begin{tabular}{llll}
\hline WAGE & .53 & & \\
BENE & .62 & .58 & \\
SUPR & & .54 & \\
PRFR & .50 & .61 & \\
VIEW & & .58 & \\
EXP & & .59 & .47 \\
AUT & & .49 & .69 \\
ID & & .48 & \\
KNOW & & & \\
COMM & & & \\
PROD & & & \\
EFF & & & \\
\hline
\end{tabular}

